University of Louisville

ThinkIR: The University of Louisville's Institutional Repository

8-2013

\title{
Modeling risk for the development of child anxiety : the role of parent emotion socialization practices, children's emotional competence, and physiological responsiveness.
}

Sarah Ramsey Williams

University of Louisville

Follow this and additional works at: https://ir.library.louisville.edu/etd

\section{Recommended Citation}

Williams, Sarah Ramsey, "Modeling risk for the development of child anxiety : the role of parent emotion socialization practices, children's emotional competence, and physiological responsiveness." (2013). Electronic Theses and Dissertations. Paper 1579.

https://doi.org/10.18297/etd/1579

This Doctoral Dissertation is brought to you for free and open access by ThinkIR: The University of Louisville's Institutional Repository. It has been accepted for inclusion in Electronic Theses and Dissertations by an authorized administrator of ThinkIR: The University of Louisville's Institutional Repository. This title appears here courtesy of the author, who has retained all other copyrights. For more information, please contact thinkir@louisville.edu. 
MODELING RISK FOR THE DEVELOPMENT OF CHILD ANXIETY: THE ROLE OF PARENT EMOTION SOCIALIZATION PRACTICES, CHILDREN'S EMOTIONAL COMPETENCE, AND PHYSIOLOGICAL RESPONSIVENESS

\author{
By \\ Sarah Ramsey Williams \\ B.S., Virginia Polytechnic Institute and State University, 2007 \\ M.A., University of Louisville, 2010

\begin{abstract}
A Dissertation
Submitted to the Faculty of the

College of Arts and Sciences of the University of Louisville in Partial Fulfillment of the Requirements

for the Degree of
\end{abstract}

Doctor of Philosophy

Department of Psychological and Brain Sciences

University of Louisville

Louisville, KY

August 2013 
Copyright 2013 by Sarah Ramsey Williams

All Rights Reserved 

MODELING RISK FOR THE DEVELOPMENT OF CHILD ANXIETY: THE ROLE OF PARENT EMOTION SOCIALIZATION PRACTICES, CHILDREN'S EMOTIONAL COMPETENCE, AND PHYSIOLOGICAL RESPONSIVENESS

\author{
By \\ Sarah Ramsey Williams \\ B.S., Virginia Polytechnic Institute and State University, 2007 \\ M.A., University of Louisville, 2010 \\ A Dissertation Approved on
}

July 23, 2013

by the following Dissertation Committee:

Janet Woodruff-Borden, PhD - Dissertation Chair

Barbara Burns, PhD

Jill Adelson, $\mathrm{PhD}$

Cara Cashon, PhD

Sandra Sephton, PhD 


\section{ACKNOWLEDGMENTS}

I would like to express the deepest appreciation to my committee chair, Dr. Janet Woodruff-

Borden, for persevering with me throughout my work on this project. Without her supportive guidance and abiding enthusiasm for scholarship this dissertation would not have been possible.

I would like to thank my committee members, Drs. Jill Adelson, Cara Cashon, Barbara Burns, and Sandra Sephton, for their time and individual contributions to the advancement of this project.

I would also like to thank Sarah Kertz, Matt Schrock, Ryan Hosey, Elena Bortoleto, and Nick Affrunti who have provided me endless support as lab colleagues. I am appreciative of their time and assistance with my project, and most of all I am grateful for their support and friendship over the years.

Many thanks go to the families who have dedicated their time to advancing the understanding of anxiety.

Finally, this project would not have been possible without grant support from the University of Louisville's College of Arts and Sciences and the American Psychological Association's Science Directorate. 
ABSTRACT

\begin{abstract}
MODELING RISK FOR THE DEVELOPMENT OF CHILD ANXIETY: THE ROLE OF PARENT
EMOTION SOCIALIZATION PRACTICES, CHILDREN'S EMOTIONAL COMPETENCE, AND PHYSIOLOGICAL RESPONSIVENESS
\end{abstract}

Sarah R. Williams

July 23,2013

The prevalence of child anxiety is high and anxiety disorders are often left untreated throughout childhood and adolescence. Despite this, the literature on the development of anxiety is unclear. Many studies have focused on the role of parenting in understanding the development of anxiety during childhood. Given the importance of the parent-child relationship in a child's development of emotional competence, the role of the parent in facilitating their child's emotional development was proposed here to provide a more specific method of assessing the impact of parenting on risk for developing anxiety. Specifically, the current study hypothesized that parent emotion socialization would predict child emotional development. Further, the study sought to build upon the existing literature by examining the role of the child's physiological responsiveness in the relationship between parent emotion socialization and the child's emotional competence. Finally, this study hypothesized that these constructs and the relationships among them would significantly predict symptoms of child anxiety. Children were recruited from schools and various local organizations. A total of 85 parent and child dyads participated in the study. Overall, hypotheses were partially supported. The broad constructs of emotion 
understanding and emotion regulation were not significantly associated with one another. The individual factors comprising emotion regulation were significantly positively associated with cardiac variability. In terms of parenting, parents who reported higher degrees of unsupportive parental responses to negative child emotions were more likely to have children with fewer abilities in both emotion understanding and emotion regulation. Supportive parent responses failed to predict child emotion understanding or emotion regulation. Cardiac responsiveness was found to mediate the relationship between unsupportive emotion socialization and emotion regulation. Further, this model was marginally significant in predicting child anxiety symptoms. Findings are discussed in terms of theoretical implications and suggestions for future work are made. 


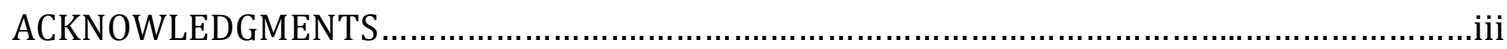

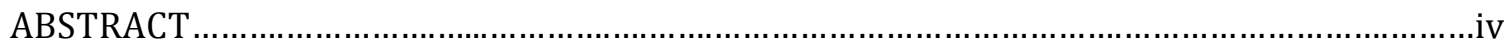

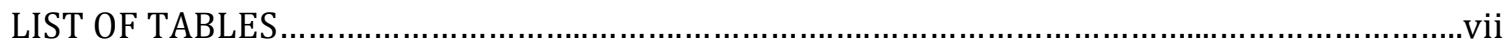

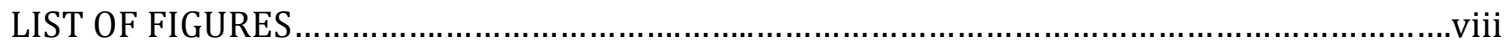

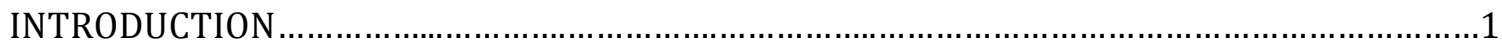

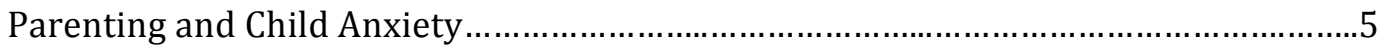

The Role of Emotion in Models of Child Anxiety ..........................................................

Parental Emotion Socialization Practices ..................................................................15

Beliefs About Emotions: Meta-Emotion Philosophy ..............................................28

Evidence Supporting Emotion Socialization in Child Anxiety....................................35

Additional Influences to Parental Emotion Socialization..........................................37

Integration and Discussion of the Model............................................................ 41

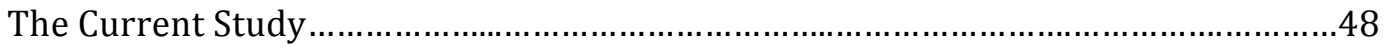

METHOD

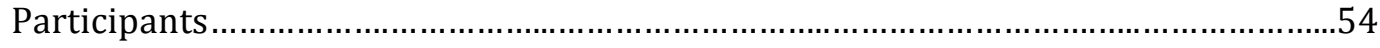

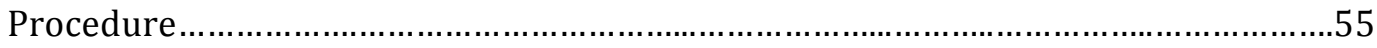

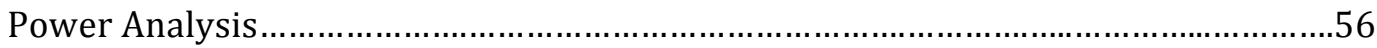

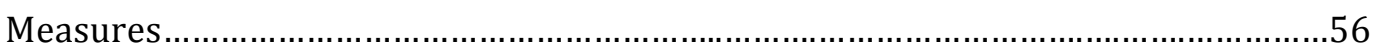

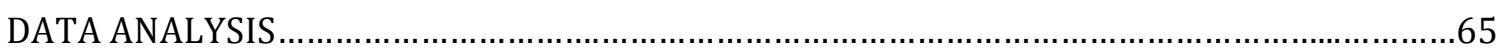

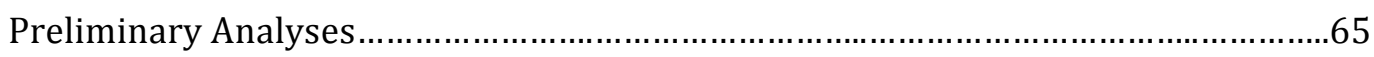

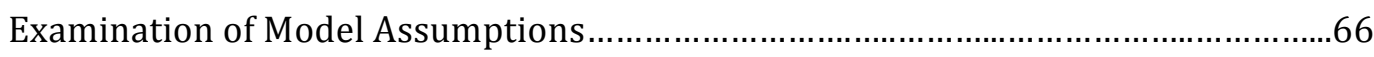

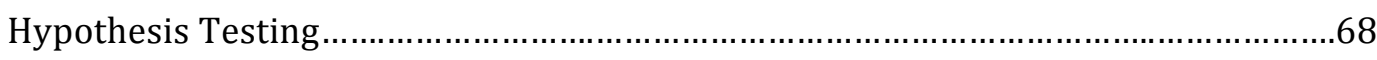

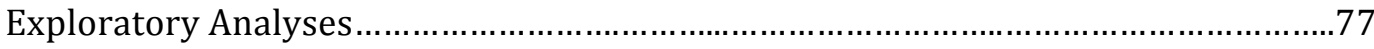

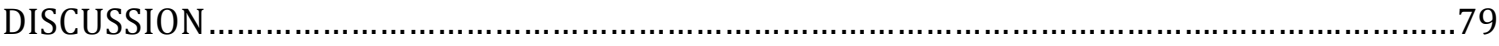

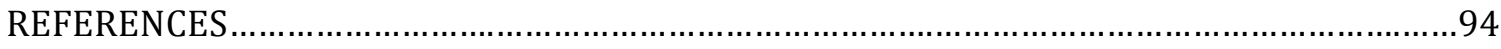

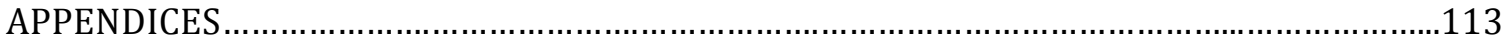

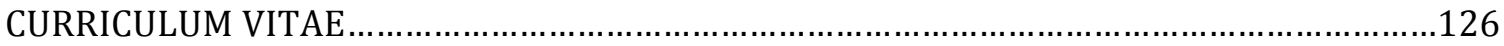




\section{LIST OF TABLES}

TABLE

PAGE

1. Correlations of Parent Emotion Socialization Factors .............................................72

2. Emotion Socialization Predicting Emotion Understanding ..................................75

3. Emotion Socialization Predicting Emotion Regulation ............................................76

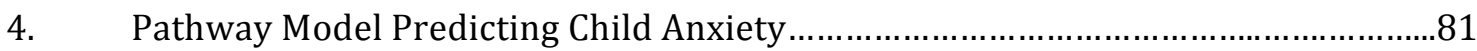

5. Estimated Marginal Means for Low and High Unsupportive Parenting...................82 


\section{LIST OF FIGURES}

\section{FIGURE}

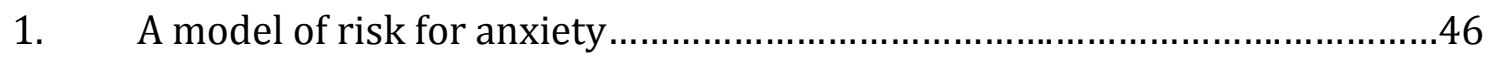

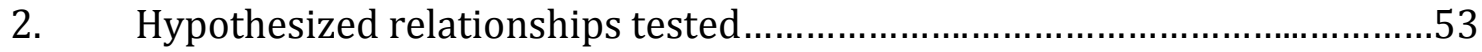

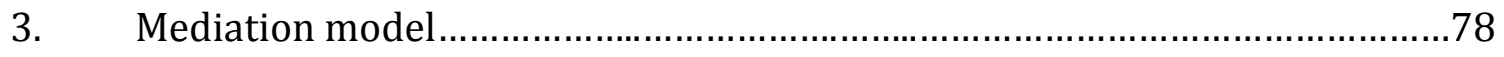




\section{INTRODUCTION}

Over the last two decades, researchers examining the development of child anxiety have utilized theoretical models that place emphasis on the role of parenting, and results from both retrospective and observational studies have been widely varied. Meta-analyses of the parenting and childhood anxiety literature have found somewhat modest support for the relationship between parenting dimensions, such as control and rejection, and child anxiety. Though this provides evidence for the association between parenting and child anxiety, marginal effect sizes achieved in these studies indicate that the dimensions examined do not fully explain the role of parental influences (McLeod, Wood, \& Weisz, 2007). In response to this lack of consistent findings, previous studies have been criticized for being overly simplistic and for failing to consider the complex nature of development. Current theories now acknowledge the dynamic process of development, which is best captured as interactions among multiple domains of functioning that unfold over time (Cicchetti \& Cohen, 2006; Cummings, Davies, \& Campbell, 2000). Not surprising, however, theoretical models of this nature have the potential to become overly complex and impede necessary empirical validation. Thus, careful identification of relevant factors may be the most critical step and is perhaps best achieved through expansions upon existing work. Due to the centrality of emotional processes in both adaptive and maladaptive development, many have advocated for 
their inclusion among developmental models of psychopathology (e.g., Cicchetti, Ackerman, \& Izard, 1995; Suveg, Southam-Gerow, Goodman, \& Kendall, 2007). Following this, empirical support has begun to emerge implicating deficient and maladaptive emotional competence among populations of at-risk and disordered children (e.g., Ciarrochi \& Scott, 2006). This work supports the inclusion of child emotional competence as a relevant factor in models of psychopathology, however, the role of these processes in the development of anxiety remains to be considered. Further, given the importance of the parent-child relationship in a child's development of emotional competence (Saarni, 1999), the role of the parent in facilitating their child's emotional development is proposed to provide a more specific method of assessing the impact of parenting on risk for developing anxiety, which has not yet been examined.

The experience of emotions and development of emotional competence have received a great deal of attention within the literature on child development. This work has provided invaluable information about the course of a child's emotional development and in delineating its association with other critical areas of development. Despite vast individual differences, emotional competence - which encompasses both a child's skills in emotion understanding and emotion regulation - follows a developmental trajectory that is concurrent with cognitive development (Harris, 1994; Izard et al., 2006; Thompson, Lewis, \& Calkins, 2008). Interestingly, use of the terms emotion understanding and emotion regulation has not been consistent and the relationship between these two constructs is still remarkably unclear. Foundational to their definitions is the acceptance of emotions as entities 
that individuals are capable of knowing and exerting regulatory control over (Izard et al., 2006). Children then acquire skills throughout their development in the identification, prediction, and explanation of both their own emotions and the emotions of others, which is broadly termed emotion understanding (De Rosnay, Harris, \& Pons, 2008). As children expand their knowledge of emotions, they also gain an understanding of their ability to initiate, control, and regulate their emotions. Thus, emotion regulation refers to the child's intrinsic and extrinsic abilities in goal oriented, moment-to-moment monitoring and modification of the intensity and duration of emotions (Thompson et al., 2008). These definitions of emotion understanding and emotion regulation suggest that emotion understanding, in some ways, acts as an impetus to emotion regulation; however, the relationship between these two constructs is not likely a linear one (Schwartz, Trabasso, Izard, Kagan, \& Zajonc, 1985). Some aspects of emotion regulation may precede emotion understanding and additional work is necessary to more clearly detail this association.

Though the development of both emotion understanding and regulation is complex and involves several factors, studies examining these constructs have primarily focused on interactions with a child's degree of arousal and parenting behaviors (Cicchetti et al., 1995; Southam-Gerow \& Kendall, 2002). Stemming in part from this work are several models of emotion socialization delineating the parent behaviors believed to shape a child's emotional development. These models provide a conceptual framework for a parent's impact on their child's skills in identifying emotions, understanding their causes, modulating their expression, and 
implementing appropriate coping strategies. Literature examining parent emotion socialization, however, has focused mainly on nonclinical populations and less is known about the likely impact emotion socialization has on the development of psychopathology (Casey, 1996; Eisenberg, Cumberland, \& Spinrad, 1998).

Models defining risk for anxiety during childhood include interactions between genetic vulnerabilities (e.g., physiological arousal and reactivity), temperamental characteristics (e.g., behavioral inhibition), and environmental influences (e.g., parenting style or behaviors) to explain the general propensity towards a pattern of exaggerated fear responses (Vasey \& Dadds, 2001). Parenting behaviors have received some support as correlates of child anxiety (Wood, McLeod, Sigman, Hwang, \& Chu, 2003); however, these studies have focused primarily on issues of behavioral control and lack of warmth and have largely ignored the contributions of both the parent's active and passive roles in their child's emotional development. Moreover, deficits in emotion understanding and maladaptive patterns of emotion regulation are thought to be foundational to the experience of anxiety (e.g., Southam-Gerow \& Kendall, 2002; Suveg, Morelen, Brewer, \& Thomassin, 2010). Parental emotion socialization may then act as an additional risk factor for the development of anxiety in childhood through its impact on the child's development of emotional competence. Additionally, investigating parent emotion socialization and their child's emotional competence may provide an important window into the modest findings within the literature on parenting and child anxiety. 
The current study reviews existing literature on emotion understanding and regulation in child psychopathology to provide a conceptual framework for the role of emotions in childhood anxiety. Literature on parent's socialization of emotions and the development of emotional competence is also reviewed. These two literatures are synthesized to propose an emotion-focused model on the parental role in risk for anxiety during childhood. Though not meant to be exhaustive, additional factors which likely act in concert to influence a parent's socialization practices, along with the child's physiological reactivity, are considered. From this model, several hypotheses are then drawn and tested.

\section{Parenting and Child Anxiety}

Anxiety is prominent in childhood and studies have shown that within pediatric primary care settings anxiety disorders are often left untreated and persist well into adolescence (Beidel \& Turner, 1997; Bosquet \& Egeland, 2006; Chavira, Stein, Bailey, \& Stein, 2004). The development of anxiety during childhood is particularly detrimental such that it places the child at an increased risk for later social, as well as educational, deficits (McLoone, Hudson, \& Rapee, 2006; Rapee, Schniering, \& Hudson, 2009). Estimates from twin and adoption studies have suggested that genetics account for approximately one third of the variance in childhood anxiety symptoms, leaving a significant portion to be explained by various environmental factors (Eley, Vasey, \& Dadds, 2001). Despite the obvious detrimental impacts anxiety has on the child's trajectory, little is known about the development and maintenance of these symptoms (Vasey \& Dadds, 2001). Several 
researchers in the field have focused on the parental influence, both through broad parenting styles and specific parenting behaviors. Though parenting style is believed to impact a child's general propensity toward trait anxiety, situation- and behavior-specific parenting behaviors are thought to uniquely account for the development of anxiety disorders (Craske, 1999).

In review of over a decade of empirical literature on parenting behavior, Wood and colleagues (2003) concluded that parental control was most consistently associated with child anxiety. Other parent behavior dimensions, such as warmth, acceptance, rejection, and negativity, were largely inconsistent in the prediction of child anxiety in studies using both self-report and observational methods. As such, several methodological and statistical limitations have been proposed to explain these mixed results (Rapee, 1997; Wood et al., 2003; Woodruff-Borden, Morrow, Bourland, \& Cambron, 2002). Though observational studies provide the opportunity for more robust methods in the measurement of parenting behaviors across interactions between parent and child, the context within which the observed behaviors occur has not received adequate attention. For example, lack of parental warmth has been found to differentiate anxious mothers from nonanxious mothers (Whaley, Pinto, \& Sigman, 1999); however, a parent exhibiting warmth following their child's withdrawal from a feared situation may serve as reinforcement for avoidant responses - a pattern that is expected to place a child at increased risk for anxiety. A meta-analysis conducted on existing studies which examine the association between child anxiety and the broad parenting dimensions of rejection and control found that, overall, parenting accounts 
for only around $4 \%$ of the variance in child anxiety (effect size $=0.21$; McLeod et al., 2007). When specific sub-dimensions of parenting behaviors were singled out of the analysis, some of these dimensions accounted for a much larger proportion of variance (e.g., lack of autonomy-granting accounted for $18 \%$ of the variance in child anxiety), warranting the investigation of additional parenting behavior dimensions. Through an application of existing knowledge on the experience of anxiety, an examination of the role of emotions may be the next step.

\section{The Role of Emotion in Models of Child Anxiety}

The field of psychopathology, initially focusing primarily on behavioral aspects, experienced significant growth following the "cognitive revolution" represented by increased attention on internal processes (Cicchetti et al., 1995). It was not until the emergence of developmental psychopathology that value was placed on the role of emotions in both typical and atypical development (Cicchetti et al., 1995; Cicchetti \& Cohen, 2006; Izard et al., 2006). While emotions indeed serve an adaptive function, consistent patterns of intense fearful, resistant, and avoidant reactions that do not match the situational context characterize a child experiencing or at risk for the development of an anxiety disorder (Vasey \& Dadds, 2001).

\subsection{Emotion understanding and at-risk children}

Lack of developmentally appropriate skills in emotion understanding is thought to be an important feature in the maintenance of psychopathology. The ability to understand the experience of emotions, as well as the causes and consequences of emotions, in part, orchestrates the child's responses to various 
situational stimuli (Cutting \& Dunn, 1999; Harris, 1994, 1999). Extensive literature exists on the development of emotion understanding among populations of nonclinical and not at-risk children, thus, will not be reviewed here (see Bretherton, Fritz, Zahn-Waxler, \& Ridgeway, 1986; Harris \& Saarni, 1989; Saarni, 1999).

Though less is known about emotion understanding among clinical populations, several studies have found support for the association between deficits in emotion understanding and behavior difficulties, as well as maladaptive skills in emotion regulation (Brown \& Dunn, 1996; Cicchetti et al., 1995; Cook, Greenberg, \& Kusche, 1994; De Rosnay \& Harris, 2002). In an early study, delays in understanding display rules of emotion and the implementation of both inhibition and expression of emotion were found among boys, ages 7 to 11 years with a history of behavioral maladjustment when compared to their typically developing peers (Taylor \& Harris, 1984). Similarly, Meerum-Terwogt (1990) examined a sample of children in Holland, between the ages of 6 and 11 years, with significant psychological or behavioral difficulties. Compared to controls, these children were less able to spontaneously identify multiple emotions and were more likely, when probed, to identify multiple negative emotions. Children rated by their parents as exhibiting moderate to severe behavior problems also have been found to experience marked difficulty generating examples of personal experiences of emotion, and in recognizing their own and other's emotions when compared to children with little to no behavioral concerns (Cook et al., 1994). Children with a history of abuse or of mothers suffering from depression exhibit deficits in several aspects of emotion understanding. Specifically, these 'at risk' children did not readily recognize facial 
expressions of emotions, reported a very limited understanding of the causes of emotions, and more often identified ineffective methods for the regulation of their emotion when compared to their lower risk counterparts (Camras, Sachs-Alter, \& Ribordy, 1996; Garber, Braafladt, \& Weis, 1995; Joormann, Gilbert, \& Gotlib, 2010).

\subsection{Emotion understanding and child anxiety}

Children with anxiety, in particular, may have difficulty identifying negative emotions and likely possess a limited understanding of the causes and consequences of emotions. Southam-Gerow and Kendall (2000) were the first to examine the emotion understanding skills of anxious children and found that, compared to a group of children recruited from the community, anxious children reported less knowledge of the ability to hide emotions and less internal strategies for changing emotions, suggesting that anxious children lack an understanding of emotions as elements within their control. Interestingly, no differences emerged in anxious children's understanding of the cues of emotion and the experience of multiple emotions, which underscores the necessity for more work on the individual components of emotion understanding. For example, skills in the prediction and explanation of emotion, particularly fear, may better differentiate anxious children from nonanxious children. It is plausible that low competence in the accurate prediction of emotional responses to various situational contexts contributes to a lack of confidence in managing their emotional responses to these situations, apart from the actual degree of their ability. Further, children who are unable to generate accurate explanations for their emotional responses and sense that they are unable to hide their emotional responses may not believe that they are able to exert some 
control over their emotions. These aspects of emotion understanding undoubtedly impact the child's behavioral responses and likely effectuate experiential avoidance - a cardinal feature of anxiety. Additionally, the use of older children (participants in the aforementioned study were between the ages of 7 and 14 years) to examine differences in, perhaps, the more rudimentary skills of emotion understanding is likely problematic. Children at this age spend a significant portion of time in school and have thereby broadened their interpersonal interactions, which provide the child with additional opportunities to gain a basic understanding of emotional cues and the experience of multiple emotions (Brown \& Dunn, 1996). Relatively few children at this stage of development continue to exhibit delays in the more unsophisticated aspects of emotional understanding, thus, making it difficult to detect large group differences (Harris, 1994). Indeed, these differences may exist among populations of younger children with anxiety, though this remains to be explored.

\subsection{Emotion regulation and child anxiety}

Emotion regulation deficits have received more conclusive support within populations of psychopathology. Similar to emotion understanding, individual differences have been extensively explored among typically developing children (see Saarni, 1999 for a review) and deficits in emotion regulation have been linked with difficulties in various developmental skills, including poor social and academic competence (Chaplin \& Cole, 2005; Cole, Dennis, Smith-Simon, \& Cohen, 2009; Cole, Michel, \& Teti, 1994; Greenberg, Kusche, Cook, \& Quamma, 1995). Differences in emotion regulation abilities have also been identified among children with 
symptoms of anxiety and depression when compared to control children (Cole \& Deater-Deckard, 2009; Cole et al., 1994; Gross \& Muñoz, 1995; Kim \& Cicchetti, 2010). For instance, in a nonclinical population of children ranging from kindergarten age to eighth grade, self-reported depressive symptoms were associated with less effective methods of regulating affect, such as responding to stressful situations with increased negative affect or avoiding problem solving (Garber et al., 1995). Similarly, older children (i.e., between the ages of 9 and 12 years), who reported more significant symptoms of anxiety and depression, exhibited greater difficulty identifying their emotions and reported more dysregulation of their anger and sadness (Zeman, Shipman, \& Suveg, 2002).

Focusing primarily on children with clinically significant anxiety, Suveg and Zeman (2004) found that 1) children diagnosed with an anxiety disorder reported having more difficulties with emotion dysregulation in terms of worry, sadness, and anger than nonanxious children, 2) anxious children reported less adaptive coping with these same emotions than their nonanxious counterparts, and 3) both anxious and nonanxious children reported more overall coping for sadness than for worry. This suggests that anxious children have greater difficulty than nonanxious children with the appropriate regulation of negative affect and may lack resources for coping with these emotions. In addition, this study reported that anxious children were perceived by their mothers as being more labile, less flexible, and more negative along with more frequently engaging in inappropriate expression of emotions and lacking self-awareness compared to nonanxious children. 
These findings have received some experimental support within an older sample of Israeli children (ages 10 to 17 years) with a primary diagnosis of anxiety and their age- and gender-matched controls with no current or past history of anxiety (Carthy, Horesh, Apter, \& Gross, 2010). To assess for emotional reactivity and regulation skills, children were presented with several, one sentence long, ambiguous situations via a computer (i.e., REAR-Situation). These situations were designed to have the potential for threatening interpretations. Participating children were asked to rate how badly they believed they would feel if they were in the situation, to report what they would do to "calm [themselves] down," and to generate as many alternate ways to think about the situation as they could. When compared to their nonanxious counterparts, anxious children reported greater reliance on strategies of avoidance, seeking others for assistance, less direct problem solving strategies, and exhibited greater difficulty generating reappraisals for the situations. Also striking, anxious children were more likely to not report any emotion regulation strategies in response to their initial negative appraisals of the situations.

Longitudinal studies have also provided some evidence for the role of emotion regulation in identifying children at risk for anxiety in adolescent years (Bowie, 2010; Hatzenbuehler, McLaughlin, \& Nolen-Hoeksema, 2008). Notwithstanding the child's biological reactivity and cognitive appraisals, persistent difficulties in the recognition and implementation of appropriate coping strategies for managing intense negative affect have received support as correlates of child anxiety. 


\subsection{Discussion}

Extant research indicates that children with deficits in emotion understanding frequently mislabel their own emotions and the emotional expressions of others, display limited understanding of the causes of their emotional responses, and lack an understanding of how to appropriately manage their emotions. As a result of this limited understanding of their emotions, these children are thought to be at augmented risk for psychological difficulties such that they are more likely to cope with emotionally arousing situations through 1) an inhibition of their emotional expression or 2) an undercontrol of their emotional expression. These two response patterns appear to correspond directly to the internalizing (i.e., anxiety or depression) - externalizing (i.e., children with problematic behavior) dichotomy. Therefore, patterns in the relationship between emotion understanding and emotion regulation may partially predict a child's experience of internalizing versus externalizing difficulties (Casey, 1996; Rosnay et al., 2008; Southam-Gerow \& Kendall, 2000, 2002). Surprisingly little is known, however, about the association between these two patterns of regulation and the individual factors of emotion understanding. Thus, identifying the nature of the relationships between components of emotion understanding and emotion regulation, which are likely bidirectional and complex, will provide opportunities for advancing the work in differentiating the development of internalizing versus externalizing difficulties.

Factors inherent to the child, such as cognitive development, are essential components in the developmental trajectories of both emotion understanding and regulation. Environmental influences, which act in concert with these biological 
factors over time, may then partially explain the shift away from typical development toward a maladaptive trajectory. Not surprisingly, theorists have suggested that parents play a significant role in impacting their child's development of emotion understanding and emotion regulation skills (Cunningham, Kliewer, \& Garner, 2009). Even at an early age, children internalize ideas and beliefs from their parents about their emotions through various emotion-related parenting behaviors (Denham, Mitchell-Copeland, Strandberg, Auerbach, \& Blair, 1997). When these parenting behaviors are largely warm, supportive, and nurturing, children likely learn that their emotions are a natural element of daily experiences, feel a sense of self-efficacy about their emotional lives, and may then be accepting of opportunities to learn and practice the skills necessary to tolerate and modulate their experience of negative affect (Saarni, 1999). Conversely, when these parenting behaviors are dismissive and not supportive, the impact on the child is two-fold. These children may internalize the belief that intense emotions are intolerable and the expression of emotions is inappropriate. Consequently, they then lack not only direct experiences through which to learn the skills of emotional competence (i.e., experience in emotionally-charged situations and practice in recognition and implementation of effective regulation), but also fail to gain adequate knowledge about emotions through discussions with their parents. Without adequate understanding of emotional experiences and sufficient skills in the management of their emotional responses, children of dismissive and unsupportive parents are motivated to inhibit their expressions of negative emotion and withdraw from potentially arousing situations in an effort to relieve distress. These responses are 
expected to be reinforced by their parents and, over time, this cyclical pattern is thought to place the child at increased risk for the development of psychopathology, such as anxiety (Vasey \& Dadds, 2001).

\section{Parental Emotion Socialization Practices}

A number of parenting factors, broadly classified as emotion-related socialization practices or emotion socialization, have been identified as influential to a child's emotional development (Eisenberg et al., 1998). Eisenberg and colleagues (1998) proposed a heuristic model of these emotion socialization practices that includes a parent's modeling of appropriate emotional expressivity and regulation, discussions of emotions, contingent responses to other's expressions of emotion (primarily the child's), and overt teaching about the causes, experience of, and regulation of emotions. The goal of these socialization practices is to assist children in the age-appropriate recognition of emotions within themselves and in others, react to them, and express them in a well-regulated manner. Generally, empirical work to date has focused on the associations between parental emotion socialization practices across typical development (Eisenberg et al., 1998) and, interestingly, no one study has attempted to validate the model in its entirety. Thus, each element of parental emotion socialization will be individually discussed with a focus on studies that suggest a relationship to risk for anxiety through emotional competence.

3.1 Parent and child discussions of emotions 
Frequent discussions of both positive and negative emotions, which occur between parent and child, have been identified as important to healthy social functioning among populations of typically developing children. Moreover, discussions of negative emotions, in particular, may assist the child in recognizing his or her emotional experience, identifying the causes of their emotions and the emotions of others, and learning appropriate regulation skills. In a very small sample $(\mathrm{N}=6)$ of children, aged 2 to 5 years, and their parents, researchers analyzed transcripts from interactions between parent and child (Lagattuta \& Wellman, 2002). No differences emerged in the quantity of discussions between positive and negative emotions; however, the quality of the discussions between parents and their children of positive and negative emotions were found to be somewhat divergent. When discussing positive emotions, parents most often referenced current experiences and expressions of positive emotions, whereas in discussions of negative emotions, parents more often referenced past experiences, past causes of emotions, as well as connections of negative emotionality with other mental processes. This suggests that discussions of negative emotions offer unique teaching opportunities for the parent to assist their child in understanding, evaluating, and learning to regulate negative affect.

Maternal discussions of emotions with their children are also related to both emotion understanding and aggressive and prosocial behaviors (Garner, Dunsmore, \& Southam-Gerrow, 2008). Specifically, mothers and their 3- to 5-year-old children were asked to look at a picture book and mothers were given the instructions to limit discussion to pictures in the book. References to emotions were coded on four 
dimensions: 1) unelaborated comments 2) explanations of 3) references to positives and 4) references to negatives. Children of mothers who engaged in more explanations of emotions performed better on a task of emotion understanding, engaged in more prosocial behaviors with their peers, and displayed less aggressive behavior. Thus, children whose mothers more frequently engage in explanations of emotion, not only exhibit greater skills in understanding emotions, but their limited engagement in aggressive behavior may also suggest that these children are more adept at regulating them. Similarly, elaborate discussions of negative emotions at early periods in development are also related to later emotion understanding skills. Dunn and colleagues (1991) found that families who more frequently discussed emotions, more frequently engaged in discussions of the causes and consequences of emotions, and discussed a diverse range of emotions had children who, at a 3year follow-up, were better able to identify emotions in themselves and others. Using a similar coding scheme, children around the age of 3 , whose parents more frequently discussed the causes and consequences of a wide range of emotions, were rated by observers as engaging in more positive and cooperative play with their siblings and peers (Dunn \& Brown, 1994). More specifically, these children more frequently discussed their inner state, such as how they were feeling and why, both of which are identified as abilities in emotion understanding.

Leibowitz and colleagues (2002) utilized a community-drawn sample of preschoolers (ages 4 to 6 years) to examine the relationship between parent and child emotional communication and various dimensions of separation anxiety. In this study, parents who most frequently referenced their child's emotions during 
discussion exhibited less overt negative emotions and had children who more often referenced their own emotions. Further, these children infrequently engaged in avoidance-style strategies for coping with anxiety about separating from their parents and reported greater self-reliant coping with the anxiety-provoking situation - a finding that may provide preliminary evidence for an indirect pathway from parent emotion socialization practices to a protection from anxiety, through the role of both emotion understanding and regulation.

It is not surprising that parent - child discussions of emotions impact the child's later emotion expression, understanding and regulation. For the most part, children are provided opportunities to learn about the emotional experiences of others through direct observation; however, understanding the internal process of emotions is much more difficult without direct teaching experiences or discourse with others regarding emotions (Michalson \& Lewis, 1985; Saarni, 1999). Parent child discussions of emotions procure the child's interpretations of the emotional valence of situations and, quite possibly, influence how effectively the child believes he or she can cope with a greater than mild affective response (Eisenberg et al., 1998). Although results have not been consistently replicated, the influence of parents on their child's affective perception of situations is evident in studies on disordered (including anxiety or oppositional-defiant disorder) and non-disordered children in discussions with their parents about ambiguous situations (Barrett, Rapee, Dadds, \& Ryan, 1996). Children (between 7 and 14 years of age) in one study were presented with twelve ambiguous scenarios then asked to discuss what they believed was occurring in the picture and to provide an example action response. 
Each of the ambiguous scenarios had the potential for a threatening interpretation (e.g., "You see a group of students from another class playing a great game. As you walk over and want to join in, you notice that they are laughing. What do you think is happening?"; Barrett et al., 1996, p. 191). The child's parent was then invited to join the child, and the dyad was given five minutes each to discuss two pre-selected situations. During that time, they were asked to reach an agreement on a solution for each of the situations. Both anxious and oppositional-defiant children perceived these situations as initially more threatening than the comparison group. Interestingly though, during discussion with their parents, anxious children reported increasingly more threatening responses and greater avoidant solutions to the situations. Similar patterns were found among the parent's responses. Parents of anxious children made greater threatening interpretations of the scenarios and more frequently chose avoidant solutions. Despite obvious limitations in the ability to make inferences about causation, these findings provide some suggestion that, through discussions with their children, parents influence their child's interpretations and responses possibly through encouraging or reinforcing particular interpretations and regulation patterns. This was particularly evident for anxious children and their parents in this study, such that avoidant responses increased following parent - child discussions of situations.

3.2 Parental responses to emotional expressions of the child

Research has also supported the impact of parents on their child's emotional development through direct reactions to their child's expressed emotions. Preschool children (ages 4 to 5 years) who performed better on tasks of emotion 
understanding had parents who were less likely to discourage the expression of negative emotion and more likely to respond with positivity to their experiences of intense negative emotion (Denham, 1997; Warren \& Stifter, 2008). More specifically, mothers who were more supportive with their child (i.e., were encouraging, more likely to validate the child's emotion, and who engaged the child in direct conversations about emotional experiences) had children who, both throughout and immediately following a distressing situation, were more likely to self-report on their own positive and negative emotions and were reported to have higher skills in emotion regulation (Davidov \& Grusec, 2006; Shaffer, Suveg, Thomassin, \& Bradbury, 2012; Warren \& Stifter, 2008). By comparison, mothers who were more likely to engage in unsupportive and harsh emotion socialization behaviors (i.e., were negative, more rejecting of emotions, and who less often discussed emotional experiences) had children who were less able to self-report on their sadness, who spent more time engaging in talk that was unrelated to the emotional expression, who were reported to be more negative and labile, and had lower emotion regulation abilities (Davidov \& Grusec, 2006; Shaffer et al., 2012; Warren \& Stifter, 2008). A retrospective, self-report study of parental responsiveness during childhood found associations between perceived parental responses to emotions and maladaptive outcome (O'Neal \& Magai, 2005). More specifically, children who reported more symptoms of behavioral difficulties at ages 11 to 14 years perceived their parents as more frequently rewarding their feelings of shame (e.g., offering comfort following their child's expression of shame) and magnifying their feelings of anger (e.g., responding with anger to their child's 
expressed anger) when they were younger. Indeed, warm and supportive parenting alone is not sufficient to promote adaptive emotional development. Perhaps even more critical to a child's burgeoning skills in emotion regulation than the presence of supportive parenting is the lack of unsupportive parenting practices (Shaffer et al., 2012).

One study to date has employed direct observation to explore parental responses to their child's expressed emotion and emotion regulation strategies. During two tasks designed to elicit anger and sadness, maternal support, defined as positivity toward the child, acceptance, sympathy and attentiveness, was positively related with the child's recognition of regulation strategies when angry (Cole et al., 2009). However, less maternal support predicted the child's actual ability to generate multiple regulation strategies of anger. This is surprising, though may provide evidence for the existence of disproportionate or even inappropriate support of children during distress. Conditional to the child's stage of development, overly supportive mothers conceivably impede their child's achievement of autonomous and self-efficacious understanding and regulation of emotional experiences. Young children, quite appropriately, rely heavily on the assistance of their mothers in managing emotional distress (Denham, 2007). However, as the child advances in development and the mother fails to make developmentally contingent adjustments in their degree of involvement, the child may not acquire a more complex understanding of their emotions and thereby be placed at risk for maintaining increasingly ineffective methods for managing affect. In a retrospective study, parental socialization of their child's expressed emotions was found to be 
related to psychological distress (Garside \& Klimes-Dougan, 2002). More specifically, across all expressions of negative emotions (i.e., sadness, anger and fear), the perception of their parent's responses of ignoring or punishing of emotional expressions during childhood predicted later psychological distress. This study did not specifically examine anxiety symptoms nor did the authors utilize a clinical population, however, the findings indicate that individuals in distress perceive their parents as attempting to suppress or minimize their emotional expression.

\subsection{Parental expressivity}

The first indirect method by which children learn appropriate expression and regulation of emotion is through a parent's overt expression of emotions (Denham et al., 1997). Regular expression of positive affect by parents, both within the family and during individual exchanges with their children, has beneficial impacts on the child's development of social competence (Halberstadt, Denham, \& Dunsmore, 2001; McDowell \& Parke, 2009). In an observational study, using a community sample of mother and toddler dyads (child age ranged between 25 and 39 months), Denham (1989) found that maternal expression of negative emotion was positively related to toddler expression of negative emotion and negatively correlated with toddler expression of positive emotions. This may suggest that parental expression of emotion, particularly with young children, has an influence on the child's expression of their own emotion and, though speculative, may impact their child's experience of emotions. Nevertheless, the contribution of genetic similarities, between both mother and child, in the experience and expression of 
emotions undoubtedly accounts for a considerable portion of this association, thus, these results must be interpreted with caution.

Studies on children's emotion understanding may, however, provide support for the notion that parental expressions of emotion have significant impacts on a child's development. A meta-analysis, examining 23 studies of parental expression of emotion and child emotion understanding, found that negative emotional expressiveness, particularly during early childhood, may be the most detrimental (Halberstadt \& Eaton, 2003). Participants within these studies were categorized into one of four groups based on age: Infant/Toddler (ages 0 to 3 years), Preschool (ages 3 to 4 years), Kindergarten/Elementary (ages 5 to 12 years), and Adolescence/Young Adult (ages 13 to 21 years). When the four age groups were examined together, no association emerged between parental expression of positive emotions and the child's emotion understanding skills. Parental expressions of negative emotions, however, yielded more compelling results such that a curvilinear growth trajectory best accounted for its relationship to emotion understanding across the four age groups. More specifically, a negative association emerged between parental expression of negative emotions and the child's performance on emotion understanding tasks solely for preschool- through elementary-aged children. This relationship then became less clear as the child approached adulthood. It is plausible that patterns of frequent parental expression of negative emotions are detrimental to a child's skills in emotion understanding and that critical periods may exist, particularly early in development, when these parental factors have a greater degree of impact on the child. Though intriguing, conclusions 
from this meta-analysis are limited and longitudinal studies are necessary to delineate the true developmental course of these interactions between parental expression of both positive and negative emotion and their child's development of emotional competence.

Studies examining parental expressivity and child psychopathology are also limited. Within a community sample, children (aged 4 to 8 years) who reported fewer symptoms of anxiety, depression, and behavior difficulties had mothers who reported low neuroticism, exhibited fewer expressions of negative emotions, and more frequently expressed positive emotions (Cumberland-Li, Eisenberg, Champion, Gershoff, \& Fabes, 2003). These results are somewhat contradictory to the aforementioned findings and suggest that parental expressions of both positive and negative emotions are influential to a child's outcome. A distinction of the later study, which may partially account for these divergent findings, is the inclusion of children with behavioral difficulties. Given the nature of the hypothesized relationship between emotion understanding and regulation in differentiating children experiencing anxiety and children with behavior difficulties, future studies are warranted to delineate whether this difference extends to parent emotion socialization practices. Additionally, this study investigated exclusively self-reported parental temperament, emotional expression and child symptoms, which undoubtedly introduces a response bias in the association between the two variables and thereby limits definitive conclusions.

The impact of parental expressions of negative emotions on a child's emotion regulation and symptoms of anxiety and depression has received support, though 
limited, as being maintained into early adulthood. A retrospective study on young adults, between the ages of 18 and 30, revealed that individuals who reported more symptoms of anxiety and depression and more maladaptive methods of emotion regulation (e.g., suppressing their thoughts and emotions), also reported that their parents had more frequently expressed negative affectivity throughout their childhood years (Krause, Mendelson, \& Lynch, 2003). Similar to above, the exclusive use of retrospective self-reports likely introduced a response bias in the relationship between these variables, and the results must be interpreted with caution. One study to date has directly explored the association between mother- and childreported expressiveness of emotion and anxiety among older children (Suveg, Zeman, Flannery-Schroeder, \& Cassano, 2005). Compared to children with at least one primary diagnosis of anxiety, children with no diagnosis and their mothers both report more expressiveness of emotions within the family. Given these findings, it may be that anxious families are more likely to suppress and avoid expressions of emotions, however, additional evidence is necessary to support this conclusion.

\subsection{Emotional climate of the family}

Patterns of emotional expressiveness by all members of the family, over time, are thought to create the emotional climate of the family, which is also hypothesized as an indirect method through which children learn about their emotions and how to regulate them (Halberstadt, Crisp, \& Eaton, 1999; Halberstadt \& Eaton, 2003). Notwithstanding its theoretical attention, the nature of the association between a family's emotional climate and various child outcomes remains uncertain (Halberstadt et al., 1999; Saarni, 1999). Generally, studies have inferred the 
emotional climate of the family predominantly through the use of maltreating or abusive populations (e.g., Sim, Adrain, Zeman, Cassano, \& Friedrich, 2009) and a minority of studies have rendered the reports of emotional expressiveness from one parent as an approximation of the emotional climate of the family as a whole (e.g., Dunn \& Brown, 1994). The use of these methodologies is problematic and serves as an indication that family-wide emotional climate has not been clearly defined. Careful delineation of the emotional climate of the family as a distinct construct (i.e., apart from the parent's individual degree of self-expression) is necessary along with additional exploration of this construct as a component of emotion socialization.

\subsection{Modeling of emotional competence}

Literature on anxiety suggests that parents model an anxious response-style through the manner in which they discuss experiences, their reactions during various potentially threatening situations, and through direct avoidance of feared situations (cf., Fisak \& Grills-Taquechel, 2007). As such, it is plausible that parents have an indirect impact on their child's emotional development through modeling of emotional competence. In general, several studies have inferred modeling as a possible mechanism for the transmission of anxiety within families, however, these conclusions are based primarily on correlations of anxious symptoms between parent and child (e.g., Muris, Merckelbach, \& Meesters, 2001). The degree to which parents model anxious response patterns to their children, as distinct from the expected genetic influence on the propensity toward an anxious response-style, remains largely unclear. Despite these substantial limitations, a review conducted on familial anxiety has suggested that modeling likely explains a significant 
proportion of the variance in the family transmission of anxiety (Fisak \& GrillsTaquechel, 2007). The dearth of adequate literature on modeling emotional competence highlights the need for carefully designed experimental or longitudinal studies which focus on accurately quantifying the process of modeling and examining this process as it relates to the construct of emotion socialization.

\subsection{Discussion}

The studies reviewed in this section provide support for the association of several components of parental emotion socialization with critical child outcomes. Additionally, emotion socialization may be implicated in an increased risk for the development of child anxiety through impacts on a child's emotional competence. The most robust of these findings are in the direct methods of discussing emotions as well as parental responses to expressed emotions and their associations with emotional competence. In contrast, indirect methods of emotion socialization have received minimal empirical attention and significant work is needed to more carefully define these influences. Investigating several of these components individually has provided the necessary foundational support for an association between emotion socialization and children's emotional development; however, this presents a remarkably narrow understanding of this construct and its impact across a child's development. Indeed, relatively few studies have attempted to substantiate the plausible relationships between individual components of emotion socialization.

Portions of these findings, though limited, also demonstrate the likelihood of differential effects of emotion socialization behaviors on child outcome. To illustrate, parents who more frequently express negative emotions in the presence 
of their child, yet engage the child in sophisticated and elaborate discussions about the causes, consequences, and modulation of these negative emotions likely have differential impacts on their child's various skills in emotion understanding and emotion regulation when compared to parents who frequently express negative emotions with little to no direct discussions of them with their child. Undeniably, this differential effect then is influenced by extraneous or moderating variables through the relationships among the components themselves and is also contingent to the developmental stage of the child (Cunningham et al., 2009; Lytton \& Romney, 1991).

The impact that both direct and indirect socialization experiences have on a child's emotional competence is not invariable as the child ages (Wong, McElwain, \& Halberstadt, 2009). A parent's role in their child's emotional development presents in varying degrees of influence, which change rapidly over the course of childhood as a function of both the cognitive and emotional growth of the child and the continual exposure to critical learning experiences (Izard, Harris, Cicchetti, \& Cohen, 1995; Saarni, 1999). In addition, parents are thought to possess an organized set of beliefs about emotions, which is believed to directly contribute to both their emotion socialization practices and child outcome (Gottman, Katz, \& Hooven, 1996). These beliefs and their associated emotion socialization practices are discussed below

4. Beliefs About Emotions: Meta-Emotion Philosophy 
Gottman's interest in the field of emotions began in 1986 following the work of Ginnott, who is partially credited for increased attention on the pivotal role parents play in their child's development through the impact of parenting on a child's emotion regulation abilities. Beginning from studies on the effect of the marital relationships on children, Gottman and his colleagues discovered that not only are a parent's abilities in recognizing the emotions of others important, but their beliefs about emotions are also strongly related to child outcome (Gottman \& Katz, 1989). Gottman coined the term "meta-emotion", similar to meta-cognition (or thoughts about thoughts), to illustrate both the ideas and beliefs that individuals maintain about the experience and expression of emotions. Despite some betweenperson variability, two broad categories emerged for classifying parents: emotion coaching and emotion dismissing. Specifically, parents who 1) reported an awareness of less intense emotions in themselves and their child, 2) believed that their child's expressions of negative emotions were opportunities for open discussions, intimacy and teaching, 3) helped their child label emotions, 4) validated their child's emotions, and 5) assisted their child in managing emotions through the use of problem solving, setting behavioral limits, and discussing outcomes characterized the emotion coaching philosophy (Gottman et al., 1996). Conversely, parents who 1) viewed their child's expressions of negative emotions as potentially harmful, 2) assisted their child in suppressing or shifting away from their negative emotions, and 3) instructed their child on the unimportant nature of negative emotions and in ignoring or denying them characterized the emotion dismissing philosophy. It was theorized that parents holding an emotion coaching philosophy 
would be skilled at recognizing and understanding their own emotions and the emotions of their children, be more accepting of the expression of negative emotions, and have greater competence in the regulation of their own emotions and in teaching their children these same skills. For parents with an emotion dismissing philosophy, it was proposed that these parents would have difficulties with identifying their own or their child's emotions, be less accepting of their child's expressions of negative emotions, choose more maladaptive strategies for regulating their emotions (e.g. "down regulation" or suppression), and encourage and reinforce the use of maladaptive emotion regulation strategies by their children.

4.1 Meta-emotion philosophy and at-risk populations

Parent's meta-emotion was first explored in a longitudinal study of 4- to 5year-old children and their parents, which resulted in several publications (Gottman et al., 1996; Hooven, Gottman, \& Katz, 1995; Katz \& Gottman, 1997). In the initial study, emotion coaching parents were less hostile in their marital relationship and physically healthier than emotion dismissing parents (i.e., they had a lower baseline heart rate, higher vagal tone, were better able to modulate their vagal tone during interactions with their children, and had lower urinary levels of catecholamines and cortisol; Hooven et al., 1995). Further, children of emotion coaching parents tended to display less negative affect during interactions with their peers and were rated as having less behavior problems. Building on these findings, results of the second study indicated that both awareness of emotions and coaching were positively associated with parenting measures of scaffolding, praise, and both their child's ratings of social competence and achievement scores three years later (Gottman et 
al., 1996). Perhaps most interestingly, path analysis revealed that emotion coaching parents had children with healthier and better regulated vagal tone, which then predicted less child illness. The final study revealed that emotion coaching parents were less hostile toward their children and more likely to praise them (Gottman, Katz, \& Hooven, 1997). Further, parental awareness and coaching together appear to act as a buffer from the negative impacts of marital discord on emotion regulation difficulties, teacher ratings of negative peer relationships, expressed negative affect during interactions with peers, and childhood illness (Katz \& Gottman, 1997).

Emotion coaching and dismissing have been explored among families of children struggling with behavioral problems and provides some indication of their function in families with a child experiencing psychopathology through the role of emotion regulation (Katz \& Windecker-Nelson, 2004; Lunkenheimer, Shields, \& Cortina, 2007; Ramsden \& Hubbard, 2002). Interestingly, in a community sample of $5^{\text {th }}$ grade children (mean age of 10 years) no direct relationships emerged in terms of either the parent's expressiveness or coaching and their child's degree of aggressive behaviors (Ramsden \& Hubbard, 2002). Path analysis, however, revealed indirect relationships through the role of emotion regulation such that greater parental expression of negative emotion and lower ratings of emotion coaching were associated with difficulties in emotion regulation, which predicted higher frequencies of aggressive child behaviors. The relationship between meta-emotion philosophy and the child's peer relationships has been investigated across a sample of 4- to 6-year-olds with conduct behavior difficulties and a matched sample of children who did not exhibit current or past conduct behavior difficulties (Katz \& 
Windecker-Nelson, 2004). Children were recorded at home interacting with their peers and interactions were coded for quality on 3 dimensions: negative conversation and affect, high-level play (i.e., the child's ability to remain engaged in the interaction), and disconnected interaction. Parents of children with conduct behavior difficulties were less aware of their own emotions and were less likely to exhibit coaching behaviors. Further, less aggressive children of mothers who exhibited greater awareness of their own emotions had the fewest disconnected interactions, the lowest rate of negative affect and the lowest instance of negative conversations. Less aggressive children of mothers who more frequently recognized their child's emotions also had the lowest incidence of negative conversation and negative affect. In terms of emotion coaching within this study, interesting results emerged. Somewhat in contrast to Ramsden and Hubbard's findings, highly aggressive children of coaching parents displayed more negative conversation and negative affect during play with their peers.

These studies provide some evidence for implicating emotion coaching and dismissing to maladaptive outcomes, primarily through the role of emotion regulation. Only one study to date, however, has examined the role of emotion coaching and dismissing and anxiety among a population of older children (aged 8 to 12 years). Specifically, children with fewer emotion regulation skills and high ratings of anxiety, depression, and problem behavior had parents who were rated as exhibiting more emotion dismissing behaviors (Lunkenheimer et al., 2007).

\subsection{Discussion}


Investigation of the role of meta-emotion philosophy and child outcome has produced interesting findings. Interestingly, the majority of these studies have emerged from a single research lab and replication attempts have brought about inconsistent results. Highly aggressive children, for example, have been found among both high coaching and low coaching parents (Katz \& Windecker-Nelson, 2004; Ramsden \& Hubbard, 2002). Differences in the ratings of aggressive behavior between teacher and parent may partially explain the differential findings, as well as temperamental differences, and additional work is necessary to more clearly understand the relationship between meta-emotion philosophy and child outcomes. Despite this primary focus on children with behavioral difficulties, the aforementioned studies provide some indication for the existence of a unique mechanism through which parental emotion socialization may be implicated in an augmented risk for developing anxiety. Though it is suggested that dismissive parents have sadder and more fearful children (Denham, 1989), little evidence has been produced to support this notion and further investigation of parental beliefs and associated dismissing behaviors in relation to emotion is warranted among clinical populations of anxious children.

Emotion coaching, however, has been identified as a correlate to several factors characterizing children at risk for developing anxiety, such as negative affectivity and degree of physiological arousal (Hooven et al., 1995; Ramsden \& Hubbard, 2002; Shipman \& Zeman, 2001). Indeed, physiological reactivity may act as a buffer against the detrimental impacts of unsupportive parental emotion socialization on a child's emotion regulation, such that children who are better able 
to physiologically regulate themselves may be less influenced by their parent's unsupportive parenting (Perry, Calkins, Nelson, Leerkes, \& Marcovitch, 2012). Thus, the relationship of the child's pattern of physiological responsiveness, parent emotion socialization practices, and the child's development of emotional competence may more clearly delineate the role of parental influence in the development of or protection against anxiety disorders in childhood. To illustrate, parents who coach and support their children during experiences of heightened emotion as well as teach appropriate regulation techniques, throughout the child's development, may affect their child's ability to maintain regulated patterns of physiological arousal in the face of intensely emotionally salient situations (Hooven et al., 1995; Lunkenheimer et al., 2007). Further, better regulation and subsequent ability in the management of the physiological symptoms in response to stress likely provides additional protection from the detriments of environmental stressors (Cicchetti et al., 1995). Preliminary support for this suggestion may be found in the association well-regulated vagal tone activity has with emotion coaching (Perlman, Camras, \& Pelphrey, 2008), in contrast to the suppressed vagal tone often found in relation to anxiety (e.g., Thayer, Friedman, Borkovec, Johnsen, \& Molina, 2000).

Due to the familial nature of anxiety (Dadds, Roth, \& Vasey, 2001), it is important for future work to explore the impact of parent psychopathology on their beliefs about emotion and emotion socialization practices. It is plausible that anxious and nonanxious parents hold differing beliefs about emotions, which then impact their responses to their children's expressed emotions. Thus, a parent's role in socializing their child's development of emotional competence may be one 
mechanism through which to partially explain the transmission of anxiety from parent to child.

\section{Evidence Supporting Emotion Socialization in Child Anxiety}

Though studies on clinical samples are limited, preliminary work implicates differential emotion socialization by parents of children with anxiety. Suveg and colleagues (2005) first examined emotion socialization practices in a sample of older children (ages 8 to 12 years), diagnosed with an anxiety disorder and their age- and gender-matched controls with no current or past psychological disturbances. Participating mothers and their children were asked to engage in brief discussions about times when the child felt worried, sad, and fearful. Transcripts were coded for several factors: total words used, number of negative and positive emotion words used, and the socialization factors of facilitation and explanation. Though total number of words spoken across the discussions did not differ between the anxious group and the control group, mothers of nonanxious children spoke more throughout the interaction than their children and used more positive words. Further, mothers of anxious children more frequently discouraged their child's expression of negative emotions than did mothers of nonanxious children. Also, both mothers and their nonanxious children reported more family expressiveness of emotions within their homes compared to mothers and their anxious children (mother and child's reports were examined separately).

In a second observational study, Suveg and colleagues (2008) used a parallel procedure to examine emotion parenting between families of older children (ages 8 
to 13 years) with and without anxiety diagnoses. Both parents participated and were asked to discuss with their child a recent time when they felt happy, anxious, or angry. Both mothers and fathers of children with an anxiety diagnosis engaged in less explanatory discussions of the causes and consequences of emotions across all emotions than mothers and fathers of nonanxious children. Interestingly, little support was found for the hypothesis that parents of anxious children would discourage the discussion of emotions such that, in terms of anger only, fathers of anxious children discouraged the discussion of emotion more than mothers and fathers of nonanxious children. The age of participating children may help account for this finding. More specifically, older children with anxiety may have been previously socialized to engage in less discussion of their emotion. Partial support can be found within this same study in that anxious children engaged in less discussions overall of their emotions than nonanxious children during these interactions.

These findings provide evidence that parents of anxious children differ in their expressiveness of emotions and may socialize their child's emotions differently than parents of nonanxious children. The causal nature of these findings, however, cannot be assumed. It is equally plausible that parents modify their emotion socialization behaviors as a result of their child's anxiety. Moreover, the interaction between course of the child's anxiety and the pattern of socialization practices over the path of development is also uncertain. It is not known whether these socialization practices are typical behaviors of the parent or whether the child's anxiety disorder is longstanding. As noted above, childhood anxiety is often left 
untreated and runs a prolonged course. Thus, children with anxiety and their parents may establish patterns of behaviors as a result of the untreated anxiety disorder - a pattern of behavior that serves as an additional maintaining factor for the symptoms.

Though these studies have supported differential socialization practices among families with anxious and nonanxious children, the developmental nature remains to be examined. Longitudinal studies are critical to examine for changes in the relationships between socialization practices of the parent, emotional competence of the child (including both emotion understanding and regulation), and anxious symptoms across the development of the child. It may be necessary for future studies to examine children specifically at-risk for the development of anxiety and track for transformations in the trajectories of these children over time, in an effort to identify the role of emotion socialization practices in the protection from or development of anxiety. Notwithstanding the importance of a parent's beliefs about emotions, additional factors have also received empirical attention as influencing parental emotion socialization practices and which unquestionably affect their relationship to child outcome.

\section{Additional Influences to Parental Emotion Socialization}

To this point, the focus of this review has been primarily grounded in literature on the impact parents have on their child's outcome. However, acknowledging a developmental psychopathology perspective reveals various factors which can impact a parent's socialization of their child's emotional 
competence (Cicchetti et al., 1995; Cummings et al., 2000). It is acknowledged that the relationships and the degree of influence of these factors is also not likely constant across the development of the child. For example, as noted previously, a parent's role as the primary socializer of their child's emotions likely waxes and wanes across development. The child's dependence on their parents for guidance regarding the identification of emotions and the skills necessary for their modulation transforms from early to late childhood and even from late childhood into adolescence (Eisenberg et al., 1998). Further, once children enter school, peers have a much larger impact on their emotion competence. This section will briefly review several parent and child factors that are hypothesized within this model to impact a parent's socialization of emotion.

\subsection{Temperament}

The relationship between parental emotion socialization behaviors and a child's temperament may be bidirectional (Yap, Allen, Leve, \& Katz, 2008). In their early work on meta-emotion philosophy, Gottman and colleagues found no associations between the mother's report of their child's temperament and emotioncoaching philosophy (Gottman et al., 1996, 1997). In contrast, research on children with ADHD provides some evidence that temperament interacts with parenting style such that both a parent's rating of their child's temperament and their selfreported parenting style (i.e., controlling and autonomy granting) predicted unique variance in both anxious and avoidant attachment (Finzi-Dottan, Manor, \& Tyano, 2006). Using a nonclinical population, an additional study found that inhibited preschool children with highly responsive mothers, who were highly responsive 
toward their child's emotional expression, exhibited greater emotion regulation strategies than inhibited children with moderately responsive mothers (Yagmurlu \& Altan, 2010). A meta-analysis on the impact of young children's negative emotionality and parenting (not specifically related to emotions) found a weak, but significant relationship across 62 studies (Paulussen-Hoogeboom, Stams, Hermanns, \& Peetsma, 2007). Thus, children with high reactivity or negative affectivity may challenge the parent's role as a teacher and coach of their child's negative emotions. Further, investigations of the interaction between temperamental characteristics of children at risk for anxiety (e.g., behaviorally inhibited and high negative affectivity) and parental socialization practices are warranted. Parents who provide early assistance to their behaviorally inhibited child in understanding their emotions and how to effectively regulate them may act as a buffer against their child's development of clinically relevant symptoms of anxiety.

\subsection{Gender}

A significant portion of research in the field of emotion socialization has focused primarily on the role of the mother (Wong et al., 2009). Nonetheless, several studies have examined both the mother and the father in the socialization of their children and findings across them suggest that the patterns of emotion socialization practices between mothers and fathers are quite complex (Cunningham et al., 2009; Denham et al., 1997; Garside \& Klimes-Dougan, 2002; Gottman et al., 1997; Wong et al., 2009). In general, fathers appear to be less supportive toward their child's expression of negative emotions than mothers (Nelson, O'Brien, Blankson, Calkins, \& Keane, 2009). 
More is known about the differences in terms of boys' and girls' experiences of emotions and separate developmental trajectories have been identified (see Brody \& Hall, 2000 for a review). In addition, an interaction likely exists between the gender of the parents and the gender of the child. Existing work has generally found that mothers report being more expressive of negative emotions with their daughters than with their sons (Brody \& Hall, 2000; Wong et al., 2009). Mothers may also more readily engage their daughters in discussions of negative affect due to differential beliefs about the expression and regulation of their daughter's emotions, which are a direct result of their own gender-specific socialization history (Dunsmore \& Karn, 2001; Wong et al., 2009). It is critical that future work include the gender of both the parent and child in examining the impact of socialization practices and beliefs about emotions on the development of child anxiety.

\subsection{Marital Relationship}

The marital relationship is also hypothesized to impact a parent's emotion socialization. Among parents of school-aged children, mothers and fathers diverged from their reports of similar responses to negative emotions when the role of the child's negative expressivity, the marital relationship, and parental beliefs about emotions were considered (Wong et al., 2009). Specifically, fathers who reported greater marital conflict and ambivalence reported responding to their highly negative children with more nonsupportive responses. In contrast, mothers reported more negative expressiveness when these same factors were considered. Stress has also been shown to impact a parent's ability to appropriately respond to their child's expression of negative emotion (Nelson et al., 2009). Overall, mothers 
are more supportive in response to their child's negative emotion compared to fathers, however, higher marital dissatisfaction was linked with less support from both parents following child negative emotions. Higher perceived family chaos was also linked with higher rates of un-supportiveness by both parents following child negative emotions. Further, when one parent reported dissatisfaction with their employment, the other spouse was equally less likely to be supportive following expressions of child negative affect.

\subsection{Discussion}

As suggested throughout this review, an examination of the differences in parent's emotion socialization practices across the development of both anxious and nonanxious children is necessary. Studies examining parental socialization behaviors within families that include both anxious and nonanxious children will also provide information into the interactional nature of emotion socialization practices and child factors. For instance, parents may socialize the emotions of their non-disordered children differently from their anxious siblings within the same household. Thus, complex and mutually influential relationships exist in the impact of outside stressors, such as job dissatisfaction, the marital relationship, and psychopathology of the parent, on a parent's individual socialization practices.

\section{Integration and Discussion of the Model}

The inclusion of emotional processes among theoretical models of psychopathology has provided the field with additional areas for empirical work. The affective system, in many ways, serves as an impetus for the "fight or flight" 
response to threat and demonstrates the necessity of emotions as an adaptive function (Baker, Holloway, Thomas, Thomas, \& Owens, 2004). When emotional responses are recurrently excessive, and not congruent with the context within which they occur (e.g., an intense fear response to a situation that is unlikely dangerous), the individual is at significant risk for impairments in functioning and psychopathology. Thus, children characterized by these response patterns along with more frequent negative affectivity, marked difficulty in regulating their negative emotions, high degrees of autonomic arousal, and behavioral inhibition are at increased risk for developing an anxiety disorder (Anthony, Lonigan, Hooe, \& Phillips, 2002; Fox, Henderson, Marshall, Nichols, \& Ghera, 2005; Rothbart, Ellis, \& Posner, 2011). These factors have historically been regarded as driven primarily by genetics and largely unaffected by forces external to the child; however, more recent approaches have rejected this overly simplistic dichotomy and now acknowledge the influence of the environment on these various risk factors for anxiety (Murray \& Kochanska, 2002). The model proposed here integrates parental emotion socialization practices and the child's emotional competence as critical factors in the process of developing anxiety during childhood (see Figure 1 below). 


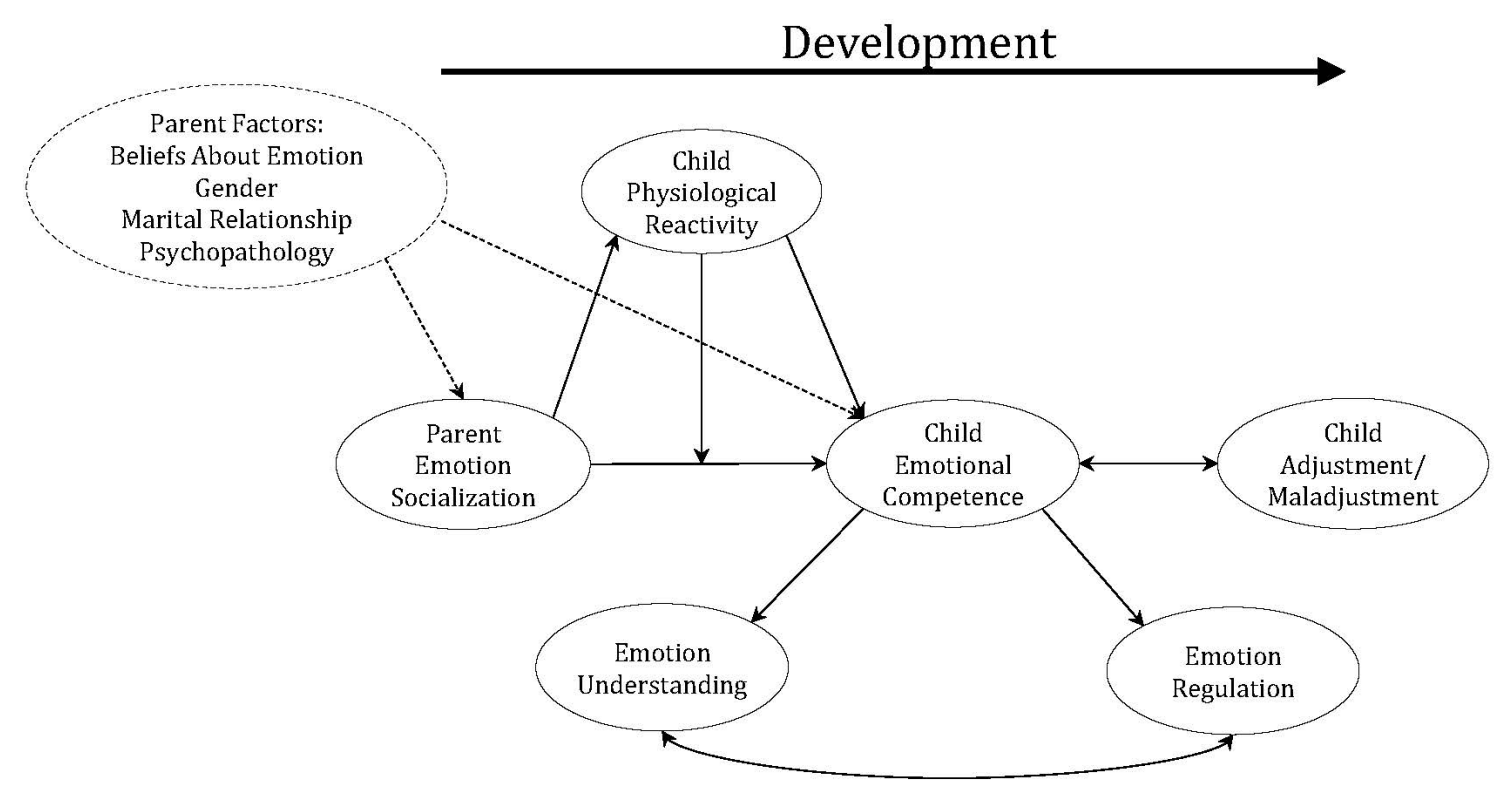

Figure 1. A model of risk for anxiety through the role of parent emotion socialization and child emotional competence.

Parents are expected to have a casual influence on their child's development of skills in understanding and regulating their emotions both directly and indirectly through patterns of behavior in relation to the experience and expression of emotion. For example, a parent who fails to assist their child in labeling and understanding emotional experiences with regard to the context in which they occurred is expected to influence their child's ability to accurately recognize, predict, and explain their emotional experiences. The impact of this pattern of responses to a child's emotion regulation is not surprising. These parents are also hypothesized to less frequently assist their children in learning emotion regulation strategies or impart ineffective methods. Further, their children are forced to endure emotionally-charged situations lacking adequate, developmentally appropriate skills for understanding their emotional responses, along with little to 
no effective methods in coping with and regulating these emotions. During emotionally salient situations, it is expected that this child would misidentify the source of their emotional experience, engage in unsuccessful attempts at coping with their affective reactions, and believe that they do not possess much control over their emotions. Through repeated unsuccessful experiences of this nature, with little to no support from their parents, the child is expected to internalize the belief that they are incapable of mastering emotionally charged situations, feel a sense of decreased self-efficacy, and attempt to control their emotions through inhibition attempts. Additionally, the child's decreased sense of control over their affective responses and lack of information on the successful navigation of potentially negative situations are thought to lead to a heightened attention towards threat in the environment along with a tendency to withdrawal from and avoid future ambiguous or potentially threatening situations. These prototypical anxious behaviors are then reinforced and maintained to the degree that they provide the child relief from their seemingly unpredictable, overwhelming and uncontrollable emotional responses.

This model also integrates a child's physiological responsiveness by way of its conjoined relationship with the affective system to the "fight or flight" response to threat. Stress, a variation of threat specifically involved in anxiety disorders, activates increased sympathetic activity, including accelerations in heart rate. Once the stressor is removed, however, the parasympathetic system prompts the vagus nerve to slow heart rate (i.e., the vagus reflex) and activate other processes to return the system to its previous state of homeostasis. Ideally, activity in the vagus nerve 
suppressing the sympathetic nervous system is dampened during periods of reduced stress and minimal threat, and heightened when stress is increased or threat is present (Porges, 2007). In terms of anxious children, support has been found for differential vagal reflex profiles, which are characterized by rapid resting heart rate (Rogeness, Cepeda, Macedo, \& Fischer, 1990), exaggerated heart rate acceleration in response to stress (van Lang et al., 2007), and low baseline vagal tone (Beauchaine, 2001; Calkins \& Dedmon, 2000; Hastings, 2005). As previously discussed, physiological response patterns were historically regarded as impervious to environmental influences, however, contemporary theoretical models have dismissed this notion and empirical data supporting these theories are mounting. Considerations in terms of patterns of physiological reactivity and environmental influences are particularly intriguing among child populations, given the ongoing maturation process of the biological system along with the differential influences of parents throughout childhood (Calkins \& Hill, 2007). Studies exploring physiological reactivity have supported its role both as a mediator and a moderator in the relationship between parent behaviors and behavior difficulties (Calkins, Graziano, Berdan, Keane, \& Degnan, 2008; Hastings \& De, 2008; Hastings et al., 2008). Further, evidence has supported physiological reactivity as a moderator in the relationship between parental responses to child distress and child emotion regulation (Perry et al., 2012). Children who exhibited profiles of physiological reactivity characterized by low vagal suppression (i.e., maladaptive) in response to a stressor and who had parents who reported more unsupportive parenting behaviors in response to their child's distress were less able to regulate their own emotions. This association 
between parent behaviors and child emotion regulation was not found, however, among children with high vagal suppression (i.e., adaptive) in response to stress. Thus, it may be that children with better internal physiological regulation are buffered from the deleterious impacts to their own regulation of emotions from their parent's unsupportive responses to distress. In contrast, it is equally plausible that physiological reactivity acts as a mediator in the relationship between parent behaviors and child emotional competence. Children with biological profiles that are prone to high degrees of autonomic arousal are at increased risk for difficulties in self-regulation (Calkins et al., 2008; Calkins \& Hill, 2007). These children may also rely on their parents more for assistance in regulating their distress, whereas children with more adaptive internal physiological reactivity likely express less outward signals of emotion dysregulation and rely on their parent's assistance for regulation more infrequently. Further, given the proposed influence from the environment on biological processes, it is possible that parental responses to expressions of distress indirectly influence their child's emotional competence by way of their child's physiological arousal (Hastings et al., 2008). To date, data have supported hypothesizing that physiological reactivity exerts both mediating and moderating effects on the relationship between parent emotion socialization and child emotional competence in determining risk for anxiety. As such, both will be explored in this study.

Though discussed in brief several times throughout this review, the developmental stage of the child is, perhaps, the cardinal factor to understanding the relationships within the model. Beginning in infancy, parents act as the primary 
regulators of their children's emotional experiences (Saarni, 1999). As children develop and thereby make gains in their cognitive capacity, parents begin to teach them emotion regulation skills, provide various opportunities to directly practice these skills (e.g., a parent who is warm but firm during a temper tantrum as the child learns to manage his or her own feelings of frustration), then gradually relinquishes the work to the child as it becomes developmentally appropriate to do so. This typically occurs around the time when children enter preschool, as they then spend more time in unfamiliar environments and, ideally, begin cultivating social connections independent of their familial attachments. Concurrent to cognitive and emotional development, the child's autonomic nervous system is also transforming, developing, and becoming better regulated (Porges, DoussardRoosevelt, \& Maita, 1994). As such, several of the relationships illustrated within the model are expected to be bidirectional in nature. It is hypothesized that the degree and direction of these relationships varies by developmental stage of the child.

The proposed model provides a unique contribution to the literature on parenting and child anxiety and may afford ancillary clues into the development of anxiety during childhood. Very little empirical work exists exploring both extrinsic factors, such as parenting behaviors, and intrinsic factors, such as physiological reactivity to stress, as they interact in complex ways to predict the development of anxiety disorders. As an additional advantage, research using this framework may shed new light on the familial transmission of anxiety, such that parents struggling with anxiety symptoms themselves would be expected to socialize their own child's experience of anxiety in ways that are divergent from that of nonanxious parents. 
Results will also inform the treatment and prevention of childhood anxiety. Several researchers have proposed a more emotion-focused, unified protocol for the treatment of children with psychopathology (Trosper, Buzzella, Bennett, \& Ehrenreich, 2009) and empirical support for this framework provides rationale for a family-based, emotion-focused treatment of anxiety in childhood.

\section{The Current Study}

Empirical validation of the model proposed here, which hypothesizes multiple relationships between various parent factors (e.g., marital relationship, beliefs about emotion, etc.), parental emotion socialization practices, and a child's emotion understanding, emotion regulation, physiological reactivity, and anxiety, is a substantial undertaking. Further, the relationships between and among these variables are expected to vary across the development of the child resulting in additional complexities. Although there appears to be empirical support for some of the associations within the model, no known study to date has attempted to examine child physiological reactivity as a mediator/moderator in the relationships between parent emotion socialization, child emotion understanding, and emotion regulation to predict child anxiety. The aim of the current study is to begin systematically testing the hypothesized relationships using a cross-sectional study design. It is anticipated that findings from this study will provide the necessary rationale for a larger, more extensive longitudinal investigation into the role of emotions and the development of anxiety disorders within childhood. 
In an effort to provide the support necessary for these future studies, it is logical to begin by validating the proposed relationships between constructs. Thus, this study examines associations between four child variables (emotion understanding, emotion regulation, physiological reactivity, and child anxiety) and one parent variable (emotion socialization). Further, it is necessary to explore for potential effects of child age and gender on each one of the associations considered. These variables and the associations tested are illustrated below in Figure 2.

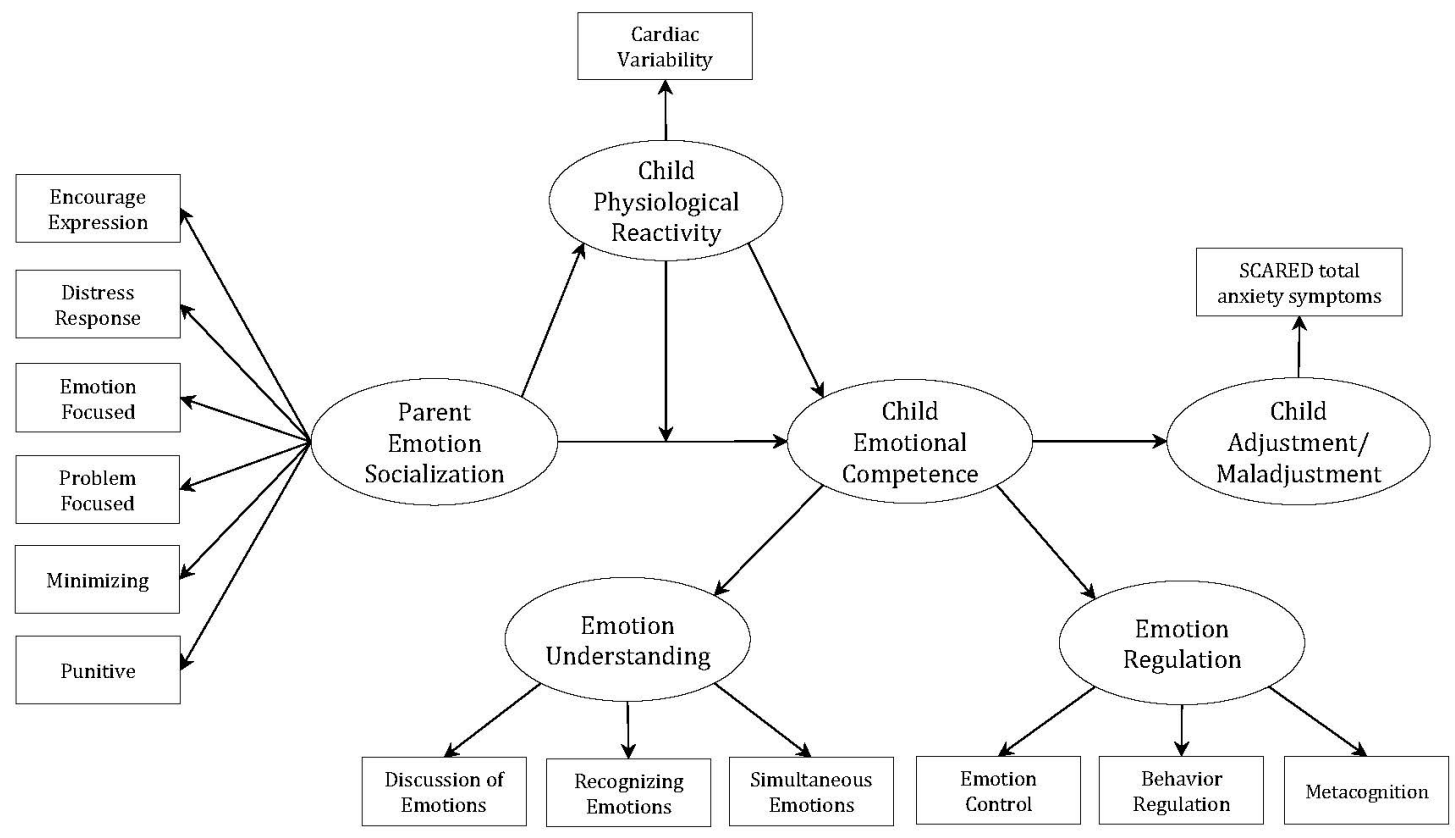

Figure 2. A model illustrating the hypothesized relationships to be tested between measures of emotion socialization, emotional competence, physiological reactivity and child outcome.

Indeed, longitudinal data are ideal in terms of more fully understanding these relationships within the context of the developing child to predict anxiety. However, apropos of the costs and time-consuming nature of longitudinal studies, a cross-sectional design is more feasible and may provide adequate justification for 
more extensive examinations. Thus, the current study focuses on cross-sectional data collected from both the parent and one biological child. Children chosen to participate in this study had reached an age when it is typical to begin formal schooling. By five years of age, most children have reached a level of cognitive development in which they are capable of understanding the nature of the mind and are aware of the connection between their internal state and their external behavior (e.g., Baird \& Moses, 2001; Wellman, Cross, \& Watson, 2001). Additionally, focusing on children prior to reaching teenage years ensures that the influence of their parents is still relatively significant (Jakes \& DeBord, 2010). Empirical validation for the hypothesized relationships among children within this age-range provides rationale for future studies to examine the strength of these associations among populations of both younger and older children.

To begin this validation, several related hypotheses were systematically tested across three levels of analysis.

Level One. Demonstration of the validity of parent emotion socialization and child emotional competence.

Prior to examining associations between the constructs of interest, it is necessary to confirm the content validity of parent emotion socialization and child emotional competence. These constructs have not been used consistently within the literature and, therefore, a demonstration of relationships existing between their contained factors was needed. 
Hypothesis 1: It was expected that variables within the construct of parent emotion socialization would be correlated.

Hypothesis 2: It was expected that variables of emotion understanding would correlate with variables of emotion regulation to establish the larger construct of child emotional competence. Both emotion understanding and emotion regulation were expected to correlate positively with child age.

Level Two. Examination of the relationships between parent emotion socialization, child emotional competence, and child physiological reactivity.

Having established the validity of parent emotion socialization and child emotional competence, the relationships between them were examined.

Hypothesis 3: It was hypothesized that parent emotion socialization would predict measures of child emotion understanding and emotion regulation. More specifically, a negative association was expected, such that parents who exhibit more unsupportive emotion socialization practices would have children who achieved lower scores of emotion understanding and emotion regulation. Child age was expected to mediate this relationship.

Next, to better understand the role of the child's arousal in the relationship between parent emotion socialization and the child's emotional competence, the effect of physiological reactivity was tested. No known study to date has attempted to examine associations between these three variables. Previous literature has somewhat supported the notion that not only does caregiver behavior affect a child's development of self-regulation (Calkins, 2004; Calkins et al., 2008; 
Crockenberg \& Leerkes, 2004, 2006), but that the degree of functioning of a child's biological regulatory system may also impact the child's acquisition of emotional competence (Calkins \& Hill, 2007; Calkins \& Keane, 2004; Gunnar, 2006). It may be that parent emotion socialization predicts child emotional competence by way of an indirect association through child physiological reactivity. However, it is equally plausible that an interaction between the child's physiological reactivity and parent emotion socialization best estimates a child's emotional competence. Existing work supports hypothesizing each; therefore, both types of associations were explored.

Hypothesis 4: The degree of a child's physiological reactivity was expected to mediate the relationship between parent emotion socialization and child emotional competence, such that it accounts for the predictive power of parent emotion socialization in estimating the child's emotional competence. More specifically, it was hypothesized that parent emotion socialization practices have an indirect influence on child emotional competence through the child's physiological responsiveness. Child age was expected to have an effect on each of the relationships between these variables.

Hypothesis 5: The degree of a child's physiological reactivity was expected to moderate the relationship between parent emotion socialization and child emotional competence. More specifically, it was hypothesized that a child's physiological reactivity would determine the strength of the association between parent emotion socialization practices and child emotional competence. Additionally, it was expected that these relationships would also be influenced by the age of the child. 
Level Three. Examination of the influence of parent emotion socialization, child emotional competence, and child physiological reactivity on child anxiety.

Finally, how these variables operate to predict anxiety was examined.

Hypothesis 6: A causal pathway was hypothesized from parent emotion socialization practices through child emotional competence to child anxiety. Given the nature of its hypothesized role, child physiological reactivity was also expected to have a causal role on child emotional competence to predict child anxiety. As with all previous hypotheses, these relationships are expected to vary depending on the age of the child. 


\section{METHOD}

\subsection{Participants}

Participants included in this study were drawn from a larger study on child anxiety. Recruitment was conducted through distribution of informational flyers and emails within the local Catholic and public school systems. Additionally, flyers describing the study were distributed at several community agencies, including libraries, coffee shops, farmer's markets, doctor's offices, and specialty clinics. All recruitment materials were submitted and received approval through the University of Louisville's Institutional Review Board prior to dissemination. Interested families were invited to contact the lab for additional information and were screened during this time to ensure that inclusion criteria for the study were met. Families with a biological child between the ages of 5 and 12 years were encouraged to enroll; however, only one child and one parent per family were eligible to participate. Children with a known developmental delay or disability were not eligible for enrollment in the study.

The final sample included 85 parent and child dyads. Very few fathers participated in the study $(n=9 ; 10.6 \%)$. Parental age ranged from 28 to 57 years of age $(M=40.63 ; S D=5.97)$. The majority of participating parents were married $(n=$ 74; 87.06\%); 6 parents (7.06\%) reported being divorced, 2 (2.35\%) reported being separated, and 3 (3.53\%) reported being single. In terms of the ethnic composition of participating parents, 80 (94.12\%) were Caucasian American, 4 (4.70\%) were 
African American, and 1 (1.18\%) was Asian. Family household income ranged from less than $\$ 5,000(n=2 ; 2.35 \%)$ to over $\$ 60,000(n=63 ; 74.12 \%)$, with almost $90 \%$ of the sample earning over $\$ 30,000$. Less than half of the participating children were female $(n=35 ; 41.18 \%)$. Child age ranged from 5 to 12 years of age $(M=8.36 ; S D=$ 1.77). In terms of ethnic composition, 77 children (90.59\%) were Caucasian American, 4 (4.70\%) were African American, 1 (1.18\%) was Asian, and 3 (3.53\%) reported as being of mixed ethnicity.

Eighty-five families completed the study questionnaires. A total of 44 (51.76\%) children from this total sample completed the optional computer task and emotion interview. To ensure maximum power, analyses were conducted utilizing the full sample, with the exception of those where physiological data were included, resulting in an $n$ of 44 for those analyses.

\subsection{Procedure}

Study participation included parent report measures, a brief interview with the child, and completion of a short computer task. Participation in the computer task and brief interview required that the family make a one-time visit to the Developmental Psychopathology Research Lab, thus this portion of the study was considered optional. Families who did not complete this additional portion of the study were sent study materials by mail. Prior to being provided a study packet, the study procedure, confidentiality, as well as risks and benefits for participating were reviewed with both parent and child. Participants were informed of the voluntary nature of enrolling in the study and any questions or concerns were addressed. Parents were asked to provide informed consent and parental assent documents for 
both their participation, as well as their child's. Children, ages 7 and up, were asked to sign an additional assent document for their participation. In terms of the computer task and interview, children were brought into a separate room to complete this portion of the study. All questionnaires along with the computer task and interview are described in detail below. Study sessions (including time to review consent and assent along with addressing questions and concerns) lasted approximately 30 minutes to one hour, and families were compensated $\$ 15$ for their time and effort.

\subsection{Power Analysis}

The required sample size was calculated a priori using $G^{*}$ Power 3.1 (Faul, Erdfelder, Buchner, \& Lang, 2009). To detect a moderate effect size (0.40) with a power of (0.80) for correlation analysis a sample size of 46 is needed. To detect a moderate effect size (0.30) with a power of $(0.80)$ for regression analysis with 7 predictor variables a sample size of 56 is needed. As a result a minimum sample size of 56 was needed for the current study.

\subsection{Measures}

Please see Appendix A for copies of both self-report and parent-report questionnaires

\subsubsection{Parent Measures}

Behavior Rating Inventory of Executive Function (BRIEF; Gioia, Isquith, Guy, \& Kenworthy, 2000): The BRIEF is a questionnaire intended for use with parents of children aged 5 to 18 years to assess executive function. The measure contains 86 items that are comprised from descriptors of various problem behaviors. Parents 
are asked to rate their child's behavior using a three-point Likert scale (Never, Sometimes, Often). Items are organized into eight nonoverlapping clinical scales (Inhibit, Shift, Emotional Control, Initiate, Working Memory, Plan/Organize, Organization of Materials, and Monitor), two clinical indexes (Behavior Regulation and Metacognition), and a Global Executive Composite. The measure also provides two validity scales: Negativity and Inconsistency of responses. Raw scores are summed for each of the ten scales and two indexes. Sums of scores are then converted to both age- and sex-specific T-scores. T-scores of 65 and above indicate the child may be experiencing clinical significant problems in that area of functioning.

The BRIEF has achieved high internal consistency for the scaled and index scores ( $\alpha$ coefficients ranging from 0.80 to 0.98 ). Test-retest reliability was assessed following a mean retest interval of approximately four weeks. Using the Global Executive Composite score, high test-retest reliability was observed $(\alpha$ coefficient $=$ 0.82). The measure correlates in expected directions with other parent rating scales of inattention, impulsivity, and learning skills, which are indicative of executive function.

For purposes of the current study, three subscales from this measure were used to assess the child's cognitive and behavioral abilities in regulating their emotions (Emotion Control, Behavior Regulation, and Metacognition). These subscales were averaged together to create an emotion regulation composite (composite $\alpha=0.86$ ). Bivariate intercorrelations between these three subscales 
provided additional evidence as to the their high degree of correlation $(r$ s from 0.55 to $0.92, p s<.001$ ).

Coping with Children's Negative Emotions Scale (CCNES; Fabes, Eisenberg, \& Bernzweig, 1990): The CCNES is a widely used measure for the assessment of parental socialization responses to their child's expressions of negative emotions. The measure consists of twelve vignettes depicting hypothetical scenarios of their child expressing distress (e.g., "If my child loses some prized possession and reacts with tears, I would: ...”). For each situation, six possible responses to the situation are provide and parents are asked to rate, on a six-point Likert scale (" 1 " = Very Unlikely to "7" = Very Likely), how likely they are to respond with each of the six responses. The measure yields six subscales (Emotion-focused, Problem-focused, Minimizing, Punitive, Expressive Encouragement, and Distress Responses), which provide an indication of how parents perceive their own responsiveness to their child's expressions of various types of negative affect (e.g., sadness, fear, anger, etc.).

In previous studies, the six subscales of the CCNES have achieved coefficients within the acceptable range in terms of the measure's internal consistency ( $\alpha$ coefficients ranged from 0.61 to 0.92 ). Test-retest reliability was assessed following a mean retest interval of approximately sixteen weeks. Across all six subscales, good test-retest reliability was observed ( $\alpha$ coefficients ranged from 0.69 to 0.85 ). Additionally, the measure correlates ( $r$ s ranging from 0.25 to 0.39 ) with other measures of parental affect expression (Linehan, Paul, \& Egan, 1983), parental control (Greenberger, 1988), and interpersonal reactivity (Davis, 1983).

According to previous studies utilizing this measure, the six subscales of the 
CCNES can be grouped further to create two composites: supportive and unsupportive parenting (DeBoard-Lucas, Fosco, Raynor, \& Grych, 2010; Nelson et al., 2009; Shaffer et al., 2012). More specifically, scores from the Minimizing Reactions, Punitive Reactions, and Distress Reactions subscales were averaged together to create the composite measure of unsupportive parent emotion socialization (composite $\alpha=0.74$ ). Similarly, scores from the Problem-Focused, Emotion-Focused, and Expressive Encouragement subscales were averaged together to create the composite measure of supportive parent emotion socialization (composite $\alpha=0.66$ ).

\section{Screen for Child Anxiety Related Disorders - Parent Version (SCARED-P;} Birmaher, Khetarpal, Cully, Brent, \& McKenzie, 1995): The SCARED-P is a 41-item questionnaire designed to assess for child and adolescent symptoms of anxiety. Parents are asked to rate items, using a 3-point Likert scale ("0" = almost never, "1" = sometimes, and " 2 " = often), according to how frequently they believe that their child experiences each symptom. Items are summed to create five subscales. Four of these subscales assess the symptoms comprising panic/somatic disorder, generalized anxiety disorder, separation anxiety disorder, and social anxiety disorder in accord with the diagnostic criteria outlined in the DSM-IV-TR (American Psychiatric Association, 2000). The fifth subscale assesses for symptoms of school anxiety, which has been identified as a common anxiety complaint among children and adolescents (Birmaher, Khetarpal, Brent, \& Cully, 1997). Additionally, the sum of all of the items contained within this instrument provides a general indication of the child's overall experiences of anxiety symptoms. Total scores falling at or above 25 
are suggestive of a child who is experiencing clinically significant symptoms of anxiety. The SCARED-P has demonstrated strong internal validity with Cronbach's

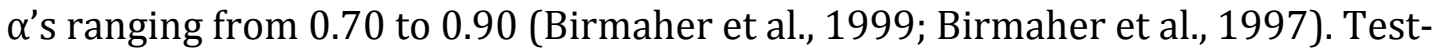
retest reliability was assessed following a mean retest interval of approximately five weeks. Using the total anxiety symptom scale, high test-retest reliability was observed (intraclass correlation coefficient $=0.86$ ). Further, test-retest reliability scores for the five subscales were also noted to be good (intraclass correlation coefficient between 0.70 and 0.90 ).

The SCARED exhibits strong divergent validity, such that it differentiates children with anxiety disorders from children with depression and disruptive difficulties (Birmaher et al., 1999; Birmaher et al., 1997). Additionally, subscales and the total anxiety symptoms scale of this measure have been found to be strongly correlated in expected ways with three widely used measures of child anxiety, namely the State-Trait Anxiety Inventory for Children (rs ranging from 0.35 to 0.73; Muris, Merckelbach, van Brakel, Mayer, \& van Dongen, 1998), the Revised Children's Manifest Anxiety Scale (rs ranging from 0.38 to 0.86; Muris et al., 1998), and the Fear Survey Schedule for Children-Revised (rs ranging from 0.32 to 0.61; Muris, Merckelbach, Mayer et al., 1998).

Responses on the SCARED-P from the current study sample had excellent internal consistency $(\alpha=0.92)$. For the purpose of this study, the total anxiety symptoms scale was used to provide an estimation of the child's overall experience of anxiety symptoms.

\subsubsection{Child Measures}


Kusche Affective Interview - Revised (KAI-R; Kusche, Greenberg, \& Beilke, 1988): The KAI-R is an interview-based assessment of children's emotion understanding at both the experiential and metacognitive level. The semi-structured interview is designed to assess various domains of emotional competence during childhood, including the ability to discuss emotion-related experiences (e.g., "Tell me about a time when you felt sad."), recognition of emotions in self and others (e.g., "How do you know when other people are feeling jealous?"), and understanding of how emotional experiences can change (e.g., "Suppose you were feeling upset, could your feelings change?" and if so, "Tell me what would happen."). Children are presented with a series of open-ended questions and responses are recorded verbatim. The responses are then transcribed and coded according to the child's degree of competence within each component. Coders are trained in a coding scheme developed specifically for this measure. Degree of developmental competence within these components is rated based on a scoring system developed according to the three Piagetian levels of cognitive development (Preoperational, Transitional, and Concrete operations; Carroll \& Steward, 1984). A forth level (Level 0 ) was added to indicate refusals to answer, inability to answer (i.e., "I don't know."), vague, unclear, and/or inappropriate answers. Only the components related to emotion understanding (Discussion of own emotional experience, Cues to recognize emotions, and Understanding simultaneous emotions) were considered for this study.

The KAI-R has sustained extensive use in both developmental and clinical research (Greenberg et al., 1995) and its coding system has demonstrated excellent 
inter-rater reliability (coefficients ranged between 0.79 and 1.0) across several studies (e.g., Bohnert, Crnic, \& Lim, 2003; Southam-Gerow \& Kendall, 2000). High internal consistency has also been reported (Cook et al., 1994; Greenberg et al., 1995). In terms of this study, a second rater coded one-third of the interviews and inter-rater reliability was shown to be within acceptable range (correlation coefficients ranged between 0.51 and 0.74 ). Additionally, internal consistency for the three factors of emotion understanding used in this study, Discussion of own emotions, Recognizing emotions, and Simultaneous emotions, were excellent ( $\alpha$ s = $0.74,0.81$, and 0.84 , respectively).

\subsubsection{Computer Task and Physiological Recordings}

Children were asked to participate in a brief computer task designed for use in this study to assess autonomic responsiveness. During this task, children were seated, facing a computer screen, and asked to passively view several images while measures of heart rate and respiration were recorded using the Biopac MP150 data acquisition software for QRS wave detection. Hardware settings were as follows: Gain - 1000; Mode - NORM; LPN Filter - 35Hz; HP Filter - 0.5Hz. To minimize possible discomfort resulting from the typical number of leads used with adults for heart rate recordings, the 3-lead method was employed and electrode placement was made according to Einthoven's triangle. All three leads were attached using sterile adhesive disks, which were moistened with a nonirritating, conductivity gel. Electrodes were attached to both wrists on the side facing the palm of the hand and one electrode was placed on the medial surface of the left leg. To record respiration, 
a respirator transducer was fitted snuggly across the child's chest, over clothing, wrapped under the armpits, and attached at the back.

The child was asked to remain quiet, in front of the screen, with arms relaxed and in a comfortable position throughout the recording process. To assess physiological variability, material presented to the child included ten images depicting either threatening or neutral content (see Appendix A). The images were displayed in color on a computer screen. Prior to the presentation of material, baseline EKG was gathered for sixty seconds. Each image was then displayed for 8 seconds with a 10 second intertrial interval, during which a white crossbar on a black background was presented in the center of the screen as a focal point. Image presentation was ordered randomly with no more than three consecutive images containing content of the same type (i.e., threat or neutral).

EKG recordings were then inspected, cleaned, transformed, and analyzed using the Biopac AcqKnowledge software program. Waveforms were cleaned using FIR band pass. Filter was set to between 0.5 and $35 \mathrm{~Hz}$, using 8000 coefficients. This digital filter served to remove baseline drift, as well as high frequency noise, such as that associated with excessive movement. Waveforms were then visually inspected for artifacts. Any artifacts noted in the data were removed using Equation Generator, which sets the artifact to a value of 0 thereby eliminating it mathematically from any calculations performed on the waveform.

Physiological responsiveness was measured as change in cardiac beats per minute (BPM) in response to threatening versus neutral stimuli. More specifically, measurements of BPM were collected during the period following removal of the 
stimulus, or the intertrial interval. Mean scores across the 5 trials each of threatening and nonthreatening content were computed. Cardiac variability was then calculated by subtracting the mean BPM measurement following neutral stimuli from the mean BPM measured following threatening stimuli. Positive differences are indicative of higher decreases in cardiac activity in response to neutral, or non-threatening, stimuli, and are suggestive of stronger vagal control (Calkins, 1997). Lower values indicate decreased variability, or less change, in response to threatening and neutral information. 


\section{DATA ANALYSIS}

\subsection{Preliminary Analyses}

Variables were explored for group differences in terms of parent or child gender, marital status of the parent, household income, and parent education level. Given that not all participants within this sample completed the optional computer task and interview, these two groups (completers versus non-completers) were tested for differences in terms of demographic variables, anxiety symptomatology, and emotion regulation skills using a one-way Analysis of Variance. Pairwise comparisons indicated that children who participated in the optional computer task and emotion interview exhibited more symptoms of anxiety $(M=3.85, S D=1.48)$ than those who chose not to complete this portion of the study $(M=2.97, S D=1.86$; $F(75)=5.29, p=.02$ ). Further, children who completed the computer task and interview had parents who were more highly educated $(M=5.65, S D=1.60)$ than those who did not $(M=4.78, S D=1.57 ; F(83)=6.31, p=.01)$.

Significant relationships among parent or child age and gender, and the study variables were also explored. The subscales of the BRIEF and SCARED-P total scores were not related to any study variables. Several interesting findings emerged in terms of the CCNES. Specifically, Expressive Encouragement was significantly and negatively correlated with child age $(r=-0.24, p=.03)$, indicating that parents reported being more likely to encourage their younger children to express their emotions when they are upset. In terms of Problem-Focused reactions, mothers 
were significantly more likely to report using problem-focused approaches when their child is upset $(M=5.92, S D=0.59)$, than fathers $(M=5.43 S D=0.95 ; t(78)=-$ 2.21, $p=.03$ ). Significant positive correlations were also found between Minimizing Reactions and both child age $(r=0.23, p=.02)$ and child gender (gender coded as female $=1$ and male $=2 ; r=0.27, p=.02$ ).

In terms of emotion understanding, older children were found to perform better on all three factors: Discussion of emotions $(r=0.69, p<.001)$, Recognizing emotions $(r=0.67, p<.001)$, and Simultaneous emotions $(r=0.57, p<.001)$. Further, female children were also denoted to perform better on all three factors: Discussion of emotions ( $r=0.50, p<.001)$, Recognizing emotions $(r=0.47, p<.01)$, and Simultaneous emotions $(r=0.51, p<.001)$. In terms of emotion regulation, no significant relationships were denoted across any of the demographic variables, though all three factors were found to be significantly and positively correlated with cardiac variability: Emotion Control $(r=0.47, p=.002)$, Behavior Regulation $(r=$ $0.48, p=.001)$, and Metacognition $(r=0.34, p=.03)$.

\subsection{Examination of model assumptions}

Prior to hypothesis testing, data were examined to ensure all model assumptions had been met. This study utilized correlations and regression equations to test the proposed hypotheses, thus, the following assumptions were explored. Study design ensured independence of observations. Standardized residual values were calculated and graphed as scatterplots. These scatterplots were visually inspected for normal distribution, linearity, and homoscedasticity. Normal distribution was examined for each variable using the Kolmogorov-Smirnov 
test. Skewness and kurtosis values were also checked to ensure the data were normally distributed before hypothesis testing. Scores on the three subscales of the BRIEF were denoted to be significantly non-normal: Emotion Control $(D(81)=0.13$, $p<.01)$, Behavioral Regulation $(D(81)=0.14, p<.01)$, and Metacognition $(D(81)=$ $0.11, p=.01)$. These variables were graphed as histograms and visual inspection indicated that all three variables were positively skewed. To correct for this nonnormality, scores were transformed by taking the square root of each value. Further, scores on the Distress Reactions, Punitive Reactions, and Problem-Focused Reaction subscales of the CCNES were also found to be non-normal $(D(80)=0.11, p=.01$; $D(80)=0.11, p=.01 ; D(80)=0.11, p=.03$, respectively $)$. Visual inspection of histograms indicated that the problem-focused subscale was negatively skewed, while the other two were skewed towards the positive. Square root transformations were used for the positively skewed variables. In terms of the negatively skewed variable, values were first reversed, then square root transformed. The SCARED-P total scores were also found to be significantly non-normal $(D(76)=0.13, p<.01)$. Visual inspection of the histogram revealed that the data were skewed in the positive direction; thus, a square root transformation was conducted on this variable to correct for non-normality. Transformed variables were used in all remaining analyses.

Levene's Test for Equality of Variances was considered to ensure the assumption of equality of variances had been met across variables with regard to both child age and child gender ( $p$ values of .05 or below indicate a violation of this assumption). No significant deviations were denoted in terms of the variables, thus, 
homogeneity of variance was assumed. Two possible outliers within scores of emotion regulation were identified from the scatterplots. These suspected cases were examined during hypothesis testing for their effect on the overall model using Cook's distance values and Mahalanobis distances. Finally, multicollinearity was also examined during hypothesis testing through calculations of the variance inflation factor (values greater than 10 are considered problematic) and tolerance values (values below 0.1 are considered problematic).

10.3 Hypothesis testing

Hypothesis One. Variables comprising parent emotion socialization will be correlated.

Pearson's product-moment correlations were conducted to examine relationships between these parenting variables and child age was entered as a covariate. Results are presented in Table 1 below. Correlation coefficients among the variables comprising supportive emotion socialization (i.e., Emotion-focused, Problem-focused, and Expressive Encouragement) indicated that these variables were, indeed, significantly correlated with $r$ s ranging from 0.33 to 0.57 ( $p s<.05)$.

Table 1

Partial Correlations of Parent Emotion Socialization Factors

\begin{tabular}{|c|c|c|c|c|c|}
\hline & Distress Responses & Punitive & Minimization & Problem-focus & Emotion-focus \\
\hline Punitive & $0.52^{* *}$ & & & & \\
\hline Minimization & $0.27^{* *}$ & $0.63^{* *}$ & & & \\
\hline Problem-focus & -0.16 & -0.12 & -0.08 & & \\
\hline Emotion-focus & -0.03 & 0.17 & $0.33^{* *}$ & $0.57^{* *}$ & \\
\hline $\begin{array}{l}\text { Expressive } \\
\text { Encouragement }\end{array}$ & $-0.27^{*}$ & $-0.23^{*}$ & $-0.23^{*}$ & $0.33^{* *}$ & $0.24 *$ \\
\hline
\end{tabular}


Additionally, correlation coefficients among the variables comprising unsupportive emotion socialization (i.e., Punitive, Minimization, and Distress Reactions) indicated that these variables were also significantly correlated with $r$ s ranging from 0.27 to 0.52 ( $p s<.01)$. As expected, notwithstanding the age of the child, estimates of the correlation between supportive and unsupportive emotion socialization practices revealed that these two broad subgroups were not significantly intercorrelated $(r(77)=-0.12, p=.31)$.

Hypothesis Two. Variables comprising child emotion understanding will correlate with variables of emotion regulation to establish the larger construct of child emotional competence.

Pearson's partial product-moment correlations were conducted to examine relationships between the individual factors of emotion understanding (Discussion of emotions, Recognizing emotions, and Simultaneous emotions) and emotion regulation (Emotion Control, Behavior Regulation, and Metacognition) while controlling for the effects of child age. Results indicated that the individual factor of Simultaneous emotions was significantly and positively correlated with Emotion Control ( $r=0.39, p=.01)$ and Behavior Regulation $(r=0.35, p=.03)$. No other significant intercorrelations were denoted between the individual components of these two constructs. The relationship between the two broad composites of these constructs (i.e., emotion understanding and emotion regulation) was also tested and failed to reach significance $(r=0.28, p=0.08)$. Given these non-significant results, 
the larger constructs of emotion understanding and emotion regulation were analyzed separately in the remaining models.

Hypothesis Three. Parent emotion socialization will predict measures of child emotion understanding and emotion regulation.

To test the hypothesis that parent emotion socialization predicts child emotional competence, scores from the individual factors comprising both emotion understanding (Discussion of emotions, Cues to emotions, and Simultaneous emotions) and emotion regulation (Emotion Control, Behavior Regulation, and Metacognition) were first combined to create two composite scores ( $\alpha \mathrm{s}=0.61$ and 0.83 , respectively). Next, two regression equations were calculated using the SPSS PROCESS macro (Hayes, 2013) with parent emotion socialization dimensions entered as independent variables and the composites of both emotion understanding and emotion regulation entered as dependent variables. Given that no substantive empirical evidence exists regarding the relationships between factors of emotion socialization and either emotion understanding or emotion regulation, the predictors were entered into the model stepwise. Further, the backwards method (i.e., all predictors are entered into the model initially and then, in an iterative fashion, predictors are removed based upon calculations of their individual contribution to the outcome) was preferred, given the concern regarding suppression effects (Baron \& Kenny, 1986). To control for its effects on the relationships examined within the model, child age was entered into the model as a covariate. Also, as noted above, outliers were screened for using Cook's and 
Mahalanobis distances. For each of the models, multicollinearity was evaluated in terms of contribution to the overall model using variance inflation factor (VIF; values $>10$ are considered problematic) and tolerance (values less than .1 are considered problematic) values. All VIFs and tolerance values fell within acceptable limits unless otherwise noted.

In terms of emotion understanding, results from model testing are presented below in Table 2. Specifically, it was found that Punitive, Emotion-focused, and Problem-focused parent-reported responses to child distress best predicted child emotion understanding abilities (total effects $r=0.75, F(2,38)=25.16, p<.001$ ), after controlling for child age (indirect effects points estimate $=2.17$ ). As expected, Problem-focused and Emotion-focused responses were positively predictive of emotion understanding, and Punitive responses were negatively associated with emotion understanding abilities.

Table 2

Factors of Emotion Socialization Predicting Emotion Understanding

\begin{tabular}{lcccc}
\hline & B & SE B & $\beta$ & $p$ \\
\hline $\begin{array}{l}\text { Model for Emotion Understanding } \\
\text { Step } 1\end{array}$ & & & & \\
$\quad$ (Constant) & 7.04 & 5.92 & & .24 \\
$\quad$ Emotion-focused & 4.65 & 2.22 & 0.42 & $.04^{*}$ \\
$\quad$ Problem-focused & 4.05 & 2.01 & 0.36 & $.05^{*}$ \\
$\quad$ Minimizing & -1.15 & 2.04 & -0.13 & .58 \\
$\quad$ Punitive & -3.28 & 2.46 & -0.33 & .19 \\
$\quad-1.51$ & 1.90 & -0.14 & .43 \\
$\quad$ Expressive Encouragement & -0.97 & 1.63 & -0.11 & .56 \\
$\quad$ Distress Responses & & & & \\
Step 4 & & & & .80 \\
$\quad$ (Constant) & 3.36 & 4.20 & & $.05^{*}$ \\
$\quad$ Emotion-focused & 3.96 & 1.92 & 0.36 & $.05^{*}$ \\
$\quad$ Problem-focused & 3.96 & 1.94 & 0.35 & $<.01^{*}$ \\
$\quad$ Punitive & -4.36 & 1.50 & -0.44 & \\
\hline Note: Emotion Understanding Model $-R^{2}=0.25$ for Step $1, \Delta R^{2}(\Delta$ from Step 3) $=-0.01$ for Step $4(p=$ \\
$.02)$.
\end{tabular}


Results from model testing predicting emotion regulation are presented below in Table 3. In this model, parent-reported Distress Responses were found to negatively predict child abilities in emotion regulation (total effects $r=0.43 ; F(5$, 78 ) $=3.40, p=.01$ ), after controlling for the age of the child (indirect effects points estimate $=5.83$.

Table 3

Factors of Emotion Socialization Predicting Emotion Regulation

B

Model for Emotion Regulation

Step 1

(Constant)

Emotion-focused

Problem-focused

Minimizing

Punitive

Expressive Encouragement

Distress Reponses
B

\section{SE B}

$\beta$

\section{$p$}

$\begin{array}{cccc}-1.92 & 54.25 & & .97 \\ 14.93 & 21.38 & 0.10 & .49 \\ 8.64 & 18.77 & 0.07 & .65 \\ -8.47 & 15.37 & -0.08 & .58 \\ -16.34 & 19.58 & -0.13 & .41 \\ -14.31 & 16.53 & -0.11 & .39 \\ -45.03 & 15.14 & -0.38 & <.01^{*}\end{array}$

Step 6

(Constant)

$\begin{array}{ll}-18.02 & 20.55\end{array}$

$-44.96 \quad 14.86 \quad-0.39<.01 *$

Note: Emotion Regulation Model $-R^{2}=0.19$ for Step 1, $\Delta R^{2}(\Delta$ from Step 5) $=-0.18$ for Step $6(p<$ $.001)$.

* Denotes significance at $p \leq .05$.

Hypothesis Four. Child physiological reactivity will mediate the relationship between parent emotion socialization and child emotional competence.

To test mediation, two regression models were constructed using the SPSS PROCESS macro with bootstrapping (Hayes, 2013). These models tested for the direct effects of both supportive and unsupportive parent emotion socialization factors on the composites of emotion understanding and emotion regulation. Indirect effects through cardiac variability were also calculated in order to demonstrate a mediation relationship exists (Baron \& Kenny, 1986). The effect of 
child age was also considered for each of the associations among these variables. The equations for this are as follows:

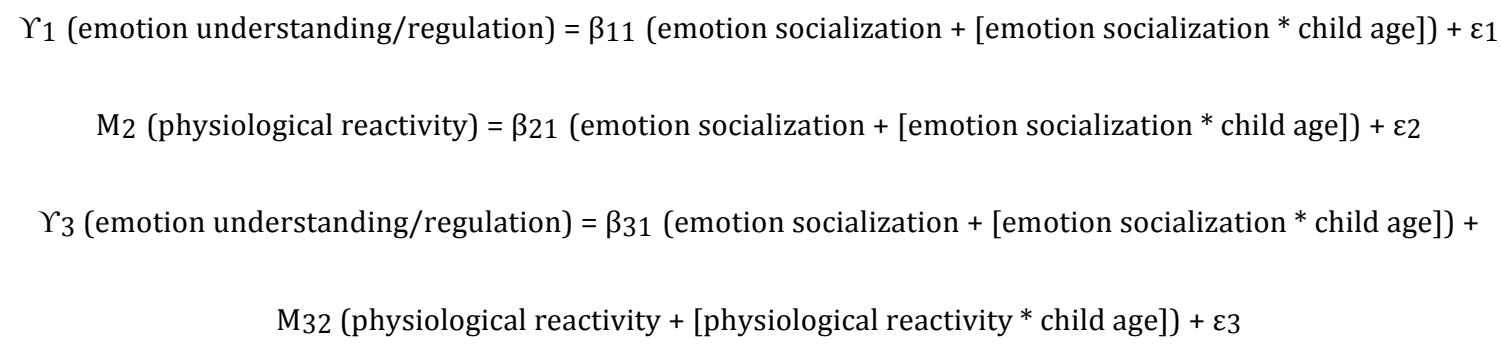

Prior literature on the guidelines required to demonstrate mediation identify that $\Upsilon_{1}$ must reach statistical significance; however, more recently this requirement has been somewhat called into question (MacKinnon, Fairchild, \& Fritz, 2007). Given this, results from model testing provided some support for cardiac variability as a mediating variable within the present sample. After controlling for child age, unsupportive parent emotion socialization was found to have an indirect effect on emotion regulation by way of its association with cardiac variability $\left(r^{2}=0.63 ; F(3\right.$, $36)=8.05, p<.001)$. Specifically, the negative association of unsupportive parental responses to child distress and a child's abilities in emotion regulation was best explained through the child's cardiac variability (indirect effect points estimate $=$ 2.90). Higher reported unsupportive parental responses were associated with less variability in child cardiac response between threatening and neutral stimuli. This in turn was predictive of less reported abilities in child emotion regulation. Supportive parent responses did not provide a significant contribution to the model. 
These findings are illustrated below in Figure 3. The model predicting emotion understanding failed to reach significance.

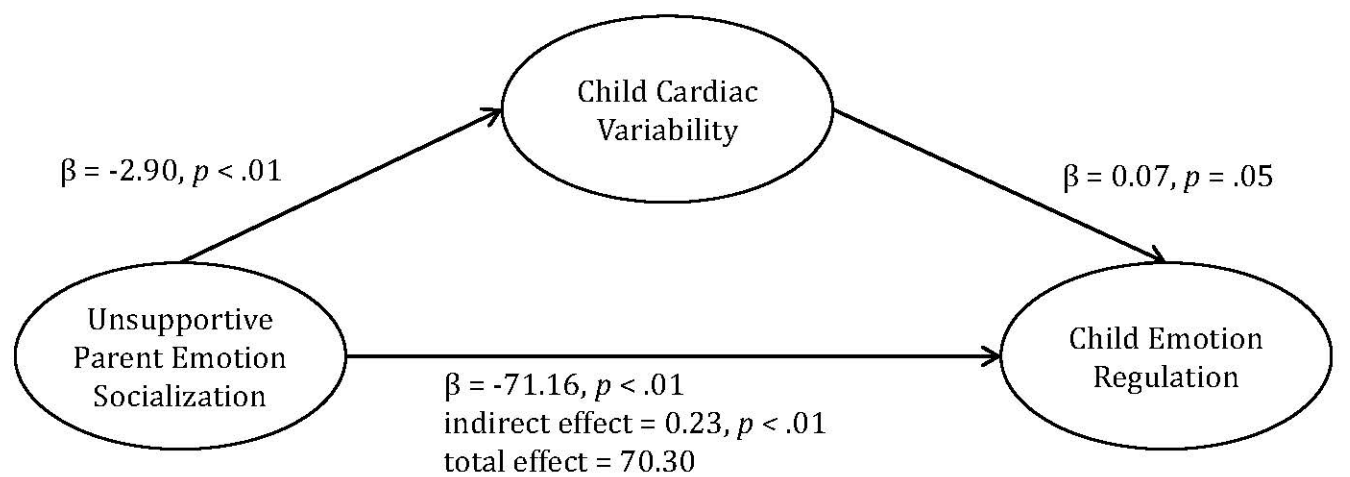

Figure 3. Mediation model illustrating the direct effects of unsupportive parent emotion socialization on child emotion regulation, as well as the indirect effect of parent emotion socialization on child emotion regulation through child cardiac variability.

Hypothesis Five. Child physiological reactivity will moderate the relationship between parent emotion socialization and child emotional competence.

To test this hypothesis, two regression models were constructed again using the SPSS PROCESS macro with bootstrapping (Hayes, 2013). These models also tested for the direct effects of supportive and unsupportive parent emotion socialization factors on the composites of emotion understanding and emotion regulation, as well as the effects of the interactions between both emotion socialization factors and vagal tone. As with the previous model, the effect of child age was also considered for each of the associations among these variables. To determine moderation effects, the interaction must make a significant contribution to the model as indicated by the statistical significance of its associated coefficient. The equations for this model are as follows: 
$\Upsilon_{1}($ emotion understanding $/$ regulation $)=\beta 11($ emotion socialization $+[$ emotion socialization $*$ child age $])+\varepsilon 1$

$\Upsilon_{2}($ emotion understanding $/$ regulation $)=\beta 21($ emotion socialization $+[$ emotion socialization $*$ child age $])+\beta 22$

(physiological reactivity $+[$ physiological reactivity $*$ child age $])+\varepsilon 2$

$\Upsilon_{3}($ emotion understanding $/$ regulation $)=\beta 31($ emotion socialization $+[$ emotion socialization $*$ child age $])+\beta 32$

$($ physiological reactivity $+[$ physiological reactivity $*$ child age $])+\beta 33([$ emotion socialization $+\{$ emotion socialization $*$ child age $\}] *$ [physiological reactivity + \{physiological reactivity $*$ child age $\}])+\varepsilon 3$

Results from model testing failed to provide adequate support for the role of cardiac variability as a moderator in the prediction of child emotional competence from parent emotion socialization. The model predicting unsupportive parent emotion socialization was significant $(r=0.62 ; F(6,38)=3.30, p=.01)$, though no significant effects in terms of the interaction coefficients were denoted.

Hypothesis Six. A causal pathway is expected from parent emotion socialization practices through child emotional competence to child anxiety. Given the nature of its hypothesized role, child physiological reactivity is also expected to have an influence on the relationships within the model.

Drawing from both the previous literature and building on findings from Hypothesis 4 and 5, path analysis was used to test the proposed causal model, which postulated the following relationships: 1) Parent unsupportive emotion socialization practices are associated with child emotion regulation, child physiological responsiveness, and child anxiety; 2) Child emotion regulation is associated with child physiological responsiveness, and both will predict child 
anxiety; 3) Parent unsupportive emotion socialization practices will have an indirect effect on child anxiety by way of their association with child emotion regulation and child physiological responsiveness; and 4) Child age influences all of the relationships among variables included in the model. Following results from Hypothesis 4 and 5, both child emotion regulation and child cardiac variability were considered as mediators within the model. As with the previous models, this pathway model was constructed using the SPSS PROCESS macro with bootstrapping and the contribution of child age was taken into account as a covariate (Hayes, 2013). Each path within the model was estimated by the standardized beta coefficient. The equations are as follows:

\footnotetext{
$\Upsilon_{1}($ child physiological reactivity $)=\beta 11($ emotion socialization $+[$ emotion socialization $*$ child age $])+\beta 12$ $($ emotion regulation $+[$ emotion regulation $*$ child age $])+\varepsilon 1$

$\Upsilon_{2}($ emotion regulation $)=\beta 21($ emotion socialization $+[$ emotion socialization $*$ child age $])+\beta 22($ physiological reactivity $+[$ physiological reactivity $*$ child age $])+\varepsilon 2$

$\Upsilon_{3}($ child anxiety $)=\beta 31($ emotion socialization $+[$ emotion socialization $*$ child age $])+\beta 32$ (physiological reactivity $+[$ physiological reactivity $*$ child age $])+\beta 33($ emotion regulation $+[$ emotion regulation $*$ child age $])+$

Results from model testing provided inadequate support for the significance of these relationships with the current sample. Specifically, only the pathway predicting emotion regulation achieved significance $(r=0.58 ; F(6,30)=8.61, p<$ .001). Additionally, though it failed to reach the cut-off for statistical significance, it 
is meaningful to note that the pathway predicting child anxiety was marginally significant $(r=0.44 ; F(9,27)=2.64, p=.07)$. Values from these regression equations are presented in Table 4 below.

Table 4

Pathway Model Predicting Child Anxiety from the Factors of Unsupportive Parent Emotion Socialization, Child Emotion Regulation, and Child Physiological Responsiveness.

Model for Child Cardiac Variability

$\beta \quad$ SE $\beta$

Model Summary: $r=0.06 ; F(6,30)=0.11, p=.74$

(Constant)

Unsupportive Emotion Socialization

1.01

6.81

.88

$-1.43$

4.29

.74

Model for Child Emotion Regulation

Model Summary: $r=0.58 ; F(6,30)=8.61, p<.001 *$

(Constant)

$-8.64$

$-54.30$

32.15

20.28

0.80

2.40

$.01 *$

Child Cardiac Variability

\section{Model for Child Anxiety}

Model Summary: $r=0.44 ; F(9,27)=2.64, p=.07$

(Constant)

0.62

1.05

1.81

.73

Unsupportive Emotion Socialization

$-0.03$

1.26

.41

Child Cardiac Variability

$-0.02$

0.05

.54

Child Emotion Regulation

0.01

.41

* Denotes significance at $p \leq .05$.

\subsection{Exploratory Analyses}

One unexpected finding from this study emerged as an inconsistent relationship between parent responses to child distress and the child factors of emotion understanding and emotion regulation given the growing body of literature on the role of emotion socialization in developing these skills during childhood. One explanation for this may be the present study's consideration of the individual factors of emotion socialization rather than the broad dimensions of supportive and unsupportive parent responses, as have been used in several previous studies (Cunningham et al., 2009; Garside \& Klimes-Dougan, 2002; Perlman et al., 2008; 
Shaffer et al., 2012). It is likely that these individual parent responses to child distress do not themselves provide any substantial contribution to the prediction of a child's emotional competence. Thus, it was hypothesized that overall patterns of parental response better predicted the influence of parent emotion socialization on their child's skills in emotion understanding and emotion regulation. A multivariate analysis of variance was conducted predicting child emotion understanding and emotion regulation with supportive and unsupportive parent responses entered as independent variables and child age entered as a covariate. Results revealed a significant main effect in terms of unsupportive parent responses for both child emotion understanding $\left(F(1,40)=4.33, p=.05\right.$, partial $\left.\eta^{2}=0.11\right)$ and child emotion regulation $\left(F(1,40)=5.84, p=.02\right.$, partial $\left.\eta^{2}=0.14\right)$. The interaction term between unsupportive and supportive parent responses failed to reach significance $(p=.08)$. Estimated marginal means are presented below in Table 5.

Table 5

Estimated Marginal Means for Low and High Unsupportive Parenting

Unsupportive Parent Emotion Socialization

\begin{tabular}{|ll|r|r|r|r|}
\hline Dependent Variable & $\begin{array}{l}\text { Unsupportive Parent } \\
\text { Responses }\end{array}$ & Mean & Std. Error & \multicolumn{2}{|c|}{$95 \%$ Confidence Interval } \\
\cline { 4 - 6 } & & & & Lower Bound & Upper Bound \\
\hline Emotion Regulation & High & $-84.98 \mathrm{a}$ & 5.67 & -96.49 & -73.47 \\
Emotion & Low & $-106.19 \mathrm{a}$ & 6.70 & -119.78 & -92.60 \\
Understanding & High & $0.29 \mathrm{a}$ & 0.31 & -0.39 & -1.38 \\
\hline
\end{tabular}

Covariates appearing in the model are evaluated at the following values: Child age $=8.05$. 


\section{DISCUSSION}

Current theoretical models on the development of anxiety during childhood are complex, such that they delineate various dynamic interactions between genetic vulnerabilities (e.g., physiological arousal and reactivity), temperamental characteristics (e.g., behavioral inhibition), and environmental influences (e.g., parenting style or behaviors) to explain the general propensity towards a pattern of exaggerated fear responses (Cicchetti \& Cohen, 2006). For some time, the large focus of empirical work in the field involved the role of the parent in this process, specifically in terms of parenting behaviors (Wood et al., 2003); however, findings from these studies remain mixed. Surprisingly, given the central role of emotion and emotion regulation in child anxiety, very little work has explored the parent's role in promoting or impeding their child's emotional development thereby impacting the child's risk for developing anxiety (Casey, 1996). The aim of this study was to build upon the existing literature on the role of parents in risk for the development of childhood anxiety by exploring parenting behaviors that specifically support the development of emotional competence within the child (i.e., emotion socialization practices) and their relation to child anxiety symptoms using a cross-sectional design. Thus, this study explored factors of parental emotion socialization, child emotion understanding, child emotion regulation, child physiological reactivity, and child anxiety among a community sample of children, ages 5 to 12 , and their parents. Several hypotheses were tested and are discussed below. 
In terms of the preliminary analyses, several interesting findings emerged with regard to parent responses to child expressions of negative emotions. Specifically, both mothers and fathers reported being more likely to encourage expressions of negative emotions with younger children than with older children. This is inconsistent with previous work on expressive encouragement, which found that parents, particularly mothers, tended to use more expressive encouragement with advancing child age (Cassano, Perry-Parrish, \& Zeman, 2007; Zeman \& Garber, 1996). Still, findings from this study may not be surprising from a developmental perspective. In early childhood (i.e., around the age of 5) children are beginning to develop a richer and more elaborate understanding of their own emotional experience, particularly for more complex emotions such as nervousness or jealousy. At this stage in development, children's emotional experiences are broadened considerably through their exposure to unfamiliar environments, such as entrance into school. Through these experiences, children gain competence in their own insight into the experience of emotions and become increasingly proficient at accessing their own emotional lexicon (Carroll \& Steward, 1984; Saarni, 1999). Thus, it is plausible that during this stage parents increase their focus on encouraging their child's expression of emotions so as to promote the development of emotion-related language and bolster their understanding of emotions. Certainly, early parental validation and encouragement of emotional expression serves as an avenue for establishing the child's internal socially- and culturally-bound rules for emotional expression, which are believed to predict later social competence (Gottman et al., 1997). This may be particularly true for negative emotions, given 
the impact expressions of negative emotions have on social interactions and interpersonal relationships (Denham, 1998; Saarni, 1999). Indeed, previous studies that found higher reported rates of expressive encouragement for older children than for younger children considered only those parental responses to their child's sadness (Carroll \& Steward, 1984; Saarni, 1999), whereas this study explored parental responses to several negative emotional expressions from their child (e.g., sadness, anger, nervousness). It may be that social acceptability in terms of specific emotions and the expression of these emotions accounts for this discrepancy in findings. Future studies should explore the role of social acceptability as it impacts a parent's responses to their child's emotionally expressive behavior across development. Possible differences in terms of the various types of emotions should be tested, as it is expected that a parent's degree of expressive encouragement in response to their child would be influenced by an interaction between the type of emotion expressed by the child, the child's age, and the child's gender.

Consistent with previous work, mothers in this study were more likely to use problem-focused strategies in response to their child's negative emotions than were fathers. This finding should be interpreted with caution, as the number of fathers participating in the study was small $(n=9)$. Interestingly, several studies have found that mothers also tended to use problem-focused strategies more with their daughters than with their sons (Garside \& Klimes-Dougan, 2002), which was not supported by the data in this study. It has been proposed that mothers perceive their daughters to be more emotionally vulnerable, and may devote more time to encouraging their daughters to develop stronger problem-solving strategies 
(Dunsmore \& Karn, 2001). In addition, parents (both mothers and fathers) in the current sample reported using more minimization responses with their older male children, which is not consistent with previous work that parents report less frequently minimizing the negative emotions of their older children (Cassano, Perry-Parrish, \& Zeman, 2007; Shipman, Zeman, \& Stegall, 2001). Similar to aforementioned studies, these findings were limited to the child's expressions of sadness only. It is plausible that unique characteristics related to acceptability of the expression of sadness, particularly during early childhood, can account for this (Brody \& Hall, 2000). Factors influencing how a parent responds to their child's distress are numerous, warranting more comprehensive and integrative models on the impact these factors have on emotion socialization.

The hypothesis that individual factors of emotion understanding and emotion regulation would be correlated was only partially supported. Emotion control and behavior regulation were both positively correlated with understanding simultaneous emotions. Knowledge of emotions and metacognition failed to reach significance. Moreover, the broad constructs of emotion understanding and emotion regulation were not associated with one another. This is somewhat surprising considering that the development of emotional competence during childhood has been characterized within the literature by a complex interplay between these two variables (Denham, 1998). Given the role of development, emotion understanding and emotion regulation may be best explained by way of a multilevel or multisystem approach (Thompson et al., 2008). Broadly, this approach considers the factors comprising both emotion understanding and emotion regulation as 
distinctly separate but related processes. As such, it is plausible that the underlying processes involved in the child's understanding of simultaneous emotions and ability to recognize emotions overlap somewhat with the processes involved in emotional and behavioral control. This conceptualization is consistent with prior studies, whose findings revealed a similar pattern of associations among aspects of emotion control and emotion understanding despite a lack of association between the two constructs (Blankson, O’Brien, Leerkes, Marcovitch, \& Calkins, 2011). Indeed, additional research is warranted to more fully delineate these two constructs of emotion understanding and emotion regulation, and their underpinnings. Given the inconsistencies in terms of the extant literature, it is clear that these constructs are multifaceted. In the future, a multi-method approach may be necessary to provide a more accurate understanding of the complexities among factors of emotion understanding and emotion regulation.

One interesting finding was that individual factors comprising emotion regulation were significantly positively associated with cardiac variability. This suggests that children whose parents indicated that they had better abilities in terms of control over their emotions and behavior, and had stronger skills in metacognition, were more likely to exhibit larger discrepancies in heart rate reactivity across threatening and neutral stimuli, which is reflective of good cardiac control. This finding is interesting to consider given previous work on the physiological responsiveness of children with difficulties in self-regulation. These children tended to exhibit cardiac profiles characterized by larger elevations in heart rate (van Lang et al., 2007) and low baseline vagal control (Beauchaine, 2001; 
Calkins \& Dedmon, 2000; Hastings, 2005). Thus, as suggested in existing work, selfregulation may be best characterized both by the initial physiological response to threat, along with the accompanying regulatory response following removal of threatening stimuli. It is important to note, however, that this study did not recruit specifically for children with known difficulties in terms of self-regulation. Though the relationships were in expected directions (i.e., better parent reported selfregulation predicting better cardiac regulation), the restricted range in terms of parent-reported child self-regulation may have obscured these findings. Indeed, the sample was drawn primarily from the community. While this study was particularly interested in anxiety, participating children were not assessed for clinically significant symptoms of anxiety. Thus, the profiles of children included in this study may not be generalizable to children diagnosed with an anxiety disorder. There is some suggestion that anxious children have unique patterns of self-regulation both in terms of their regulation of emotion (e.g., Suveg \& Zeman, 2004) and their physiological profiles (e.g., Thayer et al., 2000). These children have been described as over-regulators, though more work is necessary - utilizing populations of anxious and nonanxious children - to begin to provide support for this notion (Denham et al., 1992). It is worthy to note that children who participated in the computer task were more anxious than the total sample, which may provide some insight into conceivable patterns with regard to physiological reactivity and self-control. In all likelihood, the significant findings despite higher anxiety symptom scores suggest that these relationships may hold when explored for in children experiencing clinically relevant symptoms of anxiety. Additional work utilizing clinical 
populations of children is necessary to clarify these differences in physiological profiles of children with and without difficulties in terms of self-regulation.

The hypothesis that parent emotion socialization practices would predict child emotion understanding and emotion regulation was partially supported. Results from these analyses, which considered each of the individual factors of parent emotion socialization in relation to child emotional competence, were inconsistent. Exploratory analyses were then conducted using the more broad constructs of supportive and unsupportive parent responses to child distress, and revealed that unsupportive reactions significantly predicted child emotional competence. Specifically, parents who reported higher degrees of unsupportive parental responses to negative child emotions were more likely to have children with fewer abilities in both emotion understanding and emotion regulation. Supportive parent responses, however, failed to contribute significantly to these models. These findings are consistent with several previous studies (e.g., Shaffer et al., 2012), and provide additional support for the notion that the presence of supportive parenting practices alone is not sufficient for promoting the development of child emotional competence. Instead, the absence of unsupportive responses along with high degrees of supportive and warm reactions best characterizes parenting practices that provide the ideal context through which to nurture and encourage a child's emotional development.

Though these findings are generally in line with existing work on parent emotion socialization, limitations given the study design are important to consider. As these data are not longitudinal in nature, directionality of the associations cannot 
be determined. It is equally plausible that children with high degrees of emotional competence are less emotionally and mentally taxing to their parents when upset. Further, children with more emotional competence likely express less frequent negative affect than do children with fewer skills in emotion understanding and emotion regulation. Moreover, the level of stress a parent is under, as well as the parent-child relationship - both of which are impacted by difficult child temperament and degree of child emotion dysregulation - are key components in modeling parental emotion socialization (Cunningham et al., 2009).

The hypothesized role of child physiological reactivity in the relationship between parent emotion socialization and child emotional competence was partially supported. Similar to above, unsupportive parent responses to child expressions of distress appear to contribute more, albeit adversely, to a child's development than do supportive responses. This is not to say that supportive parenting should be disregarded in the future, as other studies have supported its association with emotion regulation abilities (Perry et al., 2012), indicating that it remains an important factor in terms of child development. Indeed, outcome data from a study examining the effectiveness of a 14-week parent training program, which focuses on teaching parents emotion socialization strategies to help improve their child's difficulty with regard to emotion regulation difficulties, suggest that both less unsupportive and more supportive parent responses were important to treatment outcome (Herbert, Harvey, Roberts, Wichowski, \& Lugo-Candelas, 2012). This treatment program was designed to target children with attention and hyperactivity difficulties and suggests that additional work is needed to clarify the impact of 
supportive parent emotion socialization among populations of internalizing children. One explanation for the incomplete findings within the current study may be that the threatening stimuli used for the computer task were not salient enough to trigger autonomic activity to the degree that would elicit a significant parasympathetic response. The methodology used for the current study was modeled after studies examining the autonomic activity of anxious adults and may not be ideal for examining the physiological responsiveness in children (Porges, Campbell, Hayne, \& Richardson, 1992). Indeed, other methods exist for measuring physiological reactivity specifically within child populations; however, given the procedural design of these methods, the primary affective reaction elicited by these tasks was frustration (Calkins, 1997; Calkins \& Dedmon, 2000; Calkins \& Keane, 2004). Though plausible, it is not known whether differential physiological profiles exist in terms of frustration versus anxiety. It seems likely that a child could be more sensitive to feelings of frustration and less sensitive to feelings of anxiety, which would undoubtedly impact the child's cardiac response to these stimuli. Future studies examining these differing affective responses would likely provide a critical contribution to our understanding of the internalizing and externalizing dichotomy.

Despite these limitations, the present study offers support for the mediating role of cardiac responsiveness in the association of unsupportive parent emotion socialization and child emotion regulation. This provides an important contribution to the existing literature on parent emotion socialization and child self-regulation, which contains contradictory evidence for the role of physiological responsiveness. Data from the current study did not support a child's physiological responsiveness 
as a moderator in the prediction of emotion regulation. Previous studies have found that children with poorer physiological regulation who have parents reporting more unsupportive responses to distress are more likely to have fewer abilities in regulating their emotions (Calkins et al., 2008; Perry et al., 2012). Children with more adaptive physiological regulation, then, are less affected by unsupportive parental responses to expressions of distress. Findings from the current study, however, do suggest that physiological responsiveness accounts for the impact unsupportive parental responses to distress have on a child's ability to regulate their emotions. That is, one mechanism by which unsupportive parent emotion socialization in response to their child's distress predicts fewer abilities in terms of a child's emotion regulation may be through its influences on the child's regulatory physiology. Additional support for this mediating association has been found among pre-school-aged children, suggesting that physiological self-regulation is impacted by parenting practices and that maladaptive parental emotion socialization is linked more broadly with a child's adjustment (Hastings et al., 2008; Parent et al., 2005).

These finding have important implications in terms of a child's development of emotion regulation abilities. More specifically, results underscore the importance of including physiological indicators in models of child self-regulation. It may be necessary to include measures of physiological reactivity when assessing emotion regulation throughout childhood. Limitations given study design do, however, prevent drawing any conclusions regarding cause and effect among these variables. It is equally plausible that children with poorer physiological regulation express more negative affect, which will likely places added stress on a parent thereby 
impacting their responses. Despite this, data from the current sample provide evidence to support a mediating relationship exists. Indeed, available literature on the associations between child physiological reactivity, emotion socialization, and emotional competence is complex and contradictory at times, warranting additional studies targeted at untangling these relationships. Future work is necessary to explore these relationships within clinical populations, as well as, to consider other potential factors impacting a parent's propensity to respond to their child's distress and the development of a child's self-regulation.

The final hypothesis did not receive adequate support within this population. Moreover, results only provided support for the pathway from unsupportive parent responses to child emotion regulation. A number of studies exist supporting this link between parent emotion socialization, particularly unsupportive responses, and child emotion regulation (e.g., Shaffer et al., 2012), suggesting that this relationship is a relatively strong one. Though it failed to reach statistical significance, the expected pathway predicting child anxiety was marginally significant and is worth mentioning. As noted above, these hypothesized associations are explored here utilizing a non-clinical population of children and may emerge when explored utilizing a population of children diagnosed with anxiety. While the final model was not well supported by the data within this sample, additional studies exploring these relationships among clinical populations is warranted. Broadly, support exists for the importance of unsupportive parenting and emotion regulation in predicting child anxiety, and other findings from current study corroborate this hypothesis. Moreover, while cardiac reactivity was found to mediate the association between 
parent response to distress and emotion regulation, this relationship was not maintained in the larger model. Undoubtedly, the nature of these relationships is dynamic and complex, therefore additional data are warranted to establish a more consistent understanding of the associations. Several explanations likely exist for this inconsistency within the data.

The present study is not without limitations. First, the large age range of children included in this sample (i.e., 5 to 12 years) is important to consider when drawing conclusions from the current study. Undoubtedly, associations among several, if not all, of the factors included in this study depend largely on the age and developmental stage of the child. Given the number of statistical analyses conducted and concerns regarding power and risk for Type I error, it was not feasible to split the sample based on child age. Further, although the impact of child age was considered statistically within each analysis, these results should be interpreted with caution. The impact of development on the relationships examined within this study will be an important consideration for future research. For instance, a child's physiological profile is expected to transform over time concurrent to their developing skills in self-regulation. Further, how other factors, such as parental stress, have a differential impact on these associations over the course of the child's development remains unknown. In addition, alpha values for the variables comprising the supportive composite were somewhat low. The small sample size and large age range included in this study may account for this. More work is necessary to explore the construct of supportive parent emotion socialization practices. 
Second, the small sample size also prevented exploring for possible differences in terms of the hypothesized models based on child sex. Similarly, the limited number of fathers included impedes the conclusions drawn regarding differences in terms of socialization practices between mothers and fathers. Numerous studies have explored differences in terms of parental response patterns based on both parent and child sex, and suggest that the associations among these factors are complex.

Third, the children included in this sample were drawn from the community, thus were not generally considered to exhibit clinically relevant degrees of anxiety. Indeed, preliminary analysis of the number of reported symptoms of anxiety indicated that this variable was significantly positively skewed. This indicated that the majority of children included within the sample were reported to be experiencing relatively few symptoms of anxiety. Several of the hypothesized associations explored in this study may be better understood if explored on a clinical population of children.

\section{Summary}

In sum, despite the above limitations, this study provides support for the role of child cardiac reactivity as one mechanism in the relationship between parent emotion socialization and child self-regulation among a community sample. It provides a significant contribution to the literature by supporting the conceptualization of children's self-regulation by way of both observer-report of emotional and behavioral regulation, and objective measures of cardiac variability. 
Thus, future work is charged with more clearly identifying directionality of the associations among these variables. Longitudinal designs are preferred, so as to best understand how these relationships develop and change over time. In addition, unsupportive parental emotion socialization was found to have a significant impact on a child's development. In terms of the present sample, unsupportive emotion socialization emerged as a robust predictor of child adjustment across several hypotheses. Supportive emotion socialization failed to reach significance in this study. The impacts of unsupportive responses specifically in terms of the affective context, parent-child relationship, both parent and child gender, psychopathology, and developmental stage of the child are important considerations for future research. Ideally, future studies will consider exploring these associations using a longitudinal design. This is expected to allow for more definitive conclusions regarding the influence of parent emotion socialization on the child's developing physiology. For instance, do unsupportive parent responses to their child's distress place that child at increased risk for developing maladaptive physiological reactivity patterns, characterized by limited variability across threat and nonthreatening stimuli? Are unsupportive parent responses to their child's distress differentially important to child self-regulation based upon that child's physiological response profile?

Though the final model predicting symptoms of anxiety failed to receive adequate support from the data, it is worth noting here. Several associations within this model were marginally significant and a number of limitations were proposed to account for this. Of note, this model was tested on a portion of the community- 
drawn sample of who were able to complete the computer task. This portion of the sample was denoted to be more anxious than the larger sample and, thus, may suggest that these relationships are present among children with anxiety. Future studies utilizing larger, preferably clinical, samples of anxious children may be warranted. Further, when investigating the role of these associations in predicting child anxiety, it will be important to consider context-, affect-, and gender-specific influences. 


\section{REFERENCES}

American Psychiatric Association. (2000). Diagnostic and statistical manual of mental disorders (4th Edition, Text Revision). Washington, DC: Author.

Anthony, J. L., Lonigan, C. J., Hooe, E. S., \& Phillips, B. M. (2002). An affect-based, hierarchical model of temperament and its relations with internalizing symptomatology. Journal of Clinical Child and Adolescent Psychology, 31(4), 480-490.

Baird, J. A., \& Moses, L. J. (2001). Do preschoolers appreciate that identical actions may be motivated by different intentions? Journal of Cognition and Development, 2(4), $413-$ 448.

Baker, R., Holloway, J., Thomas, P. W., Thomas, S., \& Owens, M. (2004). Emotional processing and panic. Behaviour Research and Therapy, 42(11), 1271-1287.

Baron, R. M., \& Kenny, D. A. (1986). The moderator - mediator variable distinction in social psychological research: Conceptual, strategic, and statistical considerations. Journal of Personality and Social Psychology, 51(6), 1173-1182.

Barrett, P. M., Rapee, R. M., Dadds, M. M., \& Ryan, S. M. (1996). Family enhancement of cognitive style in anxious and aggressive children. Journal of Abnormal Child Psychology: An official publication of the International Society for Research in Child and Adolescent Psychopathology, 24(2), 187-203.

Beauchaine, T. P. (2001). Vagal tone, development, and Gray's motivational theory: Toward an integrated model of autonomic nervous system functioning in psychopathology. Development and Psychopathology, 13(2), 183-214. 
Beidel, D. C., \& Turner, S. M. (1997). At risk for anxiety: I. Psychopathology in the offspring of anxious parents. Journal of the American Academy of Child \& Adolescent Psychiatry, 36(7), 918-924.

Birmaher, B., Brent, D., Chiappetta, L., Bridge, J., Monga, S., \& Baugher, M. (1999).

Psychometric properties of the Screen for Child Anxiety-Related Emotional Disorders (SCARED): A replication study. Journal of the American Academy of Child \& Adolescent Psychiatry, 38(10), 1230-1236.

Birmaher, B., Khetarpal, S., Brent, D., \& Cully, M. (1997). The Screen for Child Anxiety Related Emotional Disorders (SCARED): Scale construction and psychometric characteristics. Journal of the American Academy of Child \& Adolescent Psychiatry, $36(4), 545-553$.

Birmaher, B., Khetarpal, S., Cully, M., Brent, D., \& McKenzie, S. (1995). Screen for Child Anxiety Related Disorders. Western Psychiatric Institute and Clinic, University of Pittsburgh.

Blankson, A. N., O’Brien, M., Leerkes, E. M., Marcovitch, S., \& Calkins, S. D. (2011). Shyness and vocabulary: The roles of executive functioning and home environment stimulation. Merrill-Palmer Quarterly, 57(2), 105-128.

Bohnert, A. M., Crnic, K. A., \& Lim, K. G. (2003). Emotional Competence and Aggressive Behavior in School-Age Children. Journal of Abnormal Child Psychology: An official publication of the International Society for Research in Child and Adolescent Psychopathology, 31(1), 79-91.

Bosquet, M., \& Egeland, B. (2006). The development and maintenance of anxiety symptoms from infancy through adolescence in a longitudinal sample. Development and Psychopathology, 18(2), 517-550. 
Bowie, B. (2010). Emotion regulation related to children's future externalizing and internalizing behaviors. Journal of Child and Adolescent Psychiatric Nursing, 23(2), 74-83.

Bretherton, I., Fritz, J., Zahn-Waxler, C., \& Ridgeway, D. (1986). Learning to talk about emotions: A functionalist perspective. Child Development, 57(3), 529-548.

Brody, L. R., \& Hall, J. A. (2000). Gender, emotion, and expression. In M. Lewis \& J. HavilandJones (Eds.), Handbook of emotions (2 ed., pp. 338-349). New York, NY, US: Guilford Press.

Brown, J. R., \& Dunn, J. (1996). Continuities in emotion understanding from 3-6 yrs. Child Development, 67(3), 789-802.

Calkins, S. D. (1994). Origins and outcomes of individual differences in emotion regulation. Monographs of the Society for Research in Child Development, 59(2), 53-72.

Calkins, S. D. (1997). Cardiac vagal tone indices of temperamental reactivity and behavioral regulation in young children. Developmental Psychobiology, 31(2), 125-135.

Calkins, S. D., \& Dedmon, S. E. (2000). Physiological and behavioral regulation in two-yearold children with aggressive/destructive behavior problems. Journal of Abnormal Child Psychology: An official publication of the International Society for Research in Child and Adolescent Psychopathology, 28(2), 103-118.

Calkins, S. D., Graziano, P., Berdan, L., Keane, S., \& Degnan, K. (2008). Predicting cardiac vagal regulation in early childhood from maternal-child relationship quality during toddlerhood. Developmental Psychobiology, 50(8), 751-776.

Calkins, S. D., \& Hill, A. (2007). Caregiver influences on emerging emotion regulation. In J. J. Gross (Ed.), Handbook of Emotion Regulation (pp. 229-248). New York, NY: Guilford Press. 
Calkins, S. D., \& Keane, S. P. (2004). Cardiac vagal regulation across preschool: Stability, continuity, and relations to adjustment. Developmental Psychobiology, 45(3), 101112.

Camras, L. A., Sachs-Alter, E., \& Ribordy, S. C. (1996). Emotion understanding in maltreated children: Recognition of facial expressions and integration with other emotion cues. In M. Lewis \& M. W. Sullivan (Eds.), Emotional development in atypical children (pp. 203-225). Hillsdale, NJ: Lawrence Erlbaum Associates, Inc.

Carroll, J. J., \& Steward, M. S. (1984). The role of cognitive development in children's understandings of their own feelings. Child Development, 55(4), 1486-1492.

Carthy, T., Horesh, N., Apter, A., \& Gross, J. J. (2010). Patterns of emotional reactivity and regulation in children with anxiety disorders. Journal of Psychopathology and Behavioral Assessment, 32(1), 23-36.

Casey, R. J. (1996). Emotional competence in children with externalizing and internalizing disorders. In M. Lewis \& M. W. Sullivan (Eds.), Emotional development in atypical children (Vol. xii, pp. 286). Hillsdale, NJ, England: Lawrence Erlbaum Associates, Inc.

Cassano, M., Perry-Parrish, C., Zeman, J. (2007). Influence of gender on parental socialization of children's sadness regulation. Social Development, 16(2), 210-231.

Chaplin, T. M., \& Cole, P. M. (2005). The role of emotion regulation in the development of psychopathology. In B. Hankin \& J. R. Z. Abela (Eds.), Development of psychopathology: A vulnerability-stress perspective (pp. 49-74). Thousand Oaks, CA, US: Sage Publications, Inc.

Chavira, D. A., Stein, M. B., Bailey, K., \& Stein, M. T. (2004). Child Anxiety in Primary Care: Prevalent But Untreated. Depression and Anxiety, 20(4), 155-164.

Ciarrochi, J., \& Scott, G. (2006). The link between emotional competence and well-being: A longitudinal study. British Journal of Guidance \& Counselling, 34(2), 231-243. 
Cicchetti, D., Ackerman, B. P., \& Izard, C. E. (1995). Emotions and emotion regulation in developmental psychopathology. Development and Psychopathology, 7(1), 1-10.

Cicchetti, D., \& Cohen, D. J. (2006). Development and psychopathology Developmental psychopathology, Vol 1: Theory and method (2nd ed.). (pp. 1-23). Hoboken, NJ US: John Wiley \& Sons Inc.

Cole, P. M., \& Deater-Deckard, K. (2009). Emotion regulation, risk, and psychopathology. Journal of Child Psychology and Psychiatry, 50(11), 1327-1330.

Cole, P. M., Dennis, T. A., Smith-Simon, K., E., \& Cohen, L. H. (2009). Preschoolers' emotion regulation strategy understanding: Relations with emotion socialization and child self-regulation. Social Development, 18(2), 324-352.

Cole, P. M., Michel, M. K., \& Teti, L. O. D. (1994). The development of emotion regulation and dysregulation: A clinical perspective. Monographs of the Society for Research in Child Development, 59(2-3), 73-100, 250-283.

Cook, E. T., Greenberg, M. T., \& Kusche, C. A. (1994). The relations between emotional understanding, intellectual functioning, and disruptive behavior problems in elementary-school-aged children. Journal of Abnormal Child Psychology: An official publication of the International Society for Research in Child and Adolescent Psychopathology, 22(2), 205-219.

Craske, M. (1999). Anxiety disorders: Psychological approaches to theory and treatment. Boulder, CO, US: Westview Press.

Crockenberg, S., \& Leerkes, E. (2004). Infant and maternal behaviors regulate infant reactivity to novelty at 6 months. Developmental Psychology, 40, 1123-1132.

Crockenberg, S., \& Leerkes, E. (2006). Infant and maternal behavior moderate reactivity to novelty to predict anxious behavior at 2.5 years. Development and Psychopathology, $18,17-34$. 
Cumberland-Li, A., Eisenberg, N., Champion, C., Gershoff, E., \& Fabes, R. A. (2003). The relation of parental emotionality and related dispositional traits to parental expression of emotion and children's social functioning. Motivation and Emotion, 27(1), 27-56.

Cummings, E. M., Davies, P. T., \& Campbell, S. B. (2000). Developmental psychopathology and family process: Theory, research, and clinical implications. New York, NY US: Guilford Press.

Cunningham, J. N., Kliewer, W., \& Garner, P. W. (2009). Emotion socialization, child emotion understanding and regulation, and adjustment in urban African American families: Differential associations across child gender. Development and Psychopathology, 21, 261-283.

Cutting, A. L., \& Dunn, J. (1999). Theory of mind, emotion understanding, language, and family background: Individual differences and interrelations. Child Development, $70(4), 853-865$.

Dadds, M. R., Roth, J. H., \& Vasey, M. W. (2001). Family processes in the development of anxiety problems: The developmental psychopathology of anxiety. (pp. 278-303). New York, NY US: Oxford University Press.

Davidov, M., \& Grusec, J. E. (2006). Untangling the links of parental responsiveness to distress and warmth to child outcomes. Child Development, 77, 44-58.

Davis, M. H. (1983). Measuring individual differences in empathy: Evidence for a multidimensional approach. Journal of Personality and Social Psychology, 44(1), 113126.

DeBoard-Lucas, R. L., Fosco, G. M., Raynor, S. R., \& Grych, J. H. (2010). Interparental conflict in context: Exploring relations between parenting processes and children's conflict appraisals. Journal of Child and Adolescent Psychology, 39, 163-175. 
De Rosnay, M., Harris, P., \& Pons, F. (2008). Emotion understanding and developmental psychopathology in young children. In C. Sharp, P. Fonagy \& I. Goodyer (Eds.), Social cognition and developmental psychopathology (pp. 343-385). New York, NY: Oxford University Press.

De Rosnay, M., \& Harris, P. L. (2002). Individual differences in children's understanding of emotion: The roles of attachment and language. Attachment \& Human Development, 4(1), 39-54.

Denham, S. A. (1989). Maternal affect and toddler's social-emotional competence. American Journal of Orthopsychiatry, 59(3), 368-376.

Denham, S. A. (1997). "When I have a bad dream, mommy holds me": Preschoolers' conceptions of emotions, parental socialisation, and emotional competence. International Journal of Behavioral Development, 20(2), 301-319.

Denham, S. A. (2007). Dealing with feelings: How children negotiate the worlds of emotions and social relationships. Cogniție Creier Comportament, 11(1), 1-48.

Denham, S. A., Mitchell-Copeland, J., Strandberg, K., Auerbach, S., \& Blair, K. (1997). Parental contributions to preschoolers' emotional competence: Direct and indirect effects. Motivation and Emotion, 21(1), 65-86.

Dunn, J., \& Brown, J. (1994). Affect expression in the family, children's understanding of emotions, and their interactions with others. Merrill-Palmer Quarterly, 40(1), 120137.

Dunn, J., Brown, J., \& Beardsall, L. (1991). Family talk about feeling states and children's later understanding of others' emotions. Developmental Psychology, 27(3), 448-455.

Dunsmore, J. C., \& Karn, M. A. (2001). Mothers' beliefs about feelings and children's emotional understanding. Early Education and Development, 12(1), 117-138. 
Eisenberg, N., Cumberland, A., \& Spinrad, T. L. (1998). Parental socialization of emotion. Psychological Inquiry, 9(4), 241-273.

Eley, T. C., Vasey, M. W., \& Dadds, M. R. (2001). Contributions of behavioral genetics research: Quantifying genetic, shared environmental and nonshared environmental influences The developmental psychopathology of anxiety. (pp. 45-59). New York, NY US: Oxford University Press.

Fabes, R. A., Eisenberg, N., \& Bernzweig, J. (1990). Parental coping with children's negative emotions: Relations with children's emotional and social responding: Arizona State University [Available from the authors].

Faul, F., Erdfelder, E., Buchner, A., \& Lang, A. G. (2009). Statistical power analyses using G*Power 3.1: Tests for correlation and regression analyses. Behavior Research Methods, 41, 1149-1160.

Finzi-Dottan, R., Manor, I., \& Tyano, S. (2006). ADHD, temperament, and parent style as predictors of the child's attachment. Child Psychiatry \& Human Development, 37(2), 103-114.

Fisak, B., \& Grills-Taquechel, A. E. (2007). Parental modeling, reinforcement, and information transfer: Risk factors in the development of child anxiety? Clinical Child and Family Psychology, 10(3), 213-231.

Fox, N. A., Henderson, H. A., Marshall, P. J., Nichols, K. E., \& Ghera, M. M. (2005). Behavioral Inhibition: Linking Biology and Behavior within a Developmental Framework. Annual Review of Psychology, 56, 235-262.

Garber, J., Braafladt, N., \& Weis, B. (1995). Affect regulation in depressed and nondepressed children and young adolescents. Development and Psychopathology, 7(1), 93-115. 
Garner, P. W., Dunsmore, J. C., \& Southam-Gerrow, M. (2008). Mother-child conversations about emotions: Linkages to child aggression and prosocial behavior. Social Development, 17(2), 259-277.

Garside, R. B., \& Klimes-Dougan, B. (2002). Socialization of discrete negative emotions: Gender differences and links with psychological distress. Sex Roles, 47(3-4), 115128.

Gioia, G. A., Isquith, P. K., Guy, S. C., \& Kenworthy, L. (2000). Behavior Rating Inventory of Executive Function Child Neuropsychology (pp. 235-238). Odessa, FL: Psychological Assessment Resources.

Gottman, J. M., \& Katz, L. F. (1989). The effects of marital discord on young children's peer interaction and health. Developmental Psychology, 25, 373-381.

Gottman, J. M., Katz, L. F., \& Hooven, C. (1996). Parental meta-emotion philosophy and the emotional life of families: Theoretical models and preliminary data. Journal of Family Psychology, 10(3), 243-268.

Gottman, J. M., Katz, L. F., \& Hooven, C. (1997). Meta-emotion: How families communicate emotionally. Hillsdale, NJ: Lawrence Erlbaum Associates, Inc.

Greenberg, M. T., Kusche, C. A., Cook, E. T., \& Quamma, J. P. (1995). Promoting emotional competence in school-aged children: The effects of the PATHS curriculum. Development and Psychopathology, 7(1), 117-136.

Greenberger, E. (1988). New measures for research on work, parenting, and the socialization of children. Irvine, CA: University of California, Irvine.

Gross, J. J., \& Muñoz, R. F. (1995). Emotion regulation and mental health. Clinical Psychology: Science and Practice, 2(2), 151-164. 
Gunnar, M. R. (2006). Social regulation of stress in early child development. In: K. McCartney \& D. Phillips (Eds.), Blackwell handbook of early childhood development (pp. 106-125). Malden, MA: Blackwell Publishing.

Halberstadt, A. G., Crisp, V. W., \& Eaton, K. L. (1999). Family expressiveness: A retrospective and new directions for research. In P. Philippot, R. S. Feldman \& E. J. Coats (Eds.), The social context of nonverbal behavior (Vol. xiii, pp. 431). New York, NY, US: Cambridge University Press.

Halberstadt, A. G., Denham, S., \& Dunsmore, J. C. (2001). Affective social competence. Social Development, 10(1), 79-119.

Halberstadt, A. G., \& Eaton, K. L. (2003). A meta-analysis of family expressiveness and children's emotion expressiveness and understanding. Marriage \& Family Review, $34(1), 35-62$.

Harris, P. L. (1994). The child's understanding of emotion: Developmental change and the family environment. Journal of Child Psychology and Psychiatry, 35(1), 3-28.

Harris, P. L. (1999). Individual differences in understanding emotion: The role of attachment status and psychological discourse. Attachment \& Human Development, 1(3), 307-324.

Harris, P. L., \& Saarni, C. (1989). Children's understanding of emotion: An introduction Children's understanding of emotion. (pp. 3-24). New York, NY US: Cambridge University Press.

Hastings, M. E. (2005). Psychopathy and the identification and understanding of emotion. ProQuest Information \& Learning.

Hastings, P. D., \& De, I. (2008). Parasympathetic regulation and parental socialization of emotion: Biopsychosocial processes of adjustment in preschoolers. Social Development, 17(2), 211-238. 
Hastings, P. D., Nuselovici, J. N., Utendale, W. T., Coutya, J., McShane, K. E., \& Sullivan, C. (2008). Applying the polyvagal theory to children's emotion regulation: Social context, socialization, and adjustment. Biological Psychology, 79(3), 299-306.

Hatzenbuehler, M. L., McLaughlin, K. A., \& Nolen-Hoeksema, S. (2008). Emotion regulation and internalizing symptoms in a longitudinal study of sexual minority and heterosexual adolescents. Journal of Child Psychology and Psychiatry, 49(12), 12701278.

Hayes, A. F. (2013). Introduction to mediation, moderation, and conditional process analysis. New York, NY: The Guilford Press.

Herbert, S. D., Harvey, E. A., Roberts, J. L., Wichowski, K., \& Lugo-Candelas, C. I. (2012). A randomized controlled trial of a parent training and emotion socialization program for families of hyperactive preschool-aged children. Behavior Therapy, 44(2), 302316.

Hooven, C., Gottman, J. M., \& Katz, L. F. (1995). Parental meta-emotion structure predicts family and child outcomes. Cognition and Emotion, 9(2-3), 229-264.

Izard, C. E., Harris, P., Cicchetti, D., \& Cohen, D. J. (1995). Emotional development and developmental psychopathology Developmental psychopathology, Vol. 1: Theory and methods. (pp. 467-503). Oxford England: John Wiley \& Sons.

Izard, C. E., Youngstrom, E. A., Fine, S. E., Mostow, A. J., Trentacosta, C. J., Cicchetti, D., et al. (2006). Emotions and developmental psychopathology Developmental psychopathology, Vol 1: Theory and method (2nd ed.). (pp. 244-292). Hoboken, NJ US: John Wiley \& Sons Inc.

Jakes, S. S., \& DeBord, K. (2010). The interface of family, school, and community factors for the positive development of children and youth. Journal of Prevention \& Intervention in the Community, 38(3), 177-182. 
Joormann, J., Gilbert, K., \& Gotlib, I. H. (2010). Emotion identification in girls at high risk for depression. Journal of Child Psychology and Psychiatry, 51(5), 575-582.

Katz, L. F., \& Gottman, J. M. (1997). Buffering children from marital conflict and dissolution. Journal of Clinical Child Psychology, 26(2), 157-171.

Katz, L. F., \& Windecker-Nelson, B. (2004). Parental meta-emotion philosophy in families with conduct-problem children: Links with peer relations. Journal of Abnormal Child Psychology, 32(4), 385-398.

Kim, J., \& Cicchetti, D. (2010). Longitudinal pathways linking child maltreatment, emotion regulation, peer relations, and psychopathology. Journal of Child Psychology and Psychiatry, 51(6), 706-716.

Krause, E. D., Mendelson, T., \& Lynch, T. R. (2003). Childhood emotional invalidation and adult psychological distress: The mediating role of emotional inhibition. Child Abuse \& Neglect, 27, 199-213.

Kusche, C. A., Greenberg, M. T., \& Beilke, B. (1988). The Kusche Affective Interview. Unpublished manuscript, University of Washington, Department of Psychology, Seattle, WA.

Lagattuta, K. H., \& Wellman, H. M. (2002). Differences in early parent-child conversations about negative versus positive emotions: Implications for the development of psychological understanding. Developmental Psychology, 38(4), 564-580.

Leibowitz, J., Ramos-Marcuse, F., \& Arsenio, W. F. (2002). Parent-child emotion communication, attachment, and affective narratives. Attachment \& Human Development, 4(1), 55-67.

Linehan, M. M., Paul, E., \& Egan, K. J. (1983). The Parent Affect Test: Development, validity, and reliability. Journal of Clinical Child Psychology, 12(2), 161-166. 
Lunkenheimer, E. S., Shields, A. M., \& Cortina, K. S. (2007). Parental emotion coaching and dismissing in family interaction. Social Development, 16(2), 232-248.

Lytton, H., \& Romney, D. M. (1991). Parents' differential socialization of boys and girls: A meta-analysis. Psychological Bulletin, 109(2), 267-296.

MacKinnon, D. P., Fairchild, A. J., \& Fritz, M. S. (2007). Mediation Analysis. Annual Review of Psychology, 58, 593-614.

McDowell, D. J., \& Parke, R. D. (2009). Parental correlates of children's peer relations: An empirical test of a tripartite model. Developmental Psychology, 45(1), 224-235.

McLeod, B. D., Wood, J. J., \& Weisz, J. R. (2007). Examining the association between parenting and childhood anxiety: A meta-analysis. Clinical Psychology Review, 27, $155-172$.

McLoone, J., Hudson, J. L., \& Rapee, R. M. (2006). Treating Anxiety Disorders in a School Setting. Education \& Treatment of Children, 29(2), 219-242.

Meerum-Terwogt, M. (1990). Disordered children's acknowledgment of multiple emotions. Journal of General Psychology, 117(1), 59-69.

Michalson, L., \& Lewis, M. (1985). What do children know about emotions and when do they know it? In M. Lewis \& C. Saarni (Eds.), The socialization of emotions (pp. 117-139). New York: Plenum.

Muris, P., Merckelbach, H., Mayer, B., van Brakel, A., Thissen, S., Moulaert, V., et al. (1998). The Screen for Child Anxiety Related Emotional Disorders (SCARED) and traditional childhood anxiety measures. Journal of Behavior Therapy and Experimental Psychiatry, 29(4), 327-339.

Muris, P., Merckelbach, H., \& Meesters, C. (2001). Learning experiences and anxiety sensitivity in normal adolecents. Journal of Psychopathology and Behavioral Assessment, 23, 279-283. 
Muris, P., Merckelbach, H., van Brakel, A., Mayer, B., \& van Dongen, L. (1998). The Screen for Child Anxiety Related Emotional Disorders (SCARED): Relationship with anxiety and depression in normal children. Personality and Individual Differences, 24(4), 451456.

Murray, K. T., \& Kochanska, G. (2002). Effortful control: Factor structure and relation to externalizing and internalizing behaviors. Journal of Abnormal Child Psychology, $30(5), 503-514$.

Nelson, J. A., O'Brien, M., Blankson, A. N., Calkins, S. D., \& Keane, S. P. (2009). Family stress and parental responses to children's negative emotions: Tests of the spillover, crossover, and compensatory hypotheses. Journal of Family Psychology, 23(5), 671679.

O'Neal, C. R., \& Magai, C. (2005). Do parents respond in different ways when children feel different emotions? The emotional context of parenting. Development and Psychopathology, 17(2), 467-487.

Parent, C., Zhang, T. Y., Caldji, C., Bagot, R., Champagne, F. A., Pruessner et al. (2005). Maternal care and individual differences in defensive responses. Current Direction in Psychological Science, 14, 229-233.

Paulussen-Hoogeboom, M. C., Stams, G. J., Hermanns, J. M., \& Peetsma, T. T. (2007). Child negative emotionality and parenting from infancy to preschool: A meta-analytic review. Developmental Psychology, 43, 438-453.

Perlman, S. B., Camras, L. A., \& Pelphrey, K. A. (2008). Physiology and functioning: Parents' vagal tone, emotion socialization, and children's emotion knowledge. Journal of Experimental Child Psychology, 100(4), 308-315. 
Perry, N. B., Calkins, S. D., Nelson, J. A., Leerkes, E. M., \& Marcovitch, S. (2012). Mothers' responses to children's negative emotions and child emotion regulation: The moderating role of vagal suppression. Developmental Psychobiology, 54(5), 503-513.

Porges, S. W. (2007). The polyvagal perspective. Biological Psychology, 74(2), 116-143.

Porges, S. W., Campbell, B. A., Hayne, H., \& Richardson, R. (1992). Autonomic regulation and attention. In Attention and information processing in infants and adults: Perspectives from human and anmial research. (pp. 201-223). Hillsdale, NJ, England: Lawrence Erlbaum Associates, Inc.

Porges, S. W., Doussard-Roosevelt, J. A., \& Maita, A. K. (1994). Vagal tone and the physiological regulation of emotion. Monographs of the Society for Research in Child Development, 59(2-3), 167-186, 250-283.

Ramsden, S. R., \& Hubbard, J. A. (2002). Family expressiveness and parental emotion coaching: Their role in children's emotion regulation and aggression. Journal of Abnormal Child Psychology: An official publication of the International Society for Research in Child and Adolescent Psychopathology, 30(6), 657-667.

Rapee, R. M. (1997). Potential role of childrearing practices in the development of anxiety and depression. Clinical Psychology Review, 17(1), 47-67.

Rapee, R. M., Schniering, C., \& Hudson, J. L. (2009). Anxiety disorders during childhood and adolescence: Origins ad treatment. Annual Review of Clinical Psychology, 5, 311-341.

Rogeness, G. A., Cepeda, C., Macedo, C. A., \& Fischer, C. (1990). Differences in heart rate and blood pressure in children with conduct disorder, major depression, and separation anxiety. Psychiatry Research, 33(2), 199-206.

Rosnay, M. D., Harris, P. L., Pons, F., Sharp, C., Fonagy, P., \& Goodyer, I. (2008). Emotional understanding and developmental psychopathology in young children: Social 
cognition and developmental psychopathology. (pp. 343-385). New York, NY US: Oxford University Press.

Rothbart, M. K., Ellis, L. K., \& Posner, M. I. (2011). Temperament and self-regulation. In K. D. Vohs \& R. F. Baumeister (Eds.), Handbook of self-regulation: Research, theory, and applications (2 ed., pp. 592). New York, NY, US: Guilford Press.

Saarni, C. (1999). The development of emotional competence. New York, NY US: Guilford Press.

Schwartz, R. M., Trabasso, T., Izard, C. E., Kagan, J., \& Zajonc, R. B. (1985). Children's understanding of emotions. Emotions, Cognition, and Behavior. (pp. 409-437). New York, NY US: Cambridge University Press.

Shaffer, A., Suveg, C., Thomassin, K., \& Bradbury, L. L. (2012). Emotion socialization in the context of family risks: Links to child emotion regulation. Journal of Child and Family Studies, 21, 917-924.

Shipman, K. L., \& Zeman, J. (2001). Socialization of children's emotion regulation in motherchild dyads: A developmental psychopathology perspective. Development and Psychopathology, 13(2), 317-336.

Shipman, K. L., Zeman, J. L., \& Stegall, S. (2001). Regulating emotionally expressive behavior: Implications of goals and social partner from middle childhood to adolescence. Child Study Journal, 31(4), 249-268.

Sim, L., Adrain, M., Zeman, J., Cassano, M., \& Friedrich, W. N. (2009). Adolescent deliberate self-harm: Linkages to emotion regulation and family emotional climate. Journal of Research on Adolescence, 19(1), 75-91.

Southam-Gerow, M. A., \& Kendall, P. C. (2000). A preliminary study of the emotion understanding of youths referred for treatment of anxiety disorders. Journal of Clinical Child Psychology, 29(3), 319-327. 
Southam-Gerow, M. A., \& Kendall, P. C. (2002). Emotion regulation and understanding: Implications for child psychopathology and therapy. Clinical Psychology Review, 22(2), 189-222.

Suveg, C., Morelen, D., Brewer, G. A., \& Thomassin, K. (2010). The emotion dysregulation model of anxiety: A preliminary path analytic examination. Journal of Anxiety Disorders, 24(8), 924-930.

Suveg, C., Sood, E., Barmish, A., Tiwari, S., Hudson, J. L., \& Kendall, P. C. (2008). 'I'd rather not talk about it': Emotion parenting in families of children with an anxiety disorder. Journal of Family Psychology, 22(6), 875-884.

Suveg, C., Southam-Gerow, M. A., Goodman, K. L., \& Kendall, P. C. (2007). The role of emotion theory and research in child therapy development. Clinical Psychology: Science and Practice, 14(4), 358-371.

Suveg, C., \& Zeman, J. (2004). Emotion Regulation in Children With Anxiety Disorders. Journal of Clinical Child \& Adolescent Psychology, 33(4), 750-759.

Suveg, C., Zeman, J., Flannery-Schroeder, E., \& Cassano, M. (2005). Emotion socialization in families of children with an anxiety disorder. Journal of Abnormal Child Psychology, 33(2), 145-155.

Taylor, D. A., \& Harris, P. (1984). Knowledge of strategies for the expression of emotion among normal and maladjusted boys: A research note. Journal of Child Psychology and Psychiatry, 25(1), 141-145.

Thayer, J. F., Friedman, B. H., Borkovec, T. D., Johnsen, B. H., \& Molina, S. (2000). Phasic heart period reactions to cued threat and nonthreat stimuli in generalized anxiety disorder. Psychophysiology, 37(3), 361-368.

Thompson, R. A., Lewis, M. D., \& Calkins, S. D. (2008). Reassessing emotion regulation. Child Development Perspectives, 2(3), 124-131. 
Trosper, S. E., Buzzella, B. A., Bennett, S. M., \& Ehrenreich, J. T. (2009). Emotion regulation in youth with emotional disorders: Implications for a unified treatment approach. Clinical Child and Family Psychology Review, 12, 234-254.

van Lang, N. D. J., Tulen, J. H. M., Kallen, V. L., Rosbergen, B., Dieleman, G., \& Ferdinand, R. F. (2007). Autonomic reactivity in clinically referred children attentiondeficit/hyperactivity disorder versus anxiety disorder. European Child \& Adolescent Psychiatry, 16(2), 71-78.

Vasey, M. W., \& Dadds, M. R. (2001). The developmental psychopathology of anxiety. New York, NY US: Oxford University Press.

Warren, H. K., \& Stifter, C. A. (2008). Maternal emotion-related socialization and preschoolers' developing emotion self-awareness. Social Development, 17(2), 239258.

Wellman, H. M., Cross, D., \& Watson, J. (2001). Meta-analysis of theory-of-mind development: The truth about false belief. Child Development, 72(3), 655-684.

Whaley, S. E., Pinto, A., \& Sigman, M. (1999). Characterizing interactions between anxious mothers and their children. Journal of Consulting and Clinical Psychology, 67(6), 826836.

Wong, M. S., McElwain, N. L., \& Halberstadt, A. G. (2009). Parent, family, and child characteristics: Associations with mother- and father-reported emotion socialization practices. Journal of Family Psychology, 23(4), 452-463.

Wood, J. J., McLeod, B. D., Sigman, M., Hwang, W.-C., \& Chu, B. C. (2003). Parenting and childhood anxiety: Theory, empirical findings, and future directions. Journal of Child Psychology and Psychiatry, 44(1), 134-151. 
Woodruff-Borden, J., Morrow, C., Bourland, S., \& Cambron, S. (2002). The behavior of anxious parents: Examining mechanisms of transmission of anxiety from parent to child. Journal of Clinical Child and Adolescent Psychology, 31(3), 364-374.

Yagmurlu, B., \& Altan, O. (2010). Maternal socialization and child temperament as predictors of emotion regulation in Turkish preschoolers. Infant and Child Development, 19, 275-296.

Yap, M. B. H., Allen, N. B., Leve, C., \& Katz, L. F. (2008). Maternal meta-emotion philosophy and socialization of adolescent affect: The moderating role of adolescent temperament. Journal of Family Psychology, 22(5), 688-700.

Zeman, J. \& Garber, J. (1996). Display rules for anger, sadness, and pain: It depends on who is watching. Child Development, 67(3), 957-973.

Zeman, J., Shipman, K. L., \& Suveg, C. (2002). Anger and sadness regulation: Pedictions to internalizing and externalizing symptoms in children. Journal of Clinical Child \& Adolescent Psychology, 31(2), 393-398. 


\section{APPENDIX A}

\section{Parent Measures:}

\section{Behavior Rating Inventory of Executive Function}

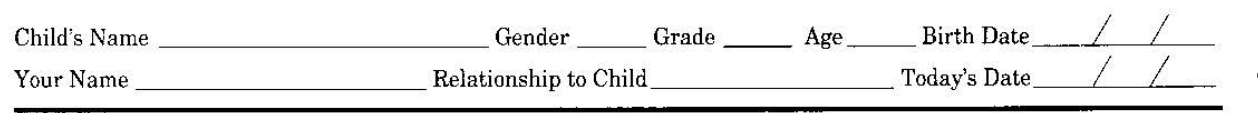

\section{$\mathrm{N}=$ Never $\quad \mathrm{S}=$ Sometimes $\quad \mathrm{O}=$ Often}
1. Overreacts to small problems
2. When given three things to do, remembers only the first or last
3. Is not a selt-starter
4. Leaves playroom a mess
5. Resists or has trouble accepting a different way to solve a problem with schoolwork, friends, chores, etc.
6. Becomes upset with new situations
7. Has explosive, angry outbursts
8. Tries the same approach to a problem over and over even when it does not work
9. Has a short attention span
10. Needs to be told to begin a task even when willing
11. Does not bring home homework, assignment sheets, materials, etc.
12. Acts upset by a change in plans
13. Is cisturbed by change of teacher or class
14. Does not check work for mistakes
15. Has good ideas but cannot get them on paper
16. Has trouble coming up with ideas for what to do in play or free time
17. Has trouble concentrating on chores, schoolwork, etc.
18. Does not connect doing tonight's homework with grades
19. Is easily distracted by noises, activity, sights, eic.
20. Becomes teartul easily
21. Makes careless errors
22. Forgets to hand in homework, even when completed
23. Resists change of routine, foods, places, etc.
24. Has trouble with chores or tasks that have more than one step
25. Has outbursts for little reason
26. Mood changes frequently
27. Needs help from an adult to stay on task
28. Gets caught up in details and misses the big picture
29. Keeps room messy
30. Has trouble getting used to new situations (classes, groups, friends)
31. Has poor handwriting
32. Forgets what he/she was doing
33. When sent to get something, forgets what he/she is supposed to get
34. Is unaware of how his/her behavior affects or bothers others
35. Has good ideas but does not get job done (lacks foliow-through)
36. Becomes overwheimed by large assignments
37. Has trouble finishing tasks (chores, homework)
38. Acts wilder or sillier than others in groups (birthday parties, recess)
39. Thinks too much about the same topic
40. Underestimates time needed to finish tasks
41. Interrupts others
42. Does not notice when his/her behavior causes negative reactions
43. Gets out of seat at the wrong times
44. Gets out of control more than friends

\begin{tabular}{|c|c|}
\hline $\mathrm{N}$ & $\mathrm{s}$ \\
\hline $\mathrm{N}$ & $s$ \\
\hline $\mathbf{N}$ & $S$ \\
\hline $\mathrm{N}$ & $S$ \\
\hline $\mathrm{N}$ & $S$ \\
\hline $\mathrm{N}$ & $S$ \\
\hline $\mathbf{N}$ & $S$ \\
\hline $\mathrm{N}$ & $S$ \\
\hline $\mathrm{N}$ & $S$ \\
\hline $\mathrm{N}$ & $S$ \\
\hline $\mathrm{N}$ & $S$ \\
\hline$N$ & $\mathrm{~S}$ \\
\hline $\mathrm{N}$ & $S$ \\
\hline $\mathrm{N}$ & $S$ \\
\hline $\mathrm{N}$ & $S$ \\
\hline $\mathrm{N}$ & $S$ \\
\hline $\mathrm{N}$ & $S$ \\
\hline $\mathrm{N}$ & $S$ \\
\hline $\mathrm{N}$ & $S$ \\
\hline $\mathrm{N}$ & $S$ \\
\hline$N$ & $S$ \\
\hline $\mathrm{N}$ & $S$ \\
\hline $\mathrm{N}$ & S \\
\hline$N$ & $S$ \\
\hline $\mathrm{N}$ & $S$ \\
\hline$N$ & $S$ \\
\hline$N$ & $S$ \\
\hline $\mathrm{N}$ & $S$ \\
\hline$N$ & $S$ \\
\hline$N$ & $S$ S \\
\hline$N$ & $S$ \\
\hline$N$ & $S$ \\
\hline$N$ & $S$ \\
\hline$N$ & $S$ \\
\hline $\mathrm{N}$ & $S$ \\
\hline $\mathrm{N}$ & $S$ \\
\hline$N$ & $s$ \\
\hline$N$ & $S$ \\
\hline$N$ & $S$ \\
\hline $\mathrm{N}$ & $S$ \\
\hline $\mathrm{N}$ & $S$ \\
\hline$N$ & S \\
\hline $\mathrm{N}$ & $\mathrm{S}$ \\
\hline$N$ & $S$ \\
\hline
\end{tabular}




\section{$\mathrm{N}=$ Never $\quad \mathrm{S}=$ Sometimes $\quad \mathrm{O}=$ Often}

45. Reacts more strongly to situations than other children

46. Starts assignments or chores at the last minute

47. Has trouble getting started on homework or chores

48. Has trouble organizing activities with friends

49. Blurts things out

50. Mood is easily influenced by the situation

51. Does not plan ahead for school assignments

52. Has poor understanding of own strengths and weaknesses

53. Written work is poorly organized

54. Acts too wild or "out of control"

55. Has trouble putting the brakes on his/her actions

56. Gets in trouble if not supervised by an aduit

57. Has trouble remembering things, even for a few minutes

58. Has trouble carrying out the actions needed to reach goals (saving money for special item, studying to get a good grade)

59. Becomes too silly

60. Work is sloppy

61. Does not take initiative

62. Angry or tearful outbursts are intense but end suddenly

63. Does not realize that certain actions bother others

64. Small events trigger big reactions

65. Talks at the wrong time

66. Complains there is nothing to do

67. Cannot find things in room or school desk

68. Leaves a trail of belongings wherever he/she goes

69. Leaves messes that others have to clean up

70. Becomes upset too easily

71. Lies around the house a lot ("couch potato")

72. Has a messy closet

73. Has trouble waiting for turn

74. Loses lunch box, lunch money, permission slips, homework, etc.

75. Cannot find clothes, glasses, shoes, toys, books, pencils, etc.

76. Tests poorly even when knows correct answers

77. Does not finish long-term projects

78. Has to be closely supervised

79. Does not think before doing

80. Has trouble moving from one activity to another

81. Is fidgety

82. Is impulsive

83. Cannot stay on the same topic when talking

84. Gets stuck on one topic or activity

85. Says the same things over and over

86. Has trouble getting through morning routine in getting ready for school

\begin{tabular}{|c|c|}
\hline$N$ & $\mathrm{~S}$ \\
\hline$N$ & $S$ \\
\hline $\mathrm{N}$ & $S$ \\
\hline $\mathrm{N}$ & $S$ \\
\hline $\mathrm{N}$ & s \\
\hline$N$ & $S$ \\
\hline $\mathrm{N}$ & $S$ \\
\hline $\mathrm{N}$ & $S$ \\
\hline$N$ & $S$ \\
\hline$N$ & $S$ \\
\hline $\mathrm{N}$ & $S$ \\
\hline $\mathrm{N}$ & $S$ \\
\hline $\mathrm{N}$ & $S$ \\
\hline $\mathrm{N}$ & $\mathrm{S}$ \\
\hline $\mathrm{N}$ & $\mathrm{s}$ \\
\hline $\mathrm{N}$ & $S$ \\
\hline $\mathrm{N}$ & $S$ \\
\hline$N$ & $S$ \\
\hline $\mathrm{N}$ & $S$ \\
\hline$N$ & $S$ \\
\hline $\mathrm{N}$ & S \\
\hline$N$ & $S$ \\
\hline $\mathrm{N}$ & $S$ \\
\hline N & $S$ \\
\hline $\mathrm{N}$ & $S$ \\
\hline$N$ & $S$ \\
\hline $\mathrm{N}$ & $S$ \\
\hline $\mathrm{N}$ & $S$ \\
\hline$N$ & $\mathrm{~S}$ \\
\hline $\mathrm{N}$ & S \\
\hline$N$ & $S$ \\
\hline$N$ & $S$ \\
\hline$N$ & $S$ \\
\hline$N$ & $S$ \\
\hline$N$ & S \\
\hline$N$ & $S$ \\
\hline$N$ & S \\
\hline $\mathrm{N}$ & $S$ \\
\hline$N$ & $S$ \\
\hline$N$ & $\mathrm{~S}$ \\
\hline $\mathrm{N}$ & S \\
\hline$N$ & $S$ \\
\hline
\end{tabular}




\section{Coping with Children's Negative Emotions Scale}

ID

Parent Attitude/Behavior Questionnaire

Instructions: In the following items, please indicate on a scale from 1 (very unlikely) to 7 (very likely) the likelihood that you would respond in the ways listed for each item. Please read each item carefully and respond as honestly and sincerely as you can. For each response, please circle a number from 1-7.

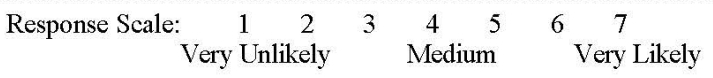

1. If my child becomes angry because he/she is sick or hurt and can't go to his/her friend's birthday party, I would:

a. send my child to his/her room to cool off

b. get angry at my child

c. help my child think about ways that he/she can still be with friends (e.g., invite some friends over after the party)

d. tell my child not to make a big deal out of missing the party

e. encourage my child to express his/her feelings of anger and frustration

f. soothe my child and do something fun with him/her to make him/her feel better about missing the party

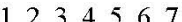

1234567

$\begin{array}{lllllll}1 & 2 & 3 & 4 & 5 & 6 & 7\end{array}$

123345567

123345567

1234567

2. If my child falls off his/her bike and breaks it, and then gets upset and cries, I would:

a. remain calm and not let myself get anxious

123345667

b. comfort my child and try to get him/her to forget about the accident

c. tell my child that he/she is over-reacting

d. help my child figure out how to get the bike fixed

e. tell my child it's OK to cry

f. tell my child to stop crying or he/she won't be allowed to ride his/her bike anytime soon

$\begin{array}{lllllll}1 & 2 & 3 & 4 & 5 & 6 & 7\end{array}$

$\begin{array}{lllllll}1 & 2 & 3 & 4 & 5 & 6 & 7\end{array}$

$\begin{array}{lllllll}1 & 2 & 3 & 4 & 5 & 6 & 7\end{array}$

123345567

$123 \quad 3 \quad 45567$

3. If my child loses some prized possession and reacts with tears, I would:

a. get upset with him/her for being so careless and then crying about it

b. tell my child that he/she is over-reacting

c. help my child think of places he/she hasn't looked yet

d. distract my child by talking about happy things

e. tell him/her it's OK to cry when you feel unhappy

f. tell him/her that's what happens when you're not careful

$\begin{array}{lllllll}1 & 2 & 3 & 4 & 5 & 6 & 7\end{array}$

$\begin{array}{lllllll}1 & 2 & 3 & 4 & 5 & 6 & 7\end{array}$

$\begin{array}{lllllll}1 & 2 & 3 & 4 & 5 & 6 & 7\end{array}$

$\begin{array}{lllllll}1 & 2 & 3 & 4 & 5 & 6 & 7\end{array}$

$\begin{array}{lllllll}1 & 2 & 3 & 4 & 5 & 6 & 7\end{array}$

$1253 \quad 45567$

4. If my child is afraid of injections and becomes quite shaky and teary while waiting for his/her turn to get a shot, I would:

a. tell him/her to shape up or he/she won't be allowed to do something he/she likes to do (e.g., watch TV)

b. encourage my child to talk about his/her fears

c. tell my child not to make big deal of the shot

d. tell him/her not to embarrass us by crying

e. comfort him/her before and after the shot

f. talk to my child about ways to make it hurt less (such as relaxing so it won't hurt or taking deep breaths).
$\begin{array}{lllllll}1 & 2 & 3 & 4 & 5 & 6 & 7\end{array}$
$\begin{array}{lllllll}1 & 2 & 3 & 4 & 5 & 6 & 7\end{array}$
$\begin{array}{lllllll}1 & 2 & 3 & 4 & 5 & 6 & 7\end{array}$
$\begin{array}{lllllll}1 & 2 & 3 & 4 & 5 & 6 & 7\end{array}$
1223445667

1234567 


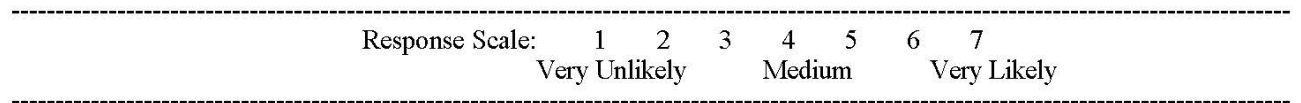

5. If my child is going over to spend the afternoon at a friend's house and becomes nervous and upset because I can't stay there with him/her, I would:

a. distract my child by talking about all the fun he/she will have with his/her friend

b. help my child think of things that he/she could do so that being at the friend's house without me wasn't scary (e.g., take a favorite book or toy with him/her)

c. tell my child to quit over-reacting and being a baby

d. tell the child that if he/she doesn't stop that he/she won't be allowed to go out anymore

e. feel upset and uncomfortable because of my child's reactions

f. encourage my child to talk about his/her nervous feelings

6. If my child is participating in some group activity with his/her friends and proceeds to make a mistake and then looks embarrassed and on the verge of tears, I would:

a. comfort my child and try to make him/her feel better

b. tell my child that he/she is over-reacting

c. feel uncomfortable and embarrassed myself

d. tell my child to straighten up or we'll go home right away

e. encourage my child to talk about his/her feelings of embarrassment

f. tell my child that I'll help him/her practice so that

he/she can do better next time

$\begin{array}{lllllll}1 & 2 & 3 & 4 & 5 & 6 & 7\end{array}$

122344567

$\begin{array}{lllllll}1 & 2 & 3 & 4 & 5 & 6 & 7\end{array}$

$\begin{array}{lllllll}1 & 2 & 3 & 4 & 5 & 6 & 7\end{array}$

$\begin{array}{lllllll}1 & 2 & 3 & 4 & 5 & 6 & 7\end{array}$ $\begin{array}{lllllll}1 & 2 & 3 & 4 & 5 & 6 & 7 \\ 1 & 2 & 3 & 4 & 5 & 6 & 7 \\ 1 & 2 & 3 & 4 & 5 & 6 & 7 \\ 1 & 2 & 3 & 4 & 5 & 6 & 7\end{array}$

12334567

122345567

7. If my child is about to appear in a recital or sports activity and becomes visibly nervous about people watching him/her, I would:

a. help my child think of things that he/she could do to get ready for his/her turn (e.g., to do some warm-ups and not to look at the audience)

b. suggest that my child think about something relaxing so that his/her nervousness will go away

c. remain calm and not get nervous myself

d. tell my child that he/she is being a baby about it

e. tell my child that if he/she doesn't calm down, we'll

have to leave and go home right away

f. encourage my child to talk about his/her nervous feelings

122345567

$\begin{array}{lllllll}1 & 2 & 3 & 4 & 5 & 6 & 7\end{array}$

$\begin{array}{lllllll}1 & 2 & 3 & 4 & 5 & 6 & 7\end{array}$

122345567

$\begin{array}{lllllll}1 & 2 & 3 & 4 & 5 & 6 & 7\end{array}$

$\begin{array}{lllllll}1 & 2 & 3 & 4 & 5 & 6 & 7\end{array}$

8. If my child receives an undesirable birthday gift from a friend and looks obviously disappointed, even annoyed, after opening it in the presence of the friend, I would:

a. encourage my child to express his/her disappointed feelings

12334567

b. tell my child that the present can be exchanged for something the child wants

c. NOT be annoyed with my child for being rude

d. tell my child that he/she is over-reacting

e. scold my child for being insensitive to the friend's feelings

f. try to get my child to feel better by doing something fun

$\begin{array}{lllllll}1 & 2 & 3 & 4 & 5 & 6 & 7\end{array}$

$\begin{array}{lllllll}1 & 2 & 3 & 4 & 5 & 6 & 7\end{array}$

$\begin{array}{lllllll}1 & 2 & 3 & 4 & 5 & 6 & 7\end{array}$

$\begin{array}{lllllll}1 & 2 & 3 & 4 & 5 & 6 & 7\end{array}$

$\begin{array}{lllllll}1 & 2 & 3 & 4 & 5 & 6 & 7\end{array}$ 


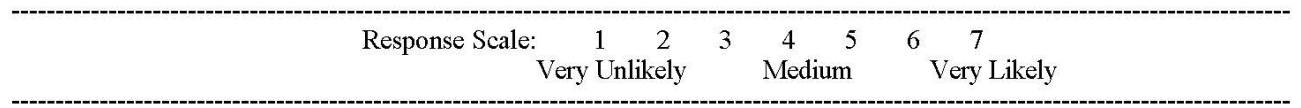

9. If my child is panicky and can't go to sleep after watching a scary TV show, I would:

a. encourage my child to talk about what scared him/her

$\begin{array}{lllllll}1 & 2 & 3 & 4 & 5 & 6 & 7\end{array}$

b. get upset with him/her for being silly

$\begin{array}{lllllll}1 & 2 & 3 & 4 & 5 & 6 & 7\end{array}$

c. tell my child that he/she is over-reacting

$\begin{array}{llllllll}1 & 2 & 3 & 4 & 5 & 6 & 7\end{array}$

d. help my child think of something to do so that he/she can get to sleep (e.g., take a toy to bed, leave the lights on)

e. tell him/her to go to bed or he/she won't be allowed to watch any more TV

f. do something fun with my child to help him/her forget about what scared him/her

10. If my child is at a park and appears on the verge of tears because the other children are mean to him/her and won't let him/her play with them, I would:

a. NOT get upset myself

b. tell my child that if he/she starts crying then we'll have to go home right away

c. tell my child it's OK to cry when he/she feels bad

d. comfort my child and try to get him/her to think about something happy

e. help my child think of something else to do

f. tell my child that he/she will feel better soon

1234567

$\begin{array}{lllllll}1 & 2 & 3 & 4 & 5 & 6 & 7\end{array}$

12334567

$\begin{array}{lllllll}1 & 2 & 3 & 4 & 5 & 6 & 7\end{array}$

$\begin{array}{lllllll}1 & 2 & 3 & 4 & 5 & 6 & 7\end{array}$

$\begin{array}{lllllll}1 & 2 & 3 & 4 & 5 & 6 & 7\end{array}$

11. If my child is playing with other children and one of them calls him/her names, and my child then begins to tremble and become tearful, I would:

a. tell my child not to make a big deal out of it

b. feel upset myself

c. tell my child to behave or we'll have to go home right away

d. help my child think of constructive things to do when other children tease him/her (e.g., find other things to do)

e. comfort him/her and play a game to take his/her mind off the upsetting event

f. encourage him/her to talk about how it hurts to be teased

123345667

$\begin{array}{llllllll}1 & 2 & 3 & 4 & 5 & 6 & 7\end{array}$

1223345567

122345567

12345567

1223445667

12. If my child is shy and scared around strangers and consistently becomes teary and wants to stay in his/her bedroom whenever family friends come to visit, I would:

a. help my child think of things to do that would make meeting my friends less scary (e.g., to take a favorite toy with him/her when meeting my friends)

123345567

b. tell my child that it is OK to feel nervous

12334567

c. try to make my child happy by talking about the fun things we can do with our friends

d. feel upset and uncomfortable because of my child's reactions

$\begin{array}{llllllll}1 & 2 & 3 & 4 & 5 & 6 & 7\end{array}$

e. tell my child that he/she must stay in the living room and visit with our friends

f. tell my child that he/she is being a baby 
Screen for Child Anxiety Related Disorders - Parent version

\section{Screen for Child Anxiety Related Disorders (SCARED) \\ Parent Version-Pg. 1 of 2 (To be filled out by the PARENT)}

Name:

Date:

Directions:

Below is a list of statements that describe how people feel. Read each statement carefully and decide if it is "Not True or Hardly Ever True" or "Somewhat True or Sometimes True" or "Very True or Often True" for your child. Then for each statement, fill in one circle that corresponds to the response that seems to describe your child for the last 3 months. Please respond to all statements as well as you can, even if some do not seem to concern your child.

\begin{tabular}{|c|c|c|c|}
\hline & $\begin{array}{c}0 \\
\text { Not True or } \\
\text { Hardly } \\
\text { Ever True }\end{array}$ & $\begin{array}{c}1 \\
\text { Somewhat } \\
\text { True or } \\
\text { Sometimes } \\
\text { True }\end{array}$ & $\begin{array}{c}2 \\
\text { Very True } \\
\text { or Often } \\
\text { True }\end{array}$ \\
\hline 1. When my child feels frightened, it is hard for him/her to breathe. & $\mathrm{O}$ & $\mathrm{O}$ & $\mathrm{O}$ \\
\hline 2. My child gets headaches when he/she is at school. & $\mathrm{O}$ & $\mathrm{O}$ & $\mathrm{O}$ \\
\hline $\begin{array}{l}\text { 3. My child doesn't like to be with people he/she doesn't know } \\
\text { well. }\end{array}$ & O & 0 & 0 \\
\hline 4. My child gets scared if he/she sleeps away from home. & $\mathrm{O}$ & $\mathrm{O}$ & $\mathrm{O}$ \\
\hline 5. My child worries about other people liking him/her. & $\mathrm{O}$ & $\mathrm{O}$ & $\mathrm{O}$ \\
\hline 6. When my child gets frightened, he/she feels like passing out. & $\mathrm{O}$ & $\mathrm{O}$ & $\mathrm{O}$ \\
\hline 7. My child is nervous. & $\mathrm{O}$ & $\mathrm{O}$ & $\mathrm{O}$ \\
\hline 8. My child follows me wherever I go. & $\mathrm{O}$ & $\mathrm{O}$ & $\mathrm{O}$ \\
\hline 9. People tell me that my child looks nervous. & $\mathrm{O}$ & $\mathrm{O}$ & $\mathrm{O}$ \\
\hline 10. My child feels nervous with people he/she doesn't know well. & O & $\mathrm{O}$ & $\mathrm{O}$ \\
\hline 11. My child gets stomachaches at school. & $\mathrm{O}$ & $\mathrm{O}$ & $\mathrm{O}$ \\
\hline $\begin{array}{l}\text { 12. When my child gets frightened, he/she feels like he/she is going } \\
\text { crazy. }\end{array}$ & 0 & 0 & 0 \\
\hline 13. My child worries about sleeping alone. & $\mathrm{O}$ & $\mathrm{O}$ & $\mathrm{O}$ \\
\hline 14. My child worries about being as good as other kids. & 0 & 0 & 0 \\
\hline $\begin{array}{l}\text { 15. When he/she gets frightened, he/she feels like things are not } \\
\text { real. }\end{array}$ & $\mathrm{O}$ & $\mathrm{O}$ & $\mathrm{O}$ \\
\hline $\begin{array}{l}\text { 16. My child has nightmares about something bad happening to } \\
\text { his/her parents. }\end{array}$ & 0 & 0 & O \\
\hline 17. My child worries about going to school. & 0 & 0 & 0 \\
\hline 18. When my child gets frightened, his/her heart beats fast. & O & $\mathrm{O}$ & $\mathrm{O}$ \\
\hline 19. He/she gets shaky. & 0 & $\bigcirc$ & 0 \\
\hline $\begin{array}{l}\text { 20. My child has nightmares about something bad happening to } \\
\text { him/her. }\end{array}$ & O & O & O \\
\hline
\end{tabular}


Screen for Child Anxiety Related Disorders (SCARED)

Parent Version -Pg. 2 of 2 (To be filled out by the PARENT)

\begin{tabular}{|c|c|c|c|}
\hline & $\begin{array}{c}0 \\
\text { Not True or } \\
\text { Hardly } \\
\text { Ever True }\end{array}$ & $\begin{array}{c}1 \\
\text { Somewhat } \\
\text { True or } \\
\text { Sometimes } \\
\text { True }\end{array}$ & $\begin{array}{c}2 \\
\text { Very True } \\
\text { or Often } \\
\text { True }\end{array}$ \\
\hline 21. My child worries about things working out for him/her. & $\mathrm{O}$ & $\mathrm{O}$ & $\mathrm{O}$ \\
\hline 22. When my child gets frightened, he/she sweats a lot. & $\mathrm{O}$ & $\mathrm{O}$ & $\mathrm{O}$ \\
\hline 23. My child is a worrier. & O & O & O \\
\hline 24. My child gets really frightened for no reason at all. & $\mathrm{O}$ & $\mathrm{O}$ & $\mathrm{O}$ \\
\hline 25. My child is afraid to be alone in the house. & $\mathrm{O}$ & $\mathrm{O}$ & $\mathrm{O}$ \\
\hline $\begin{array}{l}\text { 26. It is hard for my child to talk with people he/she doesn't know } \\
\text { well. }\end{array}$ & $\mathrm{O}$ & $\mathrm{O}$ & 0 \\
\hline $\begin{array}{l}\text { 27. When my child gets frightened, he/she feels like he/she is } \\
\text { choking. }\end{array}$ & $\mathrm{O}$ & 0 & $\mathrm{O}$ \\
\hline 28. People tell me that my child worries too much. & 0 & $\mathrm{O}$ & 0 \\
\hline 29. My child doesn't like to be away from his/her family. & 0 & 0 & 0 \\
\hline 30. My child is afraid of having anxiety (or panic) attacks. & O & $\mathrm{O}$ & O \\
\hline $\begin{array}{l}\text { 31. My child worries that something bad might happen to his/her } \\
\text { parents. }\end{array}$ & $\mathrm{O}$ & O & $\mathrm{O}$ \\
\hline 32. My child feels shy with people he/she doesn't know well. & $\mathrm{O}$ & $\mathrm{O}$ & $\mathrm{O}$ \\
\hline 33. My child worries about what is going to happen in the future. & $\mathrm{O}$ & $\mathrm{O}$ & $\mathrm{O}$ \\
\hline 34. When my child gets frightened, he/she feels like throwing up. & $\mathrm{O}$ & $\mathrm{O}$ & $\mathrm{O}$ \\
\hline 35. My child worries about how well he/she does things. & O & 0 & O \\
\hline 36. My child is scared to go to school. & $\mathrm{O}$ & $\mathrm{O}$ & $\mathrm{O}$ \\
\hline 37. My child worries about things that have already happened. & O & O & O \\
\hline 38. When my child gets frightened, he/she feels dizzy. & $\mathrm{O}$ & O & $\mathrm{O}$ \\
\hline $\begin{array}{l}\text { 39. My child feels nervous when he/she is with other children or } \\
\text { adults and he/she has to do something while they watch him/her (for } \\
\text { example: read aloud, speak, play a game, play a sport.) }\end{array}$ & $\mathrm{O}$ & 0 & O \\
\hline $\begin{array}{l}\text { 40. My child feels nervous when he/she is going to parties, dances, } \\
\text { or any place where there will be people that he/she doesn't know } \\
\text { well. }\end{array}$ & O & O & O \\
\hline 41. My child is shy. & $\mathrm{O}$ & $\mathrm{O}$ & $\mathrm{O}$ \\
\hline
\end{tabular}

\section{SCORING:}

A total score of $\geq \mathbf{2 5}$ may indicate the presence of an Anxiety Disorder. Scores higher than 30 are more specific. A score of 7 for items $1,6,9,12,15,18,19,22,24,27,30,34,38$ may indicate Panic Disorder or Significant Somatic Symptoms.

A score of 9 for items 5, 7, 14, 21, 23, 28, 33, 35, 37 may indicate Generalized Anxiety Disorder.

A score of 5 for items 4, 8, 13, 16, 20, 25, 29, 31 may indicate Separation Anxiety Disorder

A score of $\mathbf{8}$ for items $3,10,26,32,39,40,41$ may indicate Social Anxiety Disorder.

A score of 3 for items 2, 11, 17, 36 may indicate Significant School Avoidance.

Developed by Boris Birmaher, M.D., Suneeta Khetarpal, M.D., Marlane Cully, M.Ed., David Brent M.D., and Sandra

McKenzie, Ph.D., Western Psychiatric Institute and Clinic, University of Pgh. (10/95). E-mail: birmaherb@msx.upmc.edu 


\section{Child Measures:}

Kusche Affective Interview - Revised

SECTION A - Discussion of Own Emotions

1. I WANT YOU TO NAME ALL OF THE DIFFERENT FEELINGS YOU CAN THINK OF.

Record all responses (put checks after those listed, write in other responses). Continue to probe with ANY MORE? Until the child says no.

2. For the FIRST 5 EMOTIONS listed in the response sheet (happy, sad, mad/angry, scared/afraid, and love), say:

TELL ME ABOUT A TIME WHEN YOU FELT ___ _ If further probing is necessary, ask WHAT HAPPENED? Or EXPLAIN MORE ABOUT THAT.

If the child denies ever having felt the emotion him/herself, record this information and say: OK, TELL ME ABOUT A TIME WHEN YOU THOUGHT SOMEONE ELSE FELT

For the LAST 5 EMOTIONS (proud, guilty, jealous, nervous/anxious, and lonely), say:

WHAT DOES MEAN? Record the child's response, probing if necessary for clarification (Tell me more about that.). Ask the child to guess if they don't know.

Then, say: TELL ME ABOUT A TIME WHEN YOU FELT

If the child denies having directly experienced the affect, ask: OK, TELL ME ABOUT A TIME WHEN YOU THOUGHT SOMEONE ELSE FELT

SECTION B - Cues for Recognizing Emotions

3. Ask about each of the 5 emotions listed on the response sheet as follows: HOW DO YOU KNOW WHEN YOU ARE FEELING ?

If the child does not understand, say WELL, IF YOU FELT HOW WOULD YOU KNOW THAT? If the child says "I don't know" say, OK, GIVE ME YOUR BEST GUESS.

After the child has responded, probe with ARE THERE ANY OTHER WAYS THAT YOU KNOW WHEN YOU ARE FEELING ? Continue to probe until the child says no.

Then, for the same emotion, ask HOW DO YOU KNOW WHEN OTHER PEOPLE ARE FEELING ?

If the child does not understand, say WELL, IF ANOTHER PERSON FELT , HOW WOULD YOU KNOW THAT? In response to "I don't know" say 
OK, GIVE ME YOUR BEST GUESS?

Continue to probe with ARE THERE ANY OTHER WAYS YOU KNOW WHEN OTHER PEOPLE ARE FEELING ? Until the child says no.

Continue for all 6 emotions.

SECTION C - Understanding Simultaneous Emotions

4. CAN SOMEONE FEEL SAD AND MAD AT THE VERY SAME TIME? Circle yes or no as appropriate.

If no, WHY NOT?

If yes, TELL ME ABOUT A TIME WHEN YOU FELT SAD AND MAD AT THE VERY SAME TIME.

If child cannot give an example of self, say OK, TELL ME ABOUT A TIME WHEN SOMEONE ELSE FELT SAD AND MAD AT THE VERY SAME TIME.

5. CAN SOMEONE FEEL SAD AND HAPPY AT THE VERY SAME TIME? Circle yes or no as appropriate.

If no, WHY NOT?

If yes, TELL ME ABOUT A TIME WHEN YOU FELT SAD AND HAPPY AT THE VERY SAME TIME.

If child cannot give an example of self, say OK, TELL ME ABOUT A TIME WHEN SOMEONE ELSE FELT SAD AND HAPPY AT THE VERY SAME TIME.

6. CAN SOMEONE FEEL CALM AND NERVOUS AT THE VERY SAME TIME? Circle yes or no as appropriate.

If no, WHY NOT?

If yes, TELL ME ABOUT A TIME WHEN YOU FELT CALM AND NERVOUS AT THE VERY SAME TIME.

If child cannot give an example of self, say OK, TELL ME ABOUT A TIME WHEN SOMEONE ELSE FELT CALM AND NERVOUS AT THE VERY SAME TIME.

7. CAN SOMEONE LOVE SOMEONE ELSE AND BE ANGRY WITH THAT PERSON AT THE VERY SAME TIME? Circle yes or no as appropriate.

If no, WHY NOT?

If yes, TELL ME ABOUT A TIME WHEN YOU LOVED SOMEONE AND FELT ANGRY WITH THAT PERSON AT THE VERY SAME TIME. 
If child cannot give an example of self, say, OK, TELL ME ABOUT A TIME WHEN SOMEONE ELSE LOVED ANOTHER PERSON AND FELT ANGRY WITH THAT PERSON AT THE VERY SAME TIME. 
Neutral Pictures:
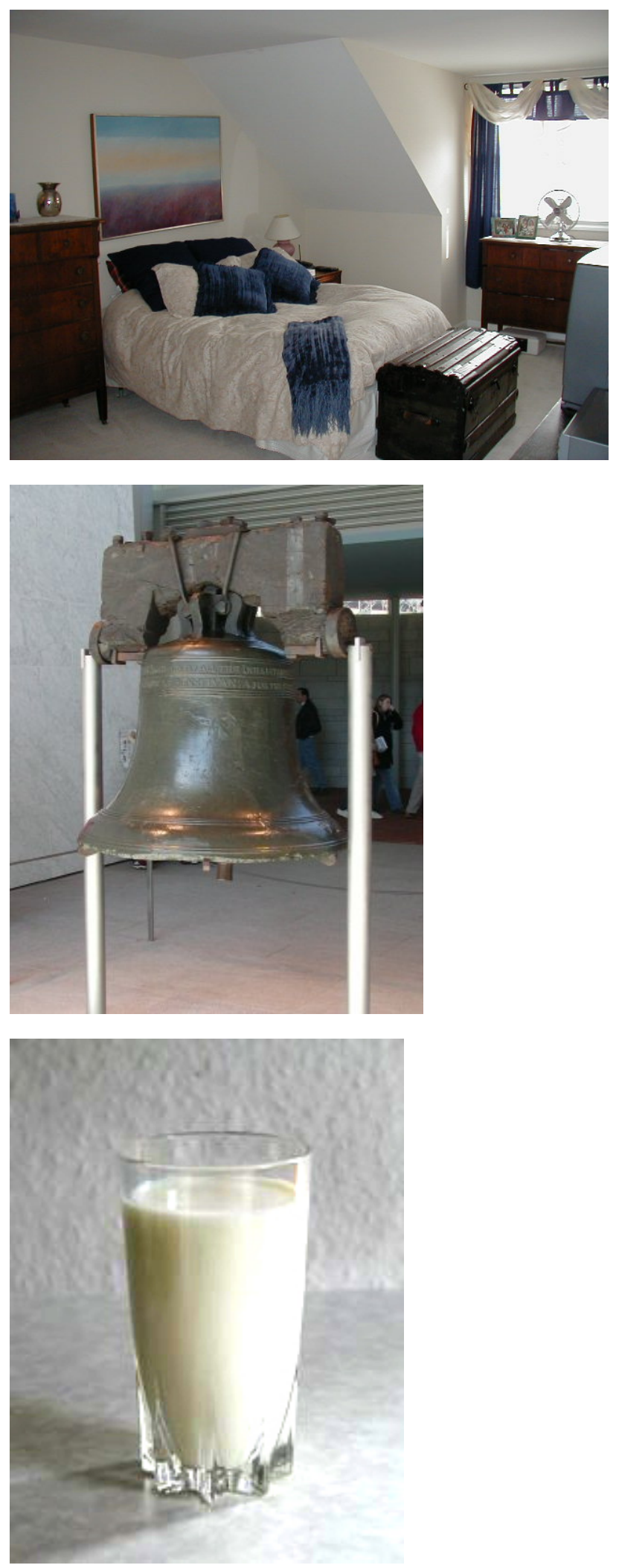

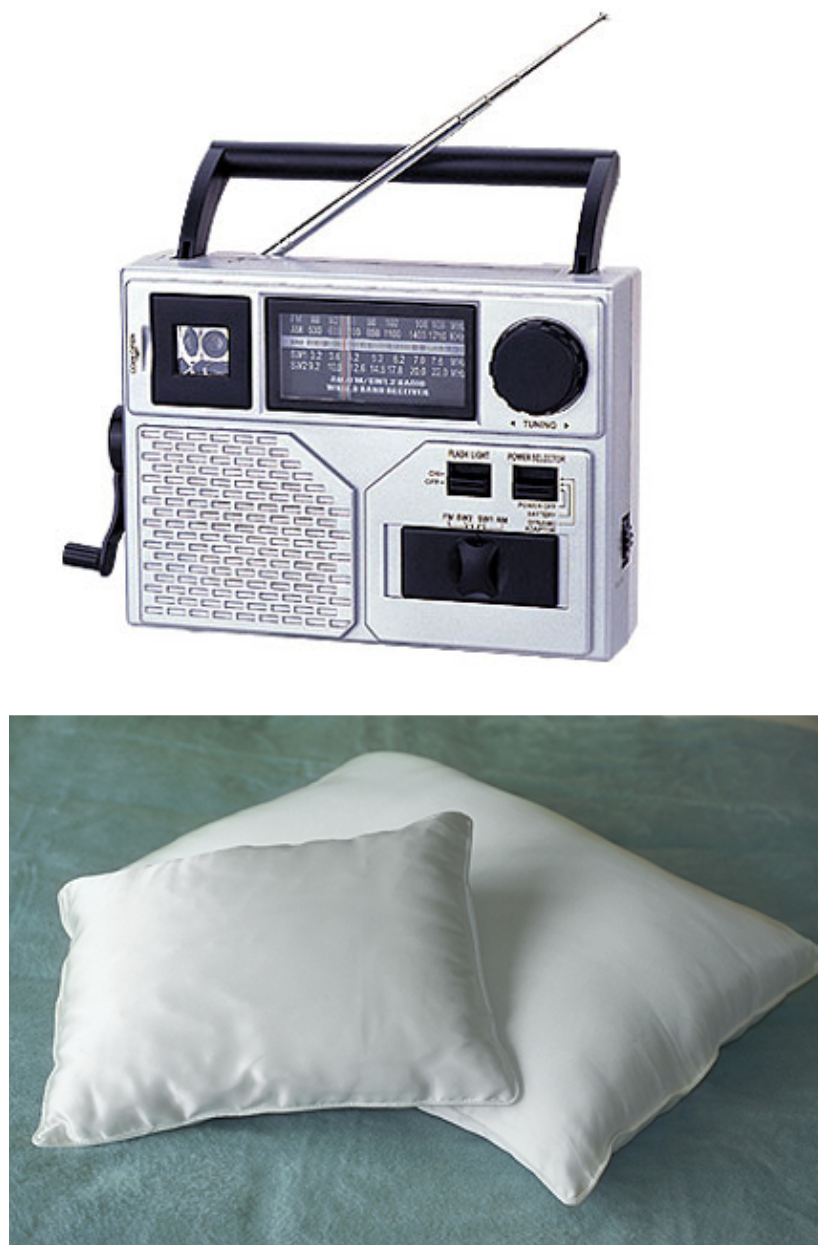

Threat Pictures:
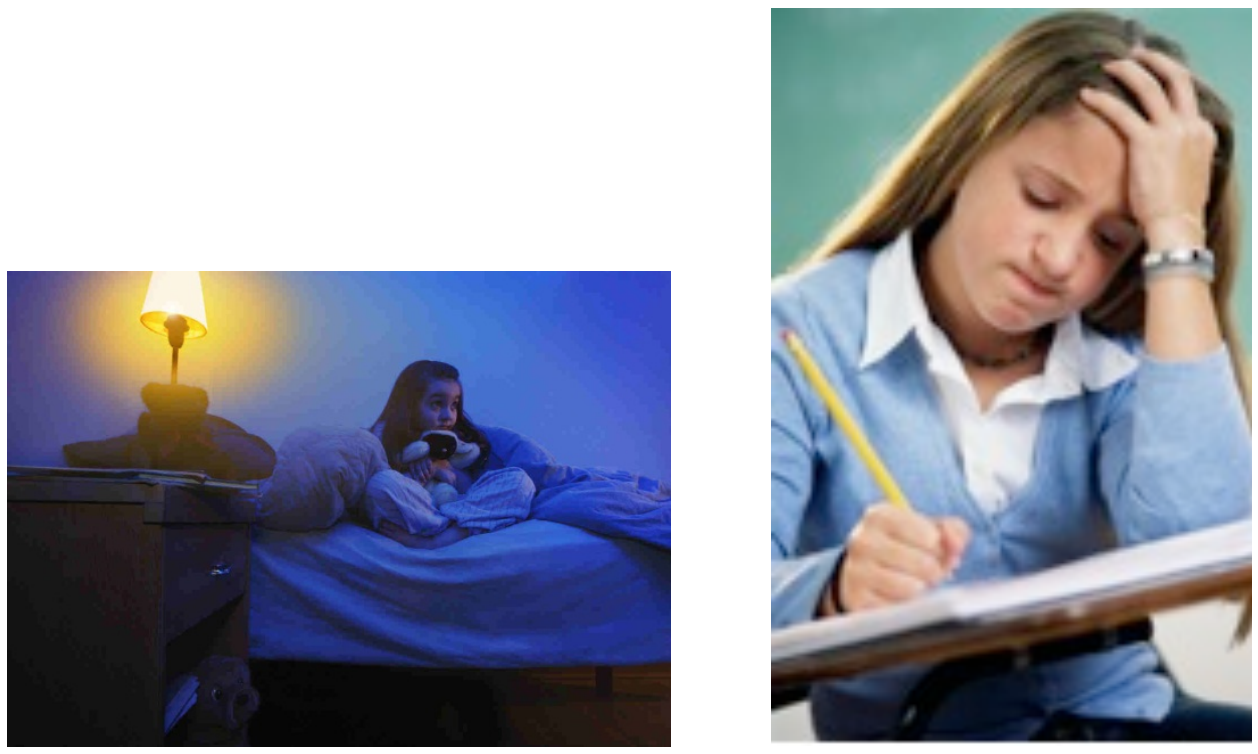


$$
\frac{x}{6}
$$




\section{CURRICULUM VITAE}

\section{SARAH R. Williams}

222 E. SARATOGa STREET \# 910

BALTIMORE, MD 21202

SARAH.WILLIAMS@JHMI.EDU

\section{EDUCATION}

B.S.

May 2007

M.A.

December 2010

Predoctoral Internship

July 2012 - June 2013
Virginia Polytechnic Institute and State University Psychology (in Honors), Summa Cum Laude Honors Thesis Title: The Impact of Childhood Maltreatment on Substance Use Problems: The Role of Self-Worth

Thesis Chair: Jungmeen Kim - Spoon, Ph.D.

University of Louisville Clinical Psychology

University of Louisville, School of Medicine

Department of Pediatrics

Division of Child and Adolescent Psychiatry and Psychology

\section{HONORS AND AWARDS}

- APA Science Directorate Dissertation Research Award

- Virginia Tech Undergraduate Award for Research Excellence

- Virginia Tech Honors Program

- Phi Sigma Pi National Honor Fraternity

- Golden Key International Undergraduate Honour Society

\section{GRANTS}

Williams, S. R. (2011, November). Modeling Risk for the Development of Child Anxiety: The Role of Parent Emotion Socialization Practices, Children's Emotional Competence, and Physiological Responsiveness. American Psychological Association Science Directorate Dissertation Research Award. Amount requested: $\$ 840$ (funded)

Schrock, M. D. \& Williams, S. R. (2011, April). Familial Anxiety: A Developmental Model Using an Accelerated-Longitudinal Design. Graduate Student Grants for Research and Creative Activities College of Arts and Sciences. Amount requested: \$987 (funded)

Schrock, M. D., Williams, S. R. \& Kertz, S. J. (2010, April). A model of worry in kids. Graduate Student Grants for Research and Creative Activities College of Arts and Sciences. Amount requested: $\$ 1,000$ (unfunded).

\section{EDITORIAL ACTIVITIES}

Ad Hoc Reviewer (October, 2011), Journal of Criminal Justice and Behavior 
Ad Hoc Reviewer (June, 2011), Journal of Criminal Justice and Behavior

Ad Hoc Reviewer (June, 2010), Journal of Criminal Justice and Behavior

\section{MANUSCRIPTS AND PUBLICATIONS}

Bortoleto, E. G., Williams, S. R., Kertz, S. J., \& Woodruff-Borden, J. (in progress). An Examination of Autonomic Inflexibility Among Children with High and Low Worry.

Williams, S. R., Cash, E. D., Daup, M. B., Geronimi, E. M. C., Sephton, S. E., \& WoodruffBorden, J. (2013). Exploring Patterns in Cortisol Synchrony Among Anxious and Nonanxious Mother and Child Dyads: A Preliminary Study, Biological Psychology, 93(2), 287-295.

Williams, S. R., Kertz, S. J., Schrock, M. D., \& Woodruff-Borden, J. (2012). A Sequential Analysis of Parent-Child Interactions in Anxious and Nonanxious Families, Journal of Clinical Child and Adolescent Psychology, 41(1), 64-74.

Chapman, L. K., Williams, S. R., Mast, B. T., \& Woodruff-Borden, J. (2009). A Confirmatory Factor Analysis of the Beck Anxiety Inventory in African American and Caucasian American Young Adults. Journal of Anxiety Disorders, 23(3), 387-392.

Kim, J. \& Williams, S. R. (2009). Linking Childhood Maltreatment to Substance Use in College Students: The Mediating Role of Self-Worth Contingencies. Journal of Aggression, Maltreatment and Trauma, 18, 88-105.

\section{PRESENTATIONS}

Williams, S. R., Shaffer, L. A., Hancock, M. S., Labar, E. M., Recchi, L., \& Honaker, S. M. (accepted). Physician Perspectives on Integrating Mental Health Providers within Primary Care Practice. Poster to be presented at the Annual Association for Behavior and Cognitive Therapies Convention, November 21-24, Nashville, TN.

Williams, S. R. \& Woodruff-Borden, J. (accepted). Parental Emotion Socialization and Symptoms of Child Anxiety: The Mediating Role of Child Self-Regulation. Poster to be presented at the Annual Association for Behavior and Cognitive Therapies Convention, November 21-24, Nashville, TN.

Williams, S. R., Bortoleto, E. G., Carrico, C., \& Woodruff-Borden, J. (2012). Physiological Symptoms of Anxiety, Family Functioning, and Parent Factors as Predictors of Salivary Cortisol Diurnal Slope in Childhood. Poster presented at the Annual Association for Behavior and Cognitive Therapies Convention, November 15-18, National Harbor, MD.

Bortoleto, E. G., Williams, S. R., Affrunti, N. W., Carrico, C., Kertz, S. J., \& Woodruff-Borden, J. (2012). Autonomic responsiveness, intolerance of uncertainty, and behavior control in child worry and anxiety. Poster presented at the Annual Association for Behavior and Cognitive Therapies Convention, November 15-18, National Harbor, MD.

Arrowood, A., Holt, N., Williams, S. R., Woodruff-Borden, J., \& Cashon, C. (2012). Fivemonth-old infants' discrimination of emotion in faces. Poster presented at the Undergraduate Research Symposium, April 17, University of Louisville, Louisville, 
KY.

Williams, S. R., Kertz, S. J., Stearns, Z. R., Lush, E., Daup, M., Sephton, S. \& Woodruff-Borden, J. (2011). Cortisol responsiveness and family environment as a mechanism of familial anxiety. Poster presented at the Annual Association for Behavior and Cognitive Therapies Convention, November 10-13, Toronto.

Bortoleto, E., Williams, S. R., Kertz, S. J., Schrock, M., Hosey, R., \& Woodruff-Borden, J. (2011) Examining the autonomic responsiveness of children with high and low worry to threat and nonthreat pictures. Poster presented at the Annual Association for Behavior and Cognitive Therapies Convention, November 10-13, Toronto.

Schrock, M., Hosey, R., Williams, S. R. \& Woodruff-Borden, J. (2011). Child internalizing symptoms: The role of child temperament, maternal anxiety, and family environment. Poster presented at the Annual Association for Behavior and Cognitive Therapies Convention, November 10-13, Toronto.

Hosey, R. P., Schrock, M., Williams, S. R. \& Woodruff-Borden, J. (2011). The role of child and parent factors in parent behavioral negativity: A path analysis. Poster presented at the Annual Association for Behavior and Cognitive Therapies Convention, November 10-13, Toronto.

Bortoleto, E. G., Williams, S. R., Kertz, S. J. \& Woodruff-Borden, J. (2011). Examining the autonomic responsiveness of children with high and low worry to threat and nonthreat pictures. Poster presented at the Undergraduate Research Symposium, April 19, University of Louisville, Louisville, KY.

Williams, S. R., Kertz, S. J., Hosey, R. P., Schrock, M., \& Woodruff-Borden, J. (2010). The Role of Anxiety on Parent Coaching and Dismissing Behaviors and Their Relationship to Child Anxiety. Poster presented at the Annual Association for Behavior and Cognitive Therapies Convention, November 18-21, San Francisco, CA.

Schrock, M., Williams, S. R., Kertz, S. J., Hosey, R. P., \& Woodruff-Borden, J. (2010). The Moderating Effect of Stressful Life Events on Anxious and Non-anxious Parents' Conditional Responses to Child Behavior. Poster presented at the Annual Association for Behavior and Cognitive Therapies Convention, November 18-21, San Francisco, CA.

Kertz, S. J., Hosey, R. P., Schrock, M., Williams, S. R., \& Woodruff-Borden, J. (2010). Child Coping Style Moderates the Relationship Between Trait Anxiety and Anxiety Symptoms. Poster presented at the Annual Association for Behavior and Cognitive Therapies Convention, November 18-21, San Francisco, CA.

Hosey, R. P., Kertz, S. J., Schrock, M. D., Williams, S. R., Woodruff-Borden, J. (2010). Maternal Anxiety Moderates the Relationship Between Child Emotion Word Use and Maternal Sensitivity. Poster presented at the Annual Association for Behavior and Cognitive Therapies Convention, November 18-21, San Francisco, CA.

Williams, S. R., Kertz, S. J., Schrock, M., \& Woodruff-Borden, J. (2009). Parental Behaviors Following Child Negativity in Anxious and Nonanxious Parents: A Sequential Analysis. 
Poster presented at the Annual Association for Behavior and Cognitive Therapies Convention, November 19-22, New York, NY.

Hosey, R. P., Schrock, M., Schwarz, R., Kertz, S. J., Williams, S. R., Briggs, N., \& WoodruffBorden, J. (2009). Language Use as a Characteristic of Anxiety in Parent-Child Interactions. Poster presented at the Annual Association for Behavior and Cognitive Therapies Convention, November 19-22, New York, NY.

Kertz, S. J., Schrock, M., Williams, S. R., \& Woodruff-Borden, J. (2009). A Sequential Analysis of the Influence of Parent and Child Anxiety on Child Responses to Parental Aversiveness. Poster presented at the Annual Association for Behavior and Cognitive Therapies Convention, November 19-22, New York, NY.

Schrock, M., Kertz, S., Williams, S. R., \& Woodruff-Borden, J. (2009). Anxious and Nonanxious Children's Response to Parental Aversiveness: A Sequential Analysis. Poster presented at the Annual Association for Behavior and Cognitive Therapies Convention, November 19-22, New York, NY.

Hosey, R. P., Schrock, M., Kertz, S. J., Williams, S. R., Chapman, L. K., Woodruff-Borden, J. \& Newton, T. (2008). Anxiety as a Function of Crime Risk in a Primary Care Sample. Poster presented at the Annual Association for Behavior and Cognitive Therapies Convention, November 13-16, Orlando, FL.

Kertz, S. J., Hosey, R. P., Schrock, M., Williams, S. R. \& Woodruff-Borden, J. (2008). A Path Analysis of Parent and Child Behaviors: Differences in Children with GAD and Other Anxiety Disorders. Poster presented at the Annual Association for Behavior and Cognitive Therapies Convention, November 13-16, Orlando, FL.

Schrock, M., Kertz, S. J., Hosey, R. P., Williams, S. R. \& Woodruff-Borden, J. (2008). Impact of Parental Anxiety on Parent's Perceptions of Child Behavior. Poster presented at the Annual Association for Behavior and Cognitive Therapies Convention, November 13-16, Orlando, FL.

Williams, S. R., Chapman, L. K., Mast, B. T. \& Woodruff-Borden, J. (2008). A Confirmatory Factor Analysis of the Beck Anxiety Inventory. Poster presented at the Annual Association for Psychological Science Convention, May 22-25, Chicago, IL.

Williams, S. R. \& Kim, J. (2008). Linking Childhood Maltreatment and Substance Use in College Students: The Role of Self-Worth. Poster presented at the Annual Association for Psychological Science Convention, May 22-25, Chicago, IL.

TEACHING EXPERIENCE

Life-Span Development Psychology (PSYC 363)

Personality Psychology (PSYC 375)

Experimental Psychology Lab (PSYC 302)

\section{CLINICAL TRAINING}

Pediatric Forensic Medicine, Assessment Practicum 
Psychological Services Center, Children with ADHD and Related Difficulties Treatment Team Supervisor: Paul Rosen, Ph.D.

July 2011 - June 2012

Psychological Services Center, Cognitive-Behavioral Therapy Treatment Team

Supervisor: Janet Woodruff-Borden, Ph.D.

January 2009 - June 2012

Psychological Services Center, Assessment Practicum

Supervisors: Bernadette Walter, Ph.D. \& David Winsch, Ph.D. J January 2009 - June 2012

Psychological Services Center, Mother-Child Worry Group

Supervisor: Janet Woodruff-Borden, Ph.D.

April 2010 - May 2010

Department of Psychiatry, Assessment Practicum

Supervisor: Tracy Eells, Ph.D.

July 2009 - June 2010

Goldsmith Elementary School, Girls Intervention Group

Supervisor: Janet Woodruff-Borden, Ph.D.

March 2008 - April 2008

Psychological Services Center, Mindfulness \& Acceptance-Based Treatment Team

Supervisor: Paul Salmon, Ph.D.

August 2007 - August 2008

\section{PROFESSIONAL DEVELOPMENT}

2011 - $2012 \quad$ Volunteer - UofL Arts \& Sciences Alumni Ambassador Program

$2010-2012 \quad$ President - UofL Arts \& Sciences Graduate Student Union

2010 - $2013 \quad$ Judge - duPont Manual Science Fair; Behavioral and Biological Sciences Divisions

$2008-2010 \quad$ University of Louisville Depression Center Conference

$2010 \quad$ Invited Guest Speaker - Family Scholar House

2009

Judge - Louisville Regional Science Fair; Physical and Life Sciences Divisions

\section{MEMBERSHIPS AND AFFILIATIONS}

- $\quad$ Student Affiliate of American Psychological Association (2005 - 2013)

- APA Division 53 - Society of Clinical Child and Adolescent Psychology (2012-2013)

- Student Affiliate of Association for Behavioral and Cognitive Therapies (2007 - 2013)

- Student Affiliate of Kentucky Psychological Association (2007 - 2013)

- Student Affiliate of Association for Psychological Science (2008 - 2009)

\section{REFERENCES}

References available upon request 